\title{
State-of-the-art review of 3DPV technology: structures and models
} Yuanlong Cui ${ }^{\text {a }}$, Jie Zhu ${ }^{\text {b,* }}$, Stamatis Zoras ${ }^{\text {a }}$, Xiangjie Chen ${ }^{\text {c }}$, Haixia Bi ${ }^{\text {d, }}$ Yaning Qiao ${ }^{\text {e, }}$ Zohreh Soleimani ${ }^{\text {a }}$

${ }^{a}$ Department of Built Environment, College of Engineering and Technology, University of Derby, Derby, DE22 3AW, UK ${ }^{\mathrm{b}}$ Department of Architecture and Built Environment, University of Nottingham, University Park, Nottingham, NG7 2RD, UK ${ }^{\mathrm{c}}$ CREST, Wolfson School of Mechanical, Electrical and Manufacturing, Loughborough University, Leicester, LE11 3TU, UK

${ }^{\mathrm{d}}$ Department of Computing, College of Engineering and Technology, University of Derby, Derby, DE22 3AW, UK

${ }^{\mathrm{e}}$ School of Mechanics and Civil Engineering, China University of Mining and Technology, Xuzhou, 221116, China

\section{Abstract}

Increasing energy conversion efficiency from sunlight to power is one of the key solutions for the world's energy shortage and greenhouse gas reduction, but the conventional flat photovoltaic module without sun tracking mechanism has the low sunlight energy collection ability. This paper presents the state-of-the-art three-dimensional photovoltaic (3DPV) technology with high photovoltaic energy conversion efficiency, which is able to absorb off-peak sunlight and reflected light more effectively, thereby it can generate more power. At first, this paper is to catalogue and critique different 3DPV structures and models, as well as assess their characteristics. Afterwards, the main influence factors on the 3DPV structures and models including shape, height and spacing of the solar cells, latitude of the installation, optimal device design and shadow cast, are reviewed. Finally, the challenges and future technological developments of 3DPV structures and models are highlighted. This study demonstrated that the 3DPV technology can increase the captured sunlight approximately 15-30\% in comparison with the conventional flat PV technology.

Keywords: Solar energy, Solar photovoltaic system, 3DPV structures and models, Energy conversion efficiency

In recent years, environmental pollution and global warming have been acquired the highest concerns, leading to wildly-pursuit and investigation of renewable energy sources [1]. Solar energy is the main energy source and anticipated to be an extraordinary portion of electrical energy production in the near future. Solar power based on photovoltaic (PV) technology is the most widely deployed due to its mature, safe, steady, non-polluting, good visibility characteristics. It is able to fulfil energy demand and solve

\footnotetext{
* Corresponding author. Tel: +44-115-8466141 Fax: +44-115-951315

E-mail address: Jie.Zhu@nottingham.ac.uk (J. Zhu)
} 
fossil fuel-oriented environmental matters [2, 3]. A PV cell is an element that converts sunlight into electricity based on the photoelectric effect. The PV cell does not require direct sunlight, it would work even on a cloudy day [4, 5]. Researchers [6] continue to enhance the PV cell design for achieving over $20 \%$ energy conversion efficiency. As awareness raised in the environmental issues, researchers persisted to improve silicon PV cell energy performance and reach the efficiency in a range of 24.5\%-29\% [6]. The performance of convectional PV technology relies on the usability of solar radiation, latitude of the installation as well as the local weather condition $[7,8]$, the evaluation of solar radiation is very useful for appropriate PV system design $[9,10]$. The assembling of PV modules has the burden of land demand, particularly in land restricted urban regions. Typically, for a small-scale system, the traditional flat PV panels are mounted at the rooftop of building, however the limited rooftop space is a big challenge $[11,12]$. Sun tracking system has been adopted in the PV system, but the demerit is extra expense in terms of operation and maintenance [13].

In order to improve the sunlight absorption ability and reduce installation, operation and maintenance costs, three-dimensional photovoltaic (3DPV) technology is developed based on different structures including Fibonacci number Photovoltaic Module (FPM), Golden Spiral (GS), 3D Dye-Sensitized Solar Cell (3D-DSSC), Cubic Silicon Solar Cell (SSC), Spherical Silicon Solar Cell (SSC), Silicon Nanowire (SiNW) and Silicon Nanocone (SiNC) structures, and various models, such as Genetic Algorithms (GA), Monte Carlo (MC), CFD-GEOM™, spherical Silicon Solar Cell (SSC), Green's Function, Discrete Dipole Approximation (DDA) and Finite-Difference Time-Domain (FDTD) models as shown in Fig.1.

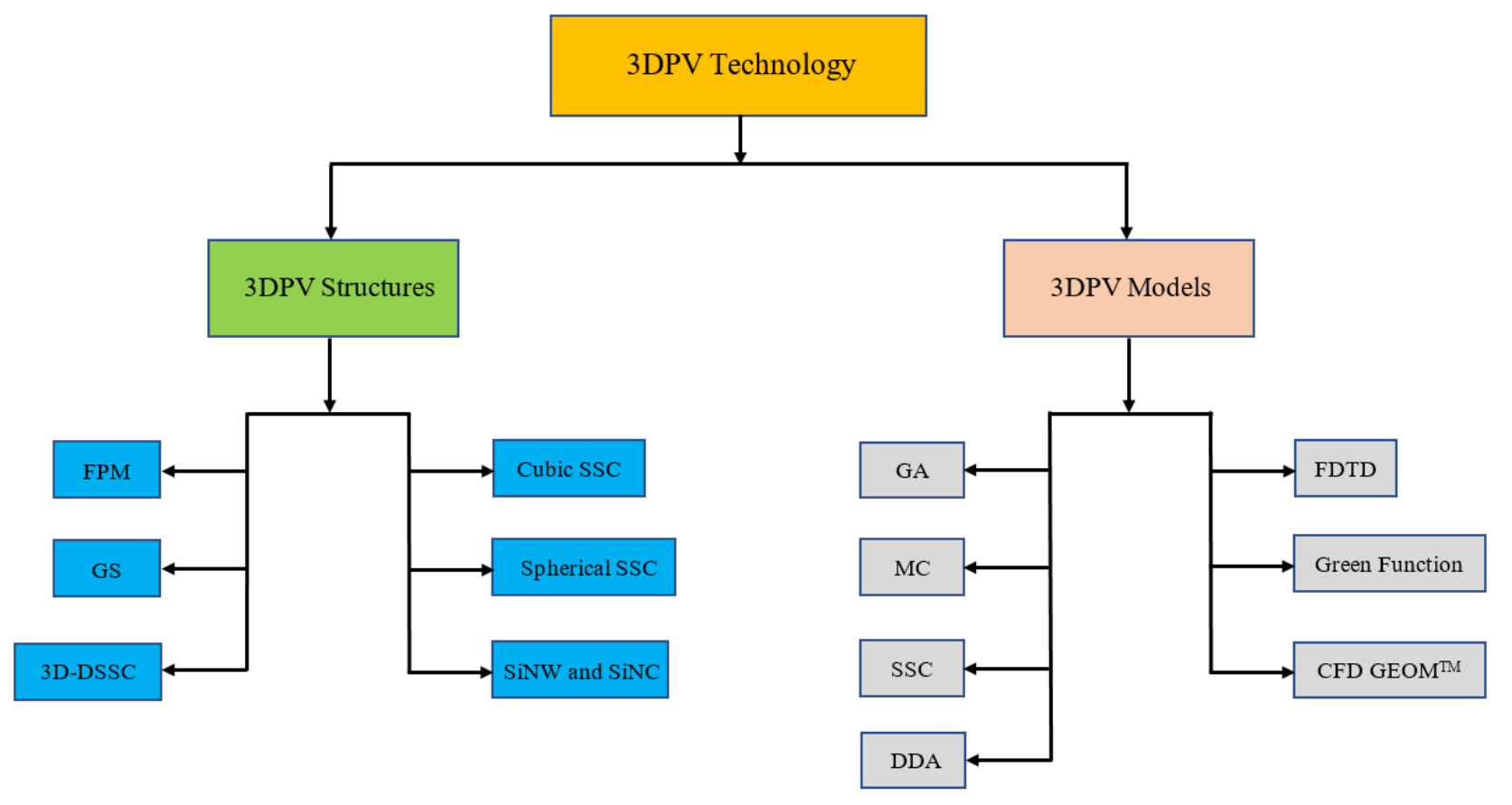

Fig. 1. 3DPV structures and models

At present, there is a research gap in light of summarizing the innovative 3DPV technology to promote better understanding through its structures and models for improving the energy conversion efficiency. The objective of this study is to fill this 
knowledge gap by providing a systematic summarizing of the 3DPV technology. A detailed comparison between the 3DPV and conventional flat PV system is also conducted to clarify the significance of the 3DPV technology. In this review paper, a brief background about the 3DPV technology is firstly illustrated in Section 2. Then, the different structures of the 3DPV technology are clarified in Section 3. Moreover, the analytical and numerical models of the 3DPV technology are generalized in Section 4. Furthermore, the challenges and future technological developments are presented in Section 5. At the end, the key findings are given in Section 6.

\section{Brief description of 3DPV technology}

Traditional PV module has comparatively low energy density, and this is owing to the fact that the output of the device is influenced by the local weather condition and latitude of the installation [14]. Conventionally the flat solar PV panels mounted at building rooftop has low electricity production, while more electricity could be produced by integrating 3DPV technology which utilizes 3D nature of the dimensional structures for example, FPM, 3D-DSSC, cubic and spherical to capture more energy in the whole volume of that material. The 3DPV technology is an innovative method for realizing the solar energy as a more reliable and economical energy source, it can improve the absorbance ability and produce more electricity in comparison to traditional flat or planar PV types $[15,16]$. Three key reasons underlying the merits of 3DPV technology are illustrated as follows [14]:

- Multiple orientations of the absorbers that achieve the effective capturing of off-peak solar energy;

- Avoidance of inner panels shadow cast;

- Re-absorption of sunlight reflected inside the 3DPV structure.

These enable the produced power density per unit area to be superior by a factor of 2 to 20 compared to conventional flat PV panels [14]. To enhance the panel energy conversion efficiency, the angles of solar irradiance and shadow cast play a vital role in the 3DPV structures.

Fig. 2 descripts the angles of solar irradiance and shadow cast on the PV panels. Global solar irradiance on a tilted surface contains the diffused and direct beam components. To be more specific, Fig. 2 (a) describes the solar angles that mainly involve altitude angle $(\alpha)$, surface tilt angle $(\beta)$, surface azimuth angle $(\gamma)$ and solar azimuth angle $\left(\gamma_{\mathrm{s}}\right)$. Fig. 2 (b) gives the areas for the panel 1, panel 2 and panel shadow 1, the part of the panel shadow cast is marked in black. In order to obtain the optimization model by considering the shadow effect, the mathematic equations are given in Table 1 [20]. 

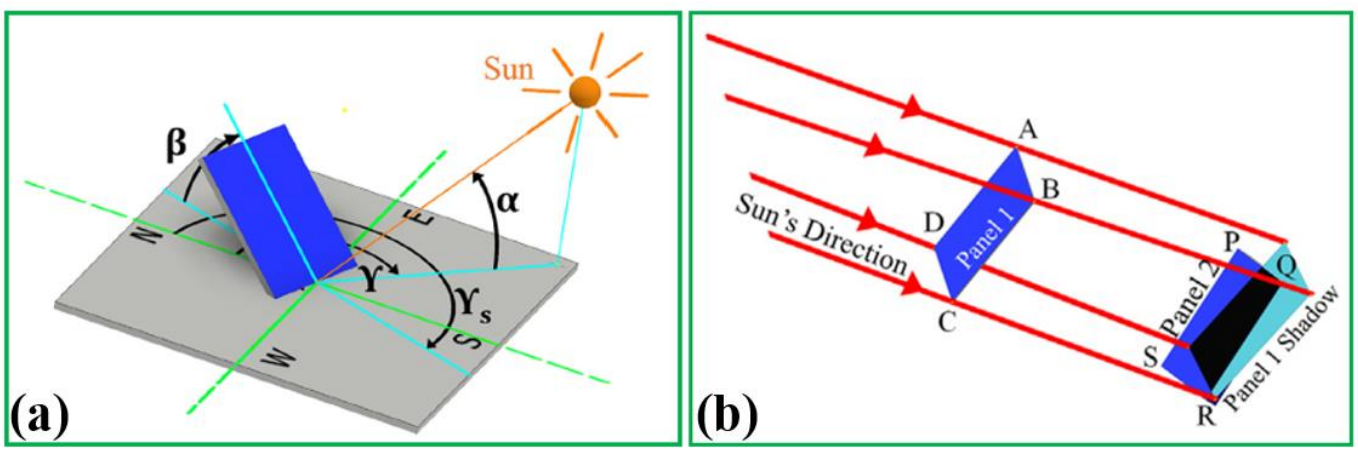

Fig. 2. Optimization factors of PV panels: (a) angles; (b) shadow cast [20]

78 Table 1 The mathematic equation of the angles and shadow cast [20]

\begin{tabular}{lll}
\hline Item & Description & Equation \\
\hline & The diffused irradiance component & $\mathrm{I}(\beta, \gamma)=\mathrm{I}_{\mathrm{b}} \frac{\cos \theta_{\mathrm{i}}}{\cos \theta_{\mathrm{z}}}+\mathrm{I}_{\mathrm{d}} \frac{1+\cos \theta_{\beta}}{2}$ \\
& The total daily energy incident & $\mathrm{E}(\beta, \gamma)=\sum_{\mathrm{day}=1}^{365} \sum_{\mathrm{h}=7 \mathrm{am}}^{5 \mathrm{pm}} \mathrm{I}(\mathrm{h}$, day $)(\beta, \gamma)$ \\
The effect of angles & $\beta_{\text {opt }}=\max (\mathrm{E}(\beta)) ; \beta \in\left[0^{\circ}, 90^{\circ}\right]$ \\
& $\begin{array}{l}\text { The optimal tilt angle } \\
\text { The optimal orientation }\end{array}$ & $\mathrm{E}_{\mathrm{l}}=\sum_{\mathrm{h}=7 \mathrm{am}}^{5 \mathrm{pm}} \mathrm{I}_{\mathrm{b}}(\beta, \gamma) \times \eta_{\mathrm{e}} \times \mathrm{A}_{\mathrm{h}}$ \\
\hline \multirow{3}{*}{ The effect of shadow cast } & The direction vector of solar radiation & $\mathrm{E}(\beta, \gamma)) ; \beta \in\left[0^{\circ}, 90^{\circ}\right], \gamma \in\left[0^{\circ}, 360^{\circ}\right]$ \\
& $\begin{array}{l}\text { The energy loss because of the shading at each } \\
\text { time instant from 7 am to } 5 \text { pm }\end{array}$ & $\mathrm{E}_{1}=\sum_{\mathrm{h}=7 \mathrm{am}}^{5 \mathrm{pm}} \mathrm{I}_{\mathrm{b}}(\beta, \gamma) \times \eta_{\mathrm{e}} \times \mathrm{A}_{\mathrm{h}}$ \\
\hline
\end{tabular}

80 Majority of PV cells on the market are made from silicon due to plentiful, inexpensive as well as the mature manufacturing 81 process. Generally speaking, high-grade crystalline can reach an efficiency of $29 \%$ theoretically, whereas most commercially available PV cells can merely achieve the efficiency of 15-19\% [21]. The essential elements that disturb the commercialization of 3DPV technology include its efficiency, price and durability. Other important factors involve the availability of materials utilized and their influences on the environment. There are different categories of PV cell generally utilized in the solar market nowadays including thin film, dye-sensitized, crystalline silicon and organic cells as given in Fig. 3 [21]. The corresponding structures of 3DPV solar cells are presented in Fig. 4 [21]. 


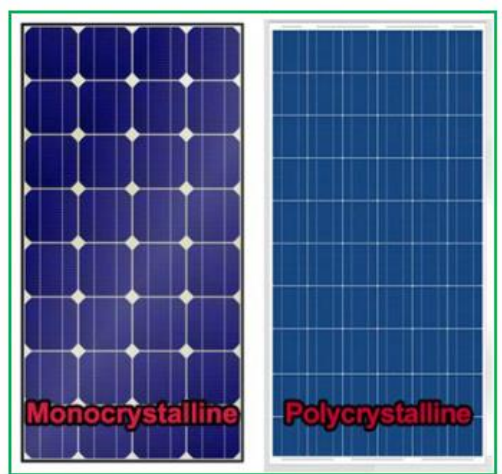

(a)

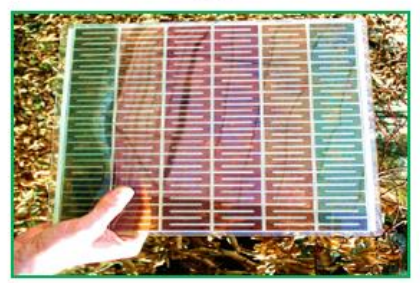

(d)

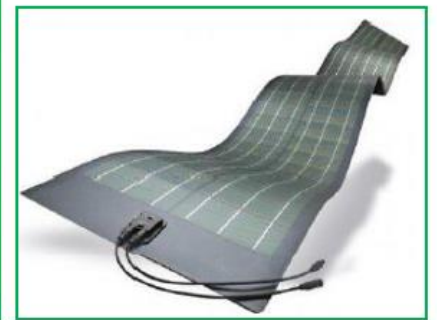

(b)

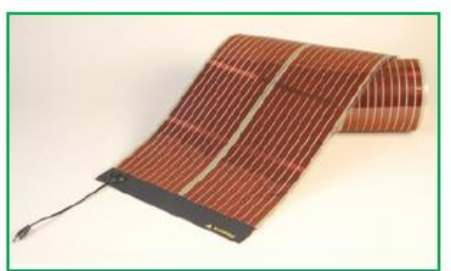

(e)

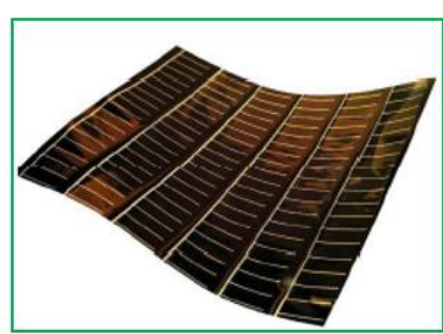

(c)

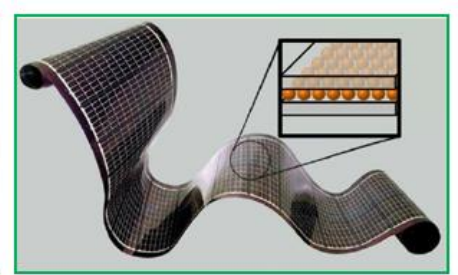

(f)

Fig. 3. Different types of PV cell: (a) crystalline silicon; (b) thin film; (c) CIGS and CdTe; (d) (e) (f) dye-sensitized [21]

Furthermore, recently progress has been achieved for organic solar cells in efficiency aspect, and more structures appear including PVC rod as a trunk of tree, Al sheets as branches of tree, solar panels as leaves of tree and a base structure made of $\mathrm{Al}$ for holding solar tree model [22]. Cao et al. [22] proposed a novel solar palm tree to assess the performance of 3DPV technology as depicted in Fig. 5. The materials of the solar palm tree mainly involve polyethylene terephthalate (PET), ZnO nanoparticle layer, poly 3-hexylthiophene (P3HT) and phenyl-C61-butyric acid methyl ester (PCBM) film.

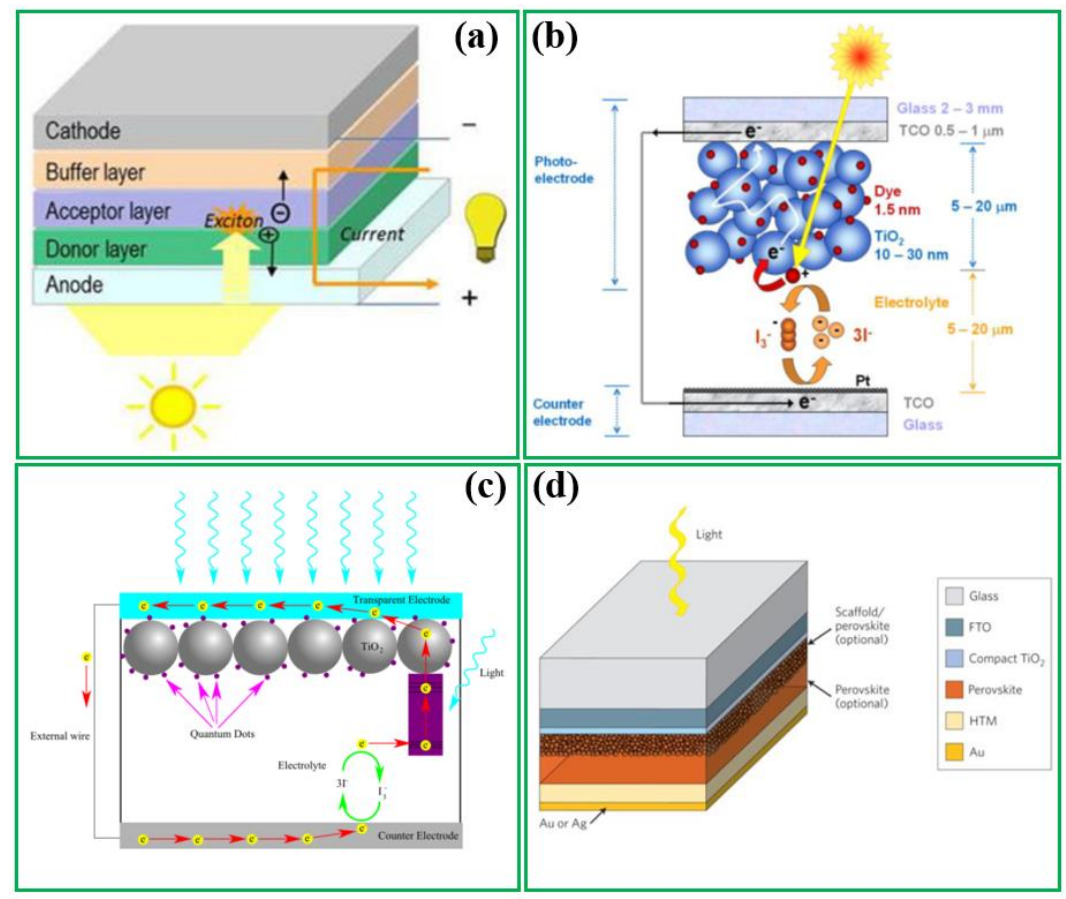

Fig. 4. Structures of (a) quantum dot; (b)dye-sensitized; (c)perovskite; (d)organic PV cells [21] 


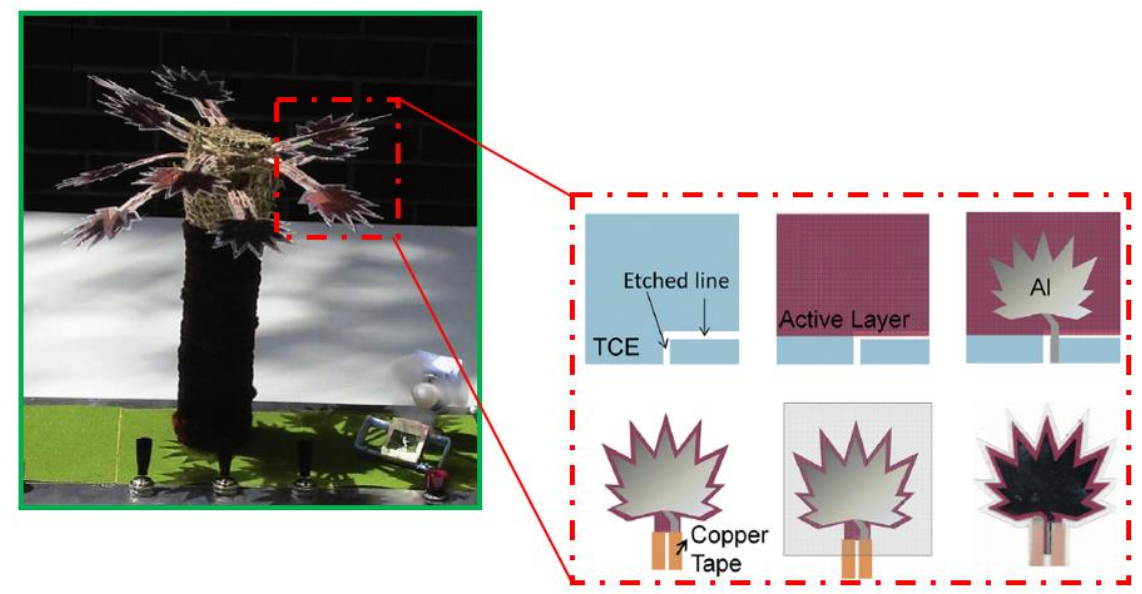

Fig. 5. Photo of a solar power tree prototype with 12 leaf-shape devices and materials [22]

\section{The structures of 3DPV technology}

There are different structure types for 3DPV technology, most of them are Fibonacci number Photovoltaic Module (FPM), Golden Spiral (GS), 3D Dye-Sensitized Solar Cell (3D-DSSC), Cubic Silicon Solar Cell (SSC), Spherical Silicon Solar Cell (SSC), Silicon Nanowire (SiNW) and Silicon Nanocone (SiNC) structures.

\subsection{FPM structure}

FPM structure is in the leaf arrangement, one of research fields on FPM is known as phyllotaxis. As the plant leaves grow around its stem in a spiral arrangement as shown in Fig. 6 (a), a similar conceptual diagram of the FPM structure is produced as indicated in Fig. 6 (b).
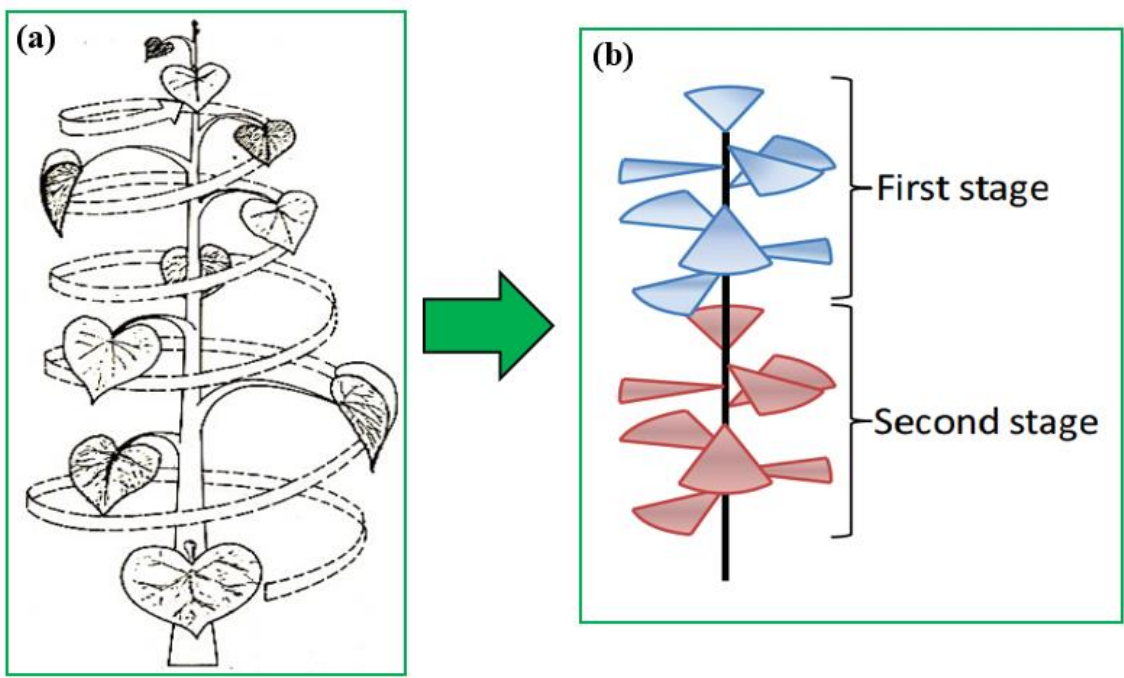

Fig. 6. Fibonacci sequence: (a) in nature; (b) conceptual diagram of a FPM [23, 24]

The FPM plays a significant role in using the nature merits of the abundant intake of sunlight. Based on analytical analysis, Fibonacci [24] concluded that the leaf grows vertically upwards the stem in the direction of the sun so as to obtain more sunlight 
111 for its photosynthesis and this growth follows a spiral arrangement called 'phyllotaxis' with various patterns [25, 26]. Specifically, 112 the angles between successive leaves of $1 / 3,2 / 5$ and $3 / 8$ phyllotaxis are $120^{\circ}, 135^{\circ}$ and $144^{\circ}$, respectively. Meanwhile, the 113 phyllotaxis is regarded as the golden ratio when the angle is $137.5^{\circ}$.

114 The basic calculation processes of Fibonacci sequence and phyllotaxis are presented in Fig. 7. $F_{n}$ is the number of turns that takes 115 place around the stem before the leaves point in the same direction. $\mathrm{F}_{\mathrm{n}+2}$ represents the number of leaves that could be attached 116 to agree with that number of turns. A FPM system is shown in Fig. 8, which has PV cells in each azimuth that produce electricity under different sunlight states. It is notable that the FPM is determined based on the maximum power point tracking (MPPT) to attain the maximum electricity output.

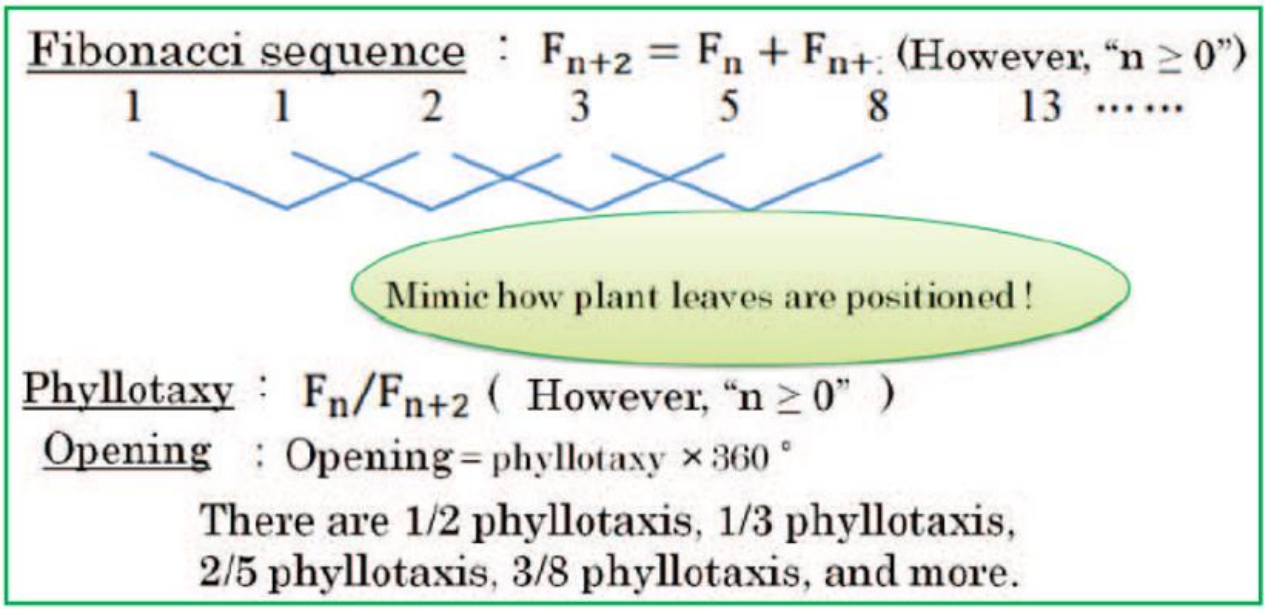

Fig. 7. Fibonacci sequence and phyllotaxis [27]

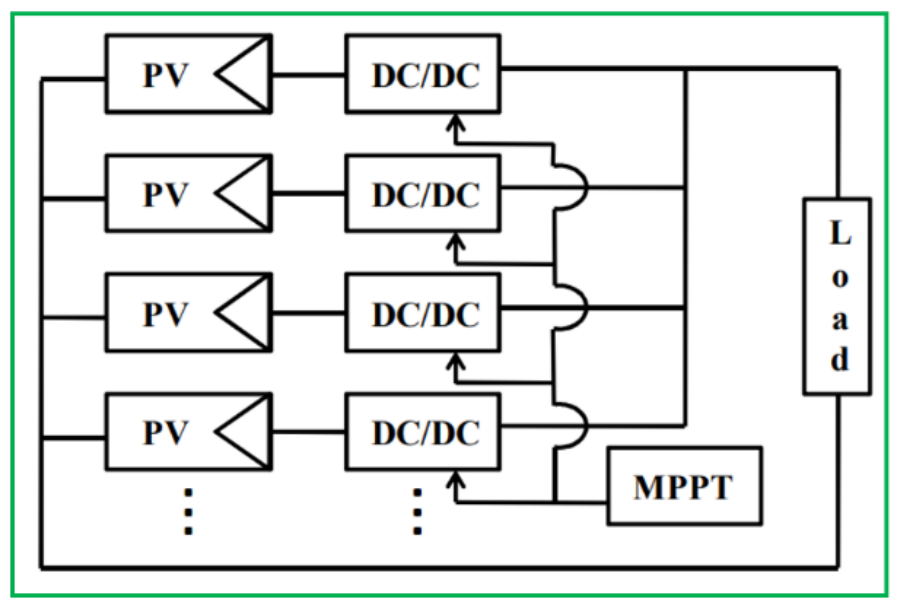

Fig. 8. FPM system [28]

123 Rawat et al. [29] developed one FPM structure for a solar power tree model in India as shown in Fig. 9, the circular distances 124 between various points are presented. 


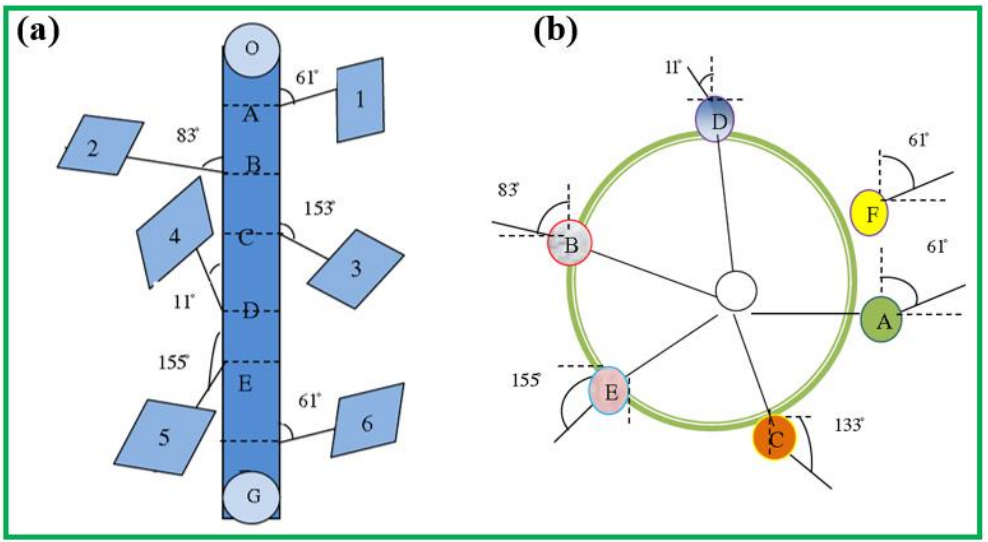

Fig. 9. Solar tree structure: (a) vertical view; (b) top-view [29]

127 The basic calculation equation is given as:

$128 \Theta_{\text {arc }}=\theta \times \mathrm{r}$

129 where $\theta$ is the angle that is made by arc at the centre of circle in radian (rad); $r$ is the radius (m).

130 Their results demonstrated that the FPM structure contributes to collecting sunlight even if others are in shade, as well as 131 generates electricity of about $110 \mathrm{MW}$. Moreover, it is also able to assist branches and trees to avoid shading from each other.

132 Meanwhile, it is not affected by the bad weather like snow as the panels are not installed in horizontal mode [29].

133 Takahashi et al. [27] calculated electricity production per unit area for the diamond, square and honeycomb structures as shown 134 in Fig. 10, and illustrated a seasonal comparison of electricity output for the four types. It can be observed from Fig. 11 that the 135 honeycomb structure (2) produces the highest electricity that is about $8 \mathrm{kWh} / \mathrm{m}^{2}$. Suto and Yachi [24] established a 3DPV technology based on the FPM structure as presented in Fig. 12. Meanwhile, the effect of a shadow cast in the FPM module is considered as given in Fig. 13.

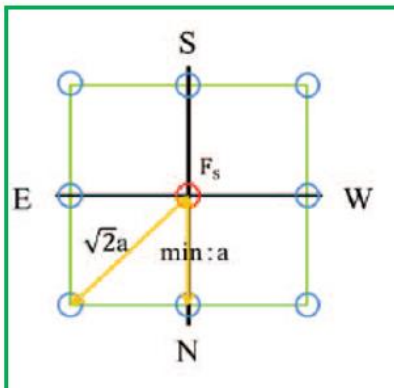

square
E

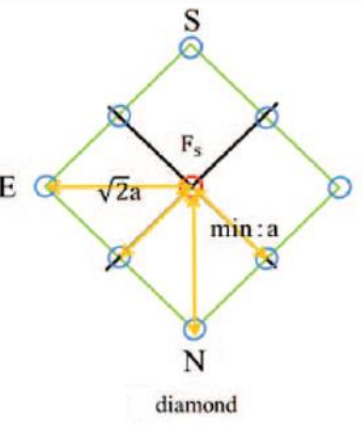

W

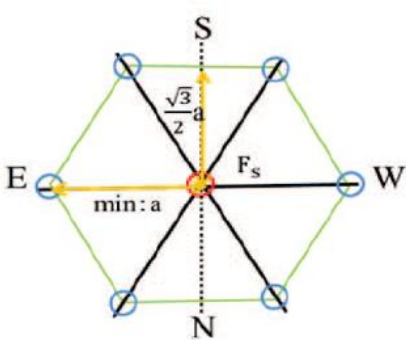

honeycomb structure (1)

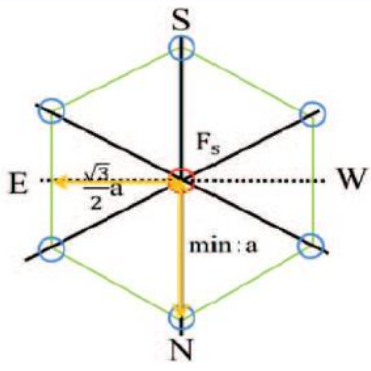

honeycomb structure (2)

Fig. 10. Schematic diagram of four FPM structures [27] 


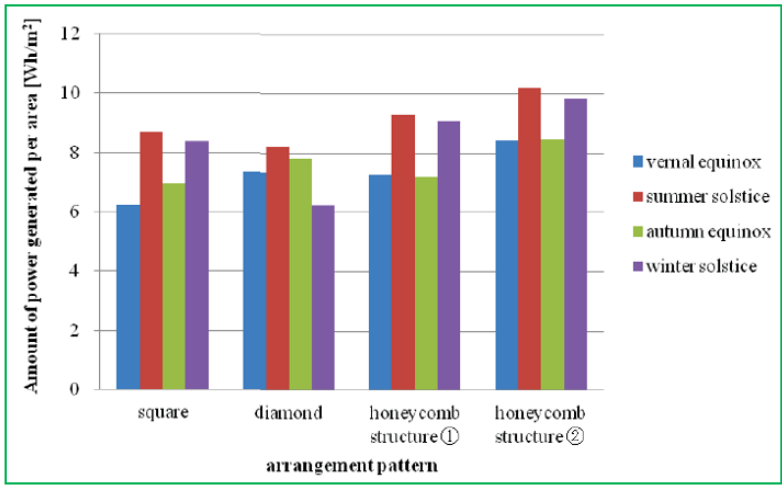

Fig. 11. The electricity output from different FPM structures at each season [27]
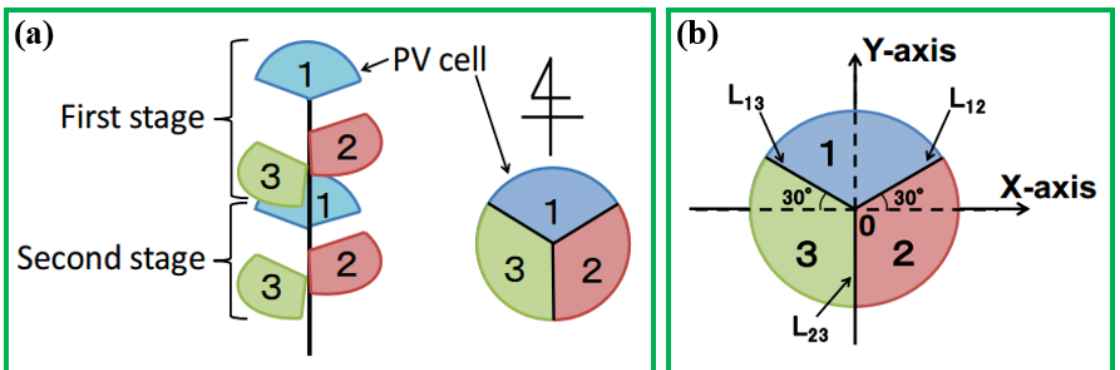

Fig. 12. Schematic diagram of FPM structure: (a) two-stages with FPM 1/3 phyllotaxis; (b) in the coordinate system [24]

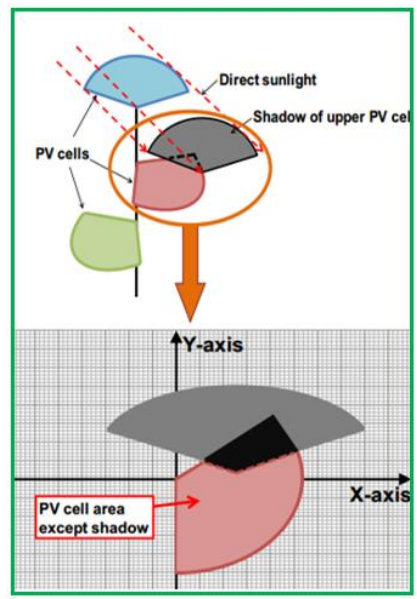

Fig. 13. The effect of shading on the FPM structure and coordinate system [24]

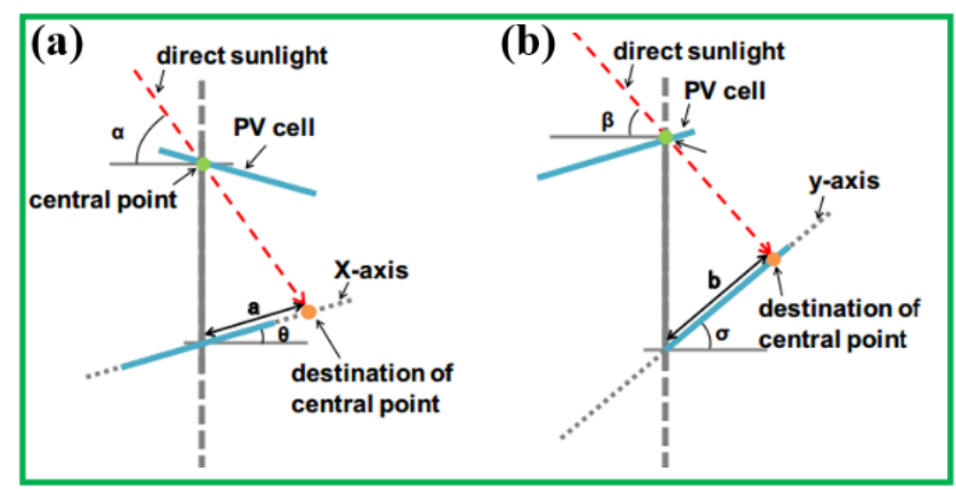

147 Fig. 14. Schematic diagram of calculating the central point of 3DPV structure: (a) $x$-axis direction; (b) $y$-axis direction [24] 
148 A 3DPV structure is depicted in Fig.14 to show the central point at $\mathrm{x}$ - and $\mathrm{y}$-axis directions. The central point is the position at

149 which the solar cell is attached to a pole, and it is obtained as follows:

$\mathrm{a}=-\frac{\mathrm{h}}{\cos \theta \cdot|\tan \alpha|-\sin \theta} \times \mathrm{m}$

$\mathrm{b}=-\frac{\mathrm{h}}{\cos \sigma \cdot|\tan \beta|-\sin \sigma} \times \mathrm{n}$

152 where $\mathrm{h}$ is the distance of each FPM structure; $\alpha$ and $\beta$ are the solar altitudes at the $\mathrm{x}$ - and $\mathrm{y}$-axis directions; $\theta$ and $\sigma$ are the angles

153 of inclination of FPM structure at the $\mathrm{x}$ - and $\mathrm{y}$-axis directions; $\mathrm{m}$ and $\mathrm{n}$ are the expansion and contraction ratios, respectively.

154 Furthermore, the expansion and contraction ratios of the shadow cast are taken into account as given in Fig. 15. The structure 155 equations in the $\mathrm{x}$ and $\mathrm{y}$-axis directions are written in Table 2.

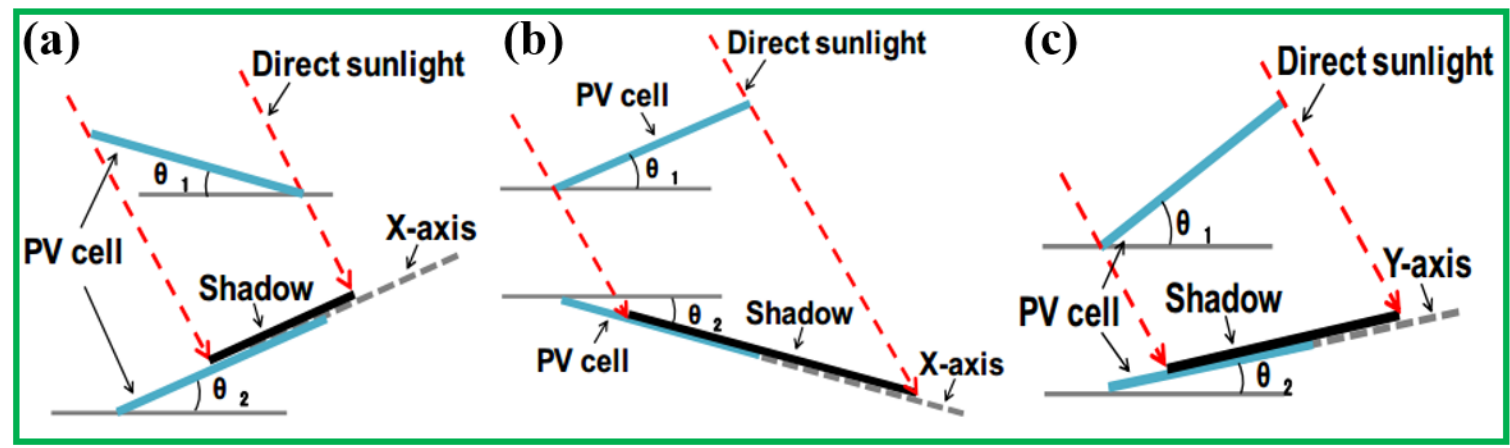

Fig. 15. The expansion and contraction ratios of a shadow cast: (a) structure 1; (b) structure 2; (c) structure 3 [24]

Table 2 The equations of shadow cast [24]

\begin{tabular}{lll}
\hline Item & Equation \\
\hline & Structure 1 & $\mathrm{~m}=\cos \left(\theta_{1}-\theta_{2}\right)+\frac{\sin \left(\theta_{1}-\theta_{2}\right)}{\tan \left(\alpha+\theta_{2}\right)}$ \\
$\begin{array}{l}\text { The ratios of expansion } \\
\text { and contraction }\end{array}$ & Structure 2 & $\mathrm{m}=\cos \left(\theta_{1}-\theta_{2}\right)-\frac{\sin \left(\theta_{1}-\theta_{2}\right)}{\tan \left(\alpha-\theta_{2}\right)}$ \\
& Structure 3 & $\mathrm{n}=\cos \left(\theta_{1}+\theta_{2}\right)+\frac{\sin \left(\theta_{1}+\theta_{2}\right)}{\tan \left(\beta+\theta_{2}\right)}$ \\
\hline
\end{tabular}




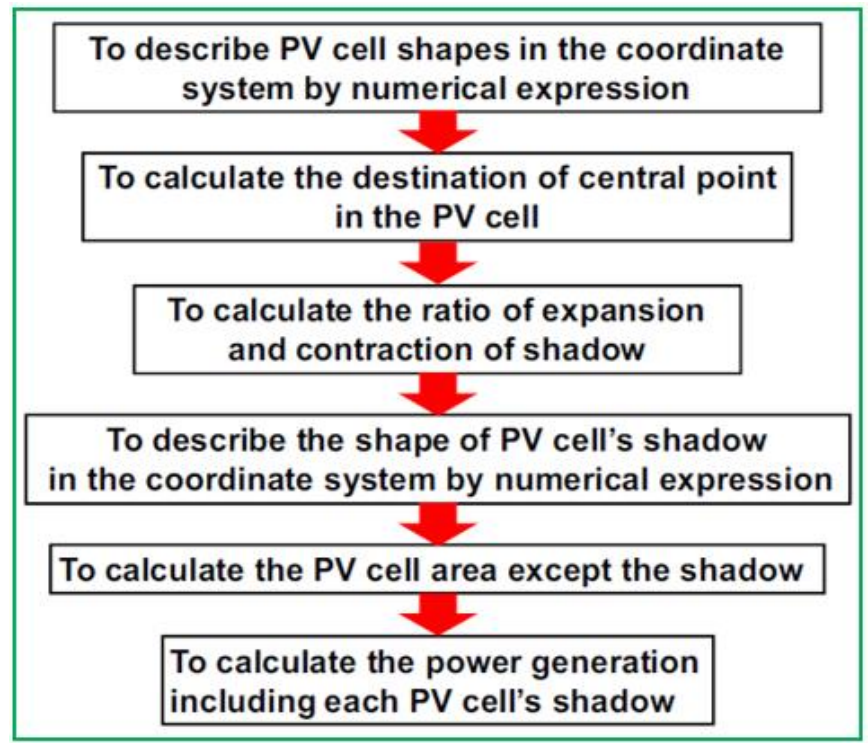

Fig. 16. The flowchart of the FPM electricity production [24]

162 The flowchart of the FPM electricity production with considering the effect of shadow cast is described in Fig. 16. As indicated 163 in Fig. 17, the electricity production reduces only slightly in the first-stage FPM structure, hence it can be concluded that there 164 is little effect of the shadow cast in the first-stage FPM structure. Additionally, as the distance between stages in the FPM structure rises, the electricity production in the second-stage FPM structure decreases in comparison with that of the first-stage FPM owing to the shading effect.

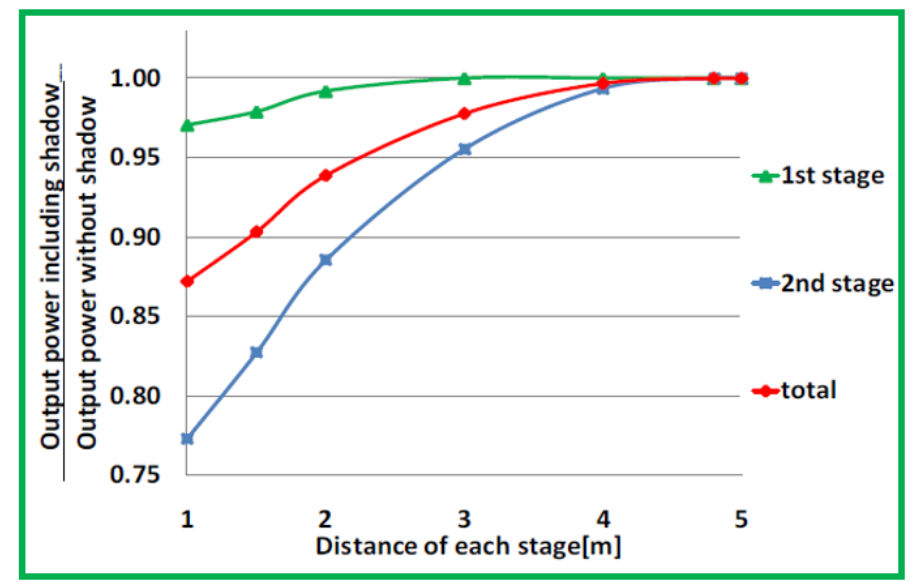

Fig. 17. Comparison of FPM structures electricity production between first and second stages [24]

170 electricity output. The structure of the FPM is described in Fig. 18. The results demonstrate that electricity output of a single171 stage FPM structure is just $90 \%$ of the traditional PV panel's whereas the output of a 2-stage FPM structure is $149 \%$ that of a 172 traditional PV module. 


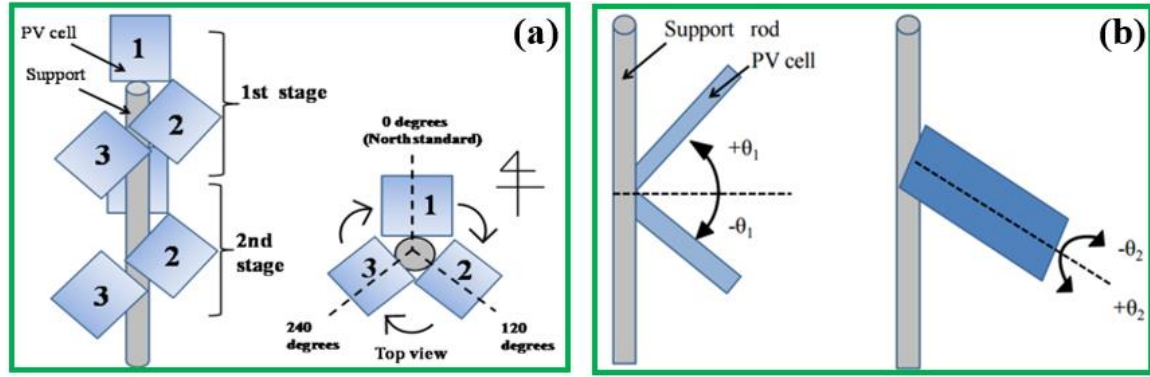

Fig. 18. (a) Structure of FPM; (b) angle of gradient and rotation; (c) actual model [30]

Mochizuki and Yachi [31] established a FPM structure using square solar cells orientated toward the north. Meanwhile, the other two PV cells are rotated via $120^{\circ}$ and $240^{\circ}$, respectively. The angle of inclination $\left( \pm \theta_{1}\right)$ of each PV cell is selected to maximize exposure to the available sunlight as shown in Fig. 19. Their results reveal that the total electricity production can be increased by approximately $30 \%$.

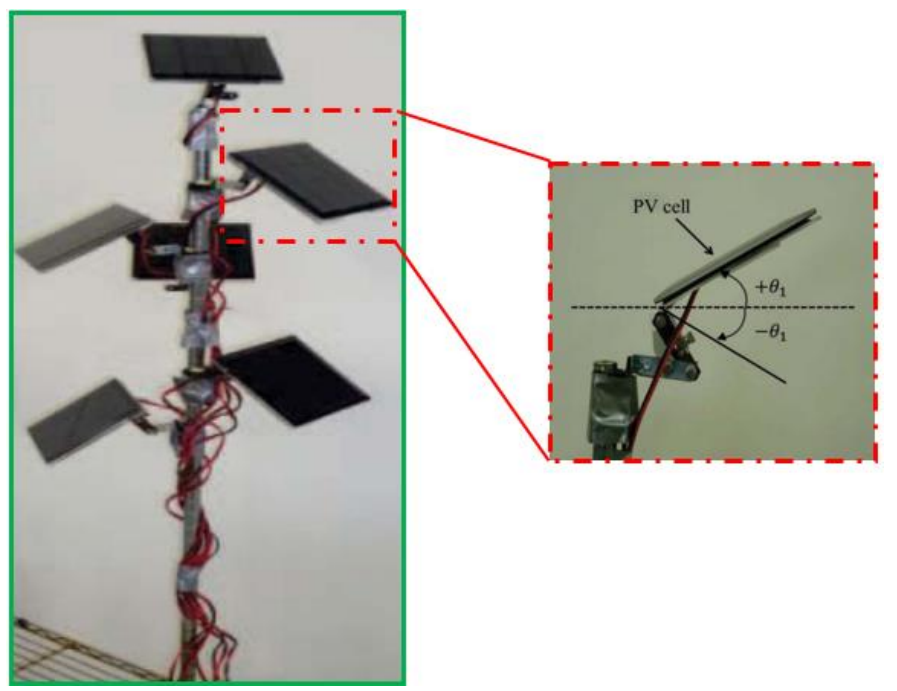

Fig. 19. FPM construction and inclination angle [31]

181 Mochizuki and Yachi [32] also developed a 3D FPM structure with a 1/3 phyllotaxis and simulated the system performance 182 considering the effect of shadow cast as illustrated in Fig. 20. To be more specific, Fig. 20 descripts the parallelogram projected 183 area of each PV panel from the sun at noon on June. 


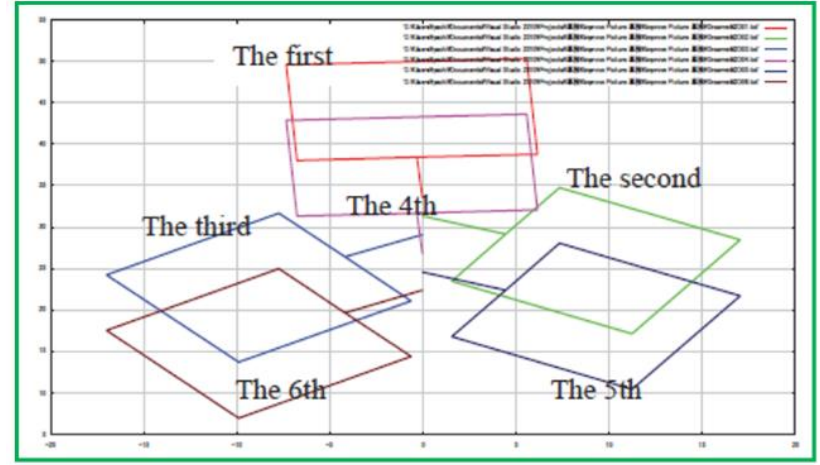

Fig. 20. FPM projected area at noon [32]

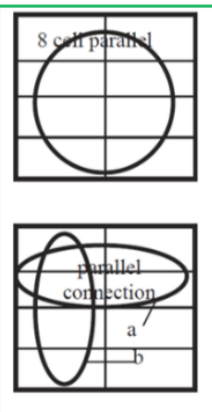

(a)

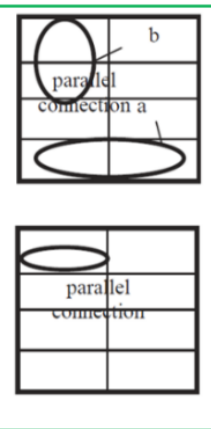

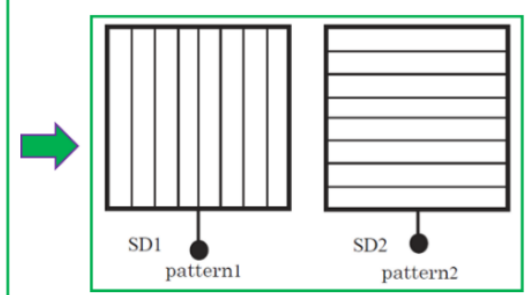

(b)

Fig. 21. FPM connection: (a) series and parallel; (b) 8-cell stripe patterns [32]

188 Fig. 21 (a) presents the solutions utilized for dividing eight cells in this simulation process including 8 parallel connections, 4 parallel and 2 series connections, 2 parallel and 4 series connections as well as 8 series connections. A solar cell with a radially divided panel, referred to a striped division pattern, is given in Fig. 21 (b). They confirmed from Fig. 22 that the electricity production of eight series connections reduces by $13 \%$ in comparison to the value of eight parallel connections. And also, it is found that the biggest reduction is approximately $15 \%$ in summer.

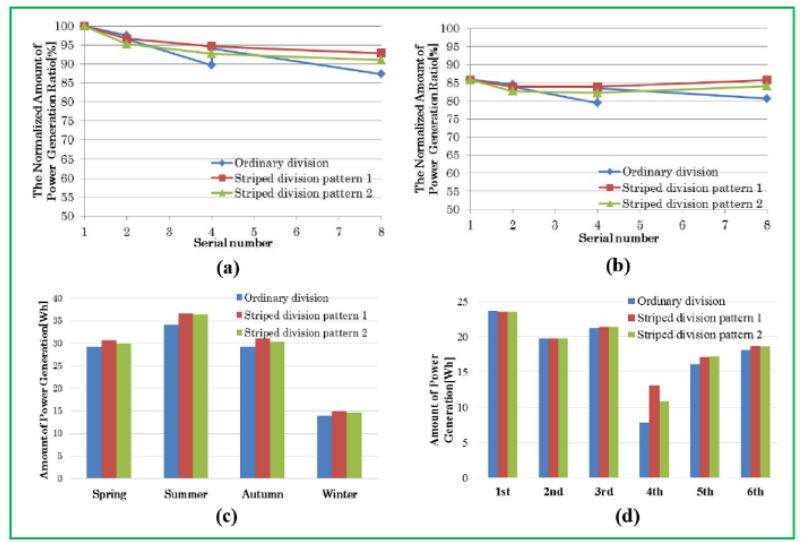

194 Fig. 22. Results comparison: (a) between power production and cell series number; (b) between power production and cell series number in installed DC-DC converter; (c) electricity production in each season; (d) electricity production for FPM structure [32] 
Khan and Gaur [33] proposed a 3DPV FPM structure to avoid environmental pollution and other natural hazards in India, the schematic diagram of normal arrangement for the 3DPV FPM is presented in Fig. 23 (a). Meanwhile, the top view of the branch structure, that has an angular separation of $144^{\circ}$, is given in Fig. 23 (b). It can be obtained that the performance of the 3DPV FPM structure is higher compared to that of traditional solar PV panel.

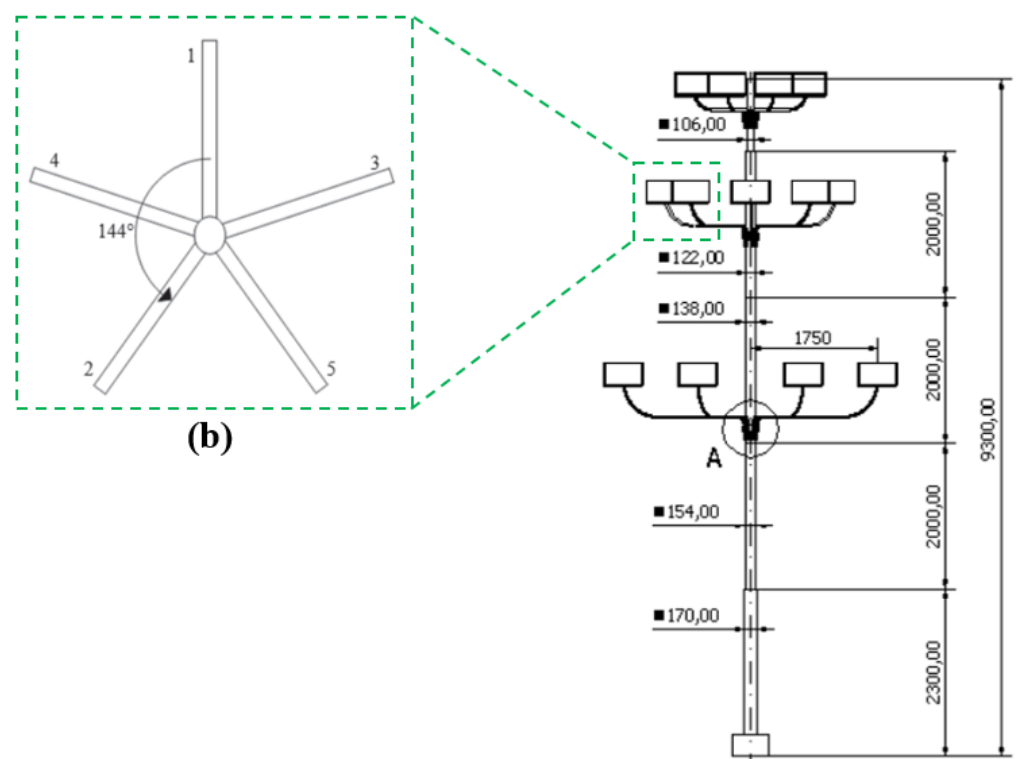

Fig. 23. Schematic diagram of 3DPV FPM structure: (a) arrangement; (b) a top view [33]

Hyder et al. [34] reviewed a hemispherical dome 3DPV FPM structure with five panels at three directions as shown in Fig. 24, and specified that the whole system capacity and annual electricity generated are about $2 \mathrm{~kW}$ and $2610.8 \mathrm{kWh}$, respectively.

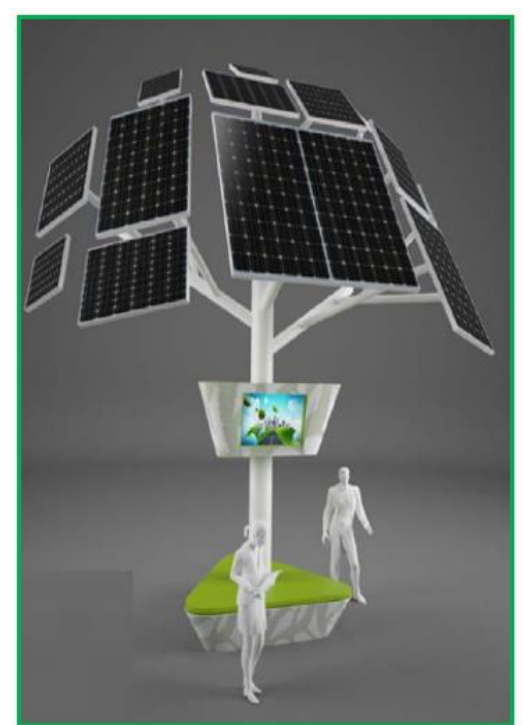

(a)

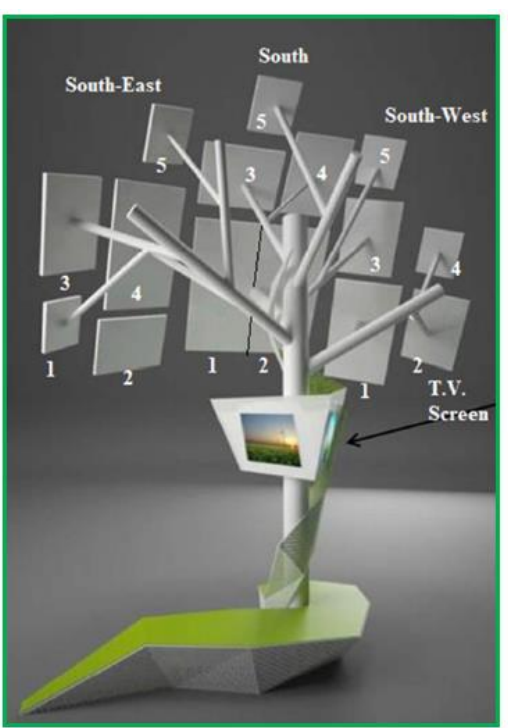

(b)

Fig. 24. Schematic diagram of hemispherical dome 3DPV FPM structure: (a) front view; (b) back view [34, 35] 

and Kuala Lumpur (Malaysia). The solar panel arrangements are given in Fig. 25, beginning from one panel in the first layer and growing by two extra panels in every next layer.

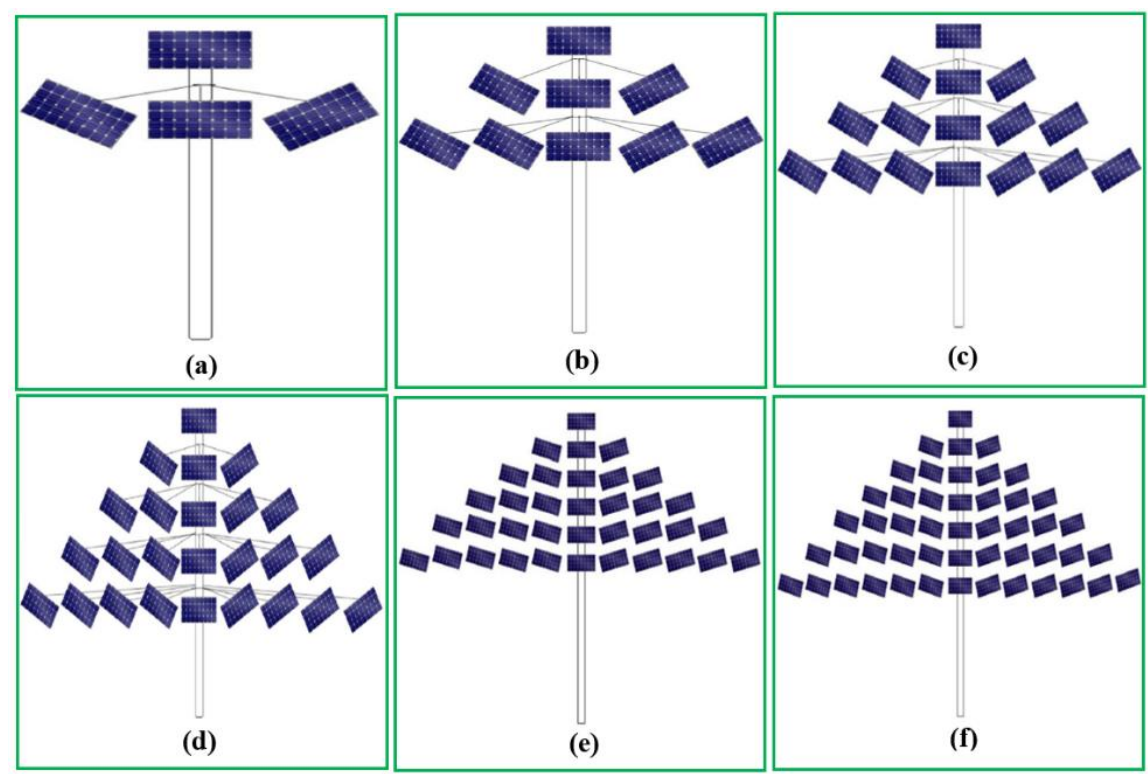

Fig. 25. Schematic diagram of 3DPV different structures [36]

211 The relationship between the panel and layer is given as:

$$
\mathrm{NPi}=\mathrm{np}(\mathrm{i}-1)+2
$$

where $\mathrm{i}$ is the number of the layers; $\mathrm{NP}_{\mathrm{i}}$ is the number of panels in the $\mathrm{i}^{\text {th }}$ particular layer.

214 The tilt angle is calculated as:

215 Tilt angle $= \pm \frac{23}{\text { Number of layers in between the centre and end layer }+1}$

Angular spread $=15 \times\left(\mathrm{NP}_{\mathrm{i}}-1\right)$

Arc Length of $i^{\text {th }}$ layer $=\mathrm{NP}_{\mathrm{i}}(1)+\left(\mathrm{NP}_{\mathrm{i}}-1\right) \times \mathrm{g}$

218 where $\mathrm{NP}_{\mathrm{i}}$ is the number of panels in the $\mathrm{i}^{\text {th }}$ layer; 1 is the solar panel length $(\mathrm{m})$; $\mathrm{g}$ is the gap between panels (m).

Arc Length of $\mathrm{i}^{\text {th }}$ layer $=\frac{\theta_{\mathrm{i}}}{360} \times 2 \pi \mathrm{r}_{\mathrm{i}}$

220 where $\theta_{\mathrm{i}}$ is the angular spread of the $\mathrm{i}^{\text {th }}$ layer

221 The radius of a layer of the 3DPV model is written as:

$\mathrm{r}_{\mathrm{i}}=\frac{360}{2 \pi \times \theta_{\mathrm{i}}} \times\left[\mathrm{NP}_{\mathrm{i}}(\mathrm{l})+\left(\mathrm{NP}_{\mathrm{i}}-1\right) \times \mathrm{g}\right]$ 
$225 \quad$ Area of $i^{\text {th }}$ layer $=\frac{\theta_{i}}{360} \times \pi r_{i}^{2}$

226 It can be found from Fig. 26 that annual electricity output of the 3DPV FPM structure could achieve 17.79\%, 41.06\% and 20.97\%

227 of the energy produced by the land-based solar energy systems at Kuala Lumpur, Bhopal and Barcelona, respectively.
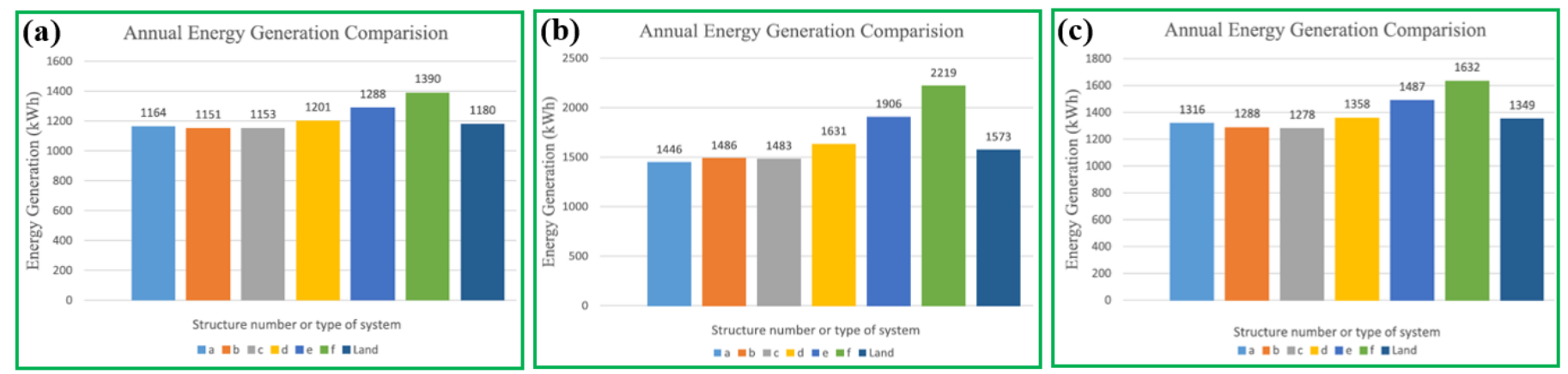

Fig. 26. Annual energy production comparison between 3DPV FPM structure and traditional PV panels at different location: (a)

Kuala Lumpur; (b) Bhopal; (c) Barcelona [36]

\subsection{GS structure}

Benguar et al. [37] proposed a novel golden spiral (GS) structure based on the theory of golden ratio and FPM structure to increase the panel energy conversion efficiency. This design process of the GS structure is exhibited in Fig. 27 (a-d). The total rectangular area of the GS structure is $1 \mathrm{~m}^{2}$, and a spiral is used to connect the edges of a square. Fig. 27 (e) presents the actual prototype that fits in the GS with the popsicle sticks and surface constructed, to accommodate the PV cells. They concluded that the 3DPV GS structure is able to produce $26.13 \%$ more electricity compared to the conventional flat solar PV panel.

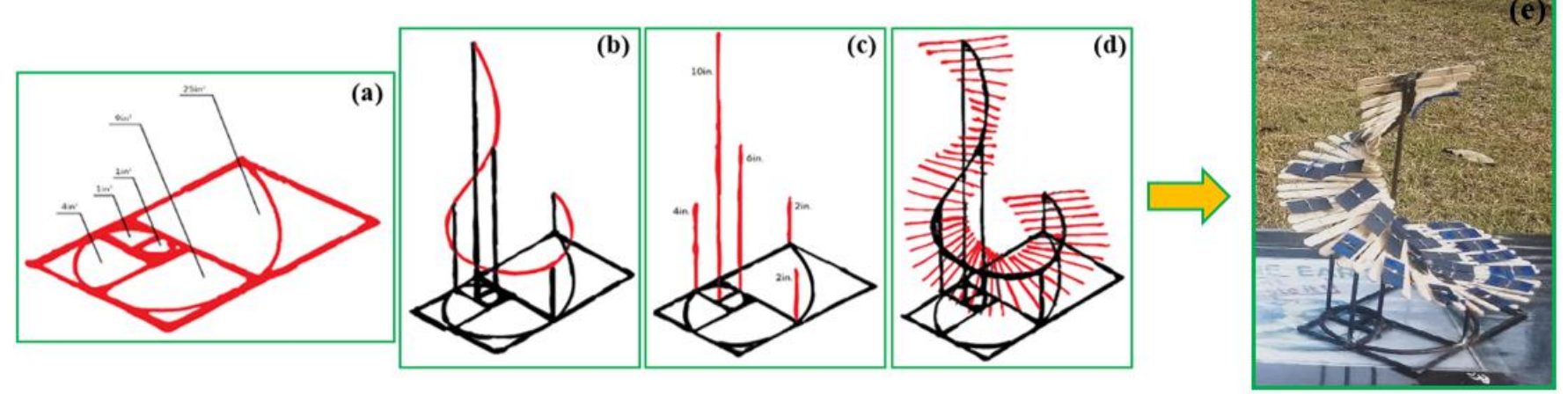

Fig. 27. The 3DPV GS structure solar panel: (a) base of GS structure solar panel; (b) base with posts for elevation; (c) attachment 


\subsection{D-DSSC structure}

241 Liu et al. [38] developed a novel 3D dye-sensitized solar cell (DSSC) technology to investigate the capability of sunlight 242 absorption at different directions, the 3D-DSSC technology is illustrated in Fig. 28, which is based on the pine tree structure 243 associated with copper wires.

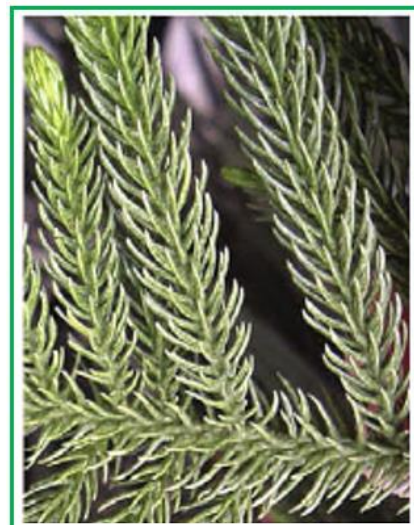

(a)
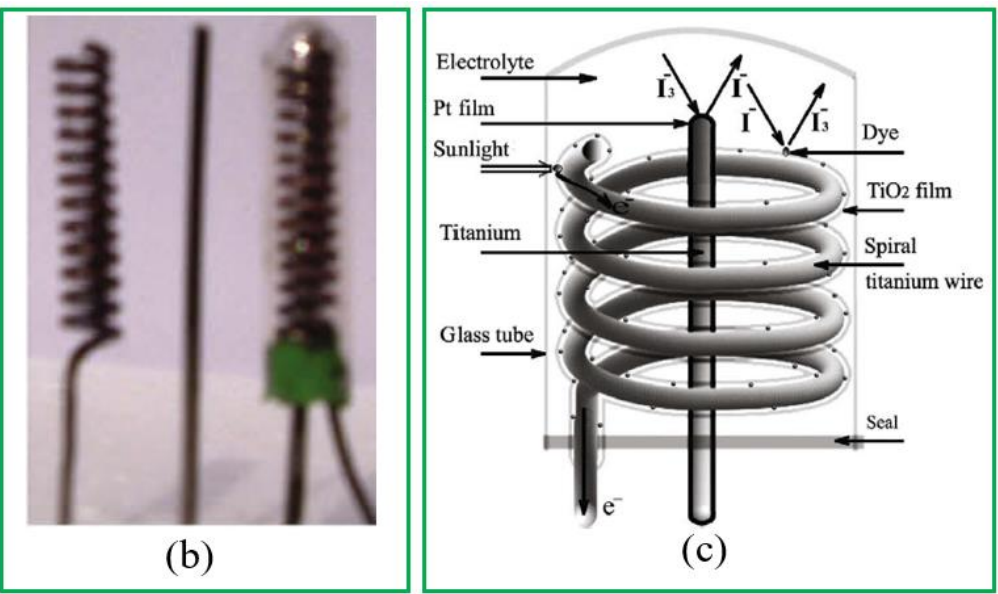

Fig. 28. Photo and diagram of 3D-DSSC: (a) actual leaves growing; (b) actual module; (c) structure and principles [38]
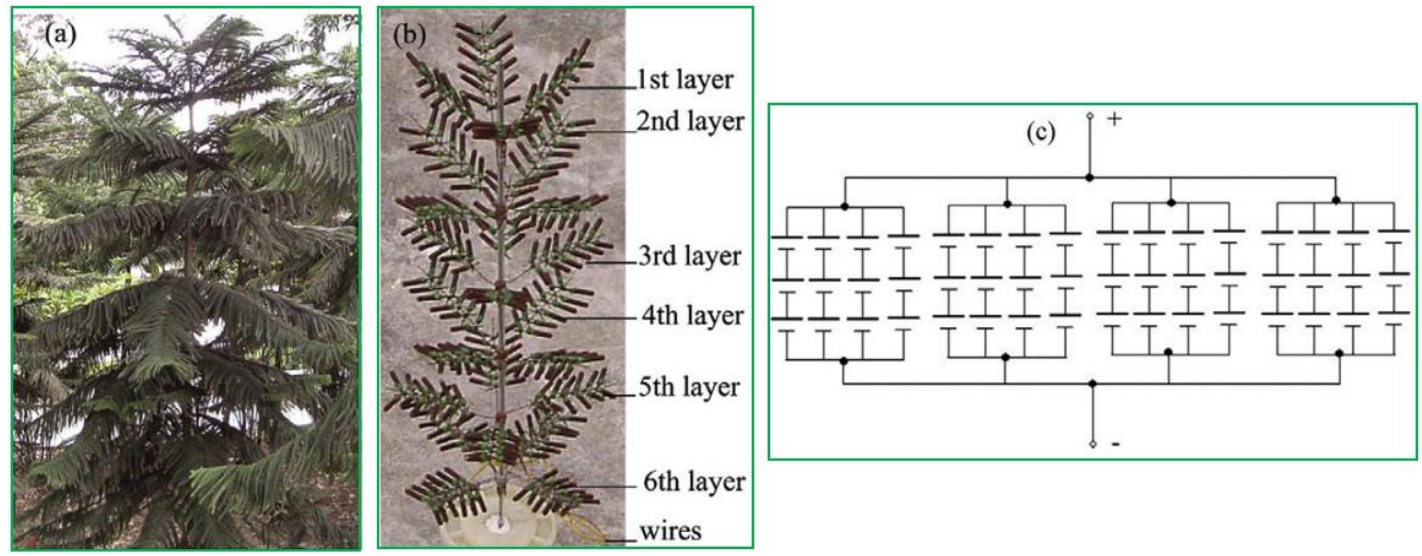

Fig. 29. Photo and diagram of 3D-DSSC structures: (a) actual pine tree; (b) 3D-DSSC; (c) series-parallel connection [38]

Furthermore, the photo and diagram of the 3D-DSSC structure are displayed in Fig. 29. Specifically, the branch of the 3D-DSSC of the 3D-DSSC structure is capable of absorbing more sunlight from all directions and increasing efficiency by $3.36 \%$ in comparison to the conventional flat solar PV cell's.

\subsection{DPV-VAWT structure}

Tarabsheh et al. $[39,40]$ developed a novel 3DPV vertical axis wind turbine (VAWT) structure to produce more power. In comparison to traditional structure, the thin film PV modules are attached on the surface of the rotating VAWT as presented in Fig. 30. Five blades in the structure are separated equally by angles of $72^{\circ}$ as shown in Fig. 31. The 3DPV-VAWT prototype is 

the top of the rotor. Meanwhile, the effects of bending and title angles are investigated as shown in Fig. 32 (b) and (c).

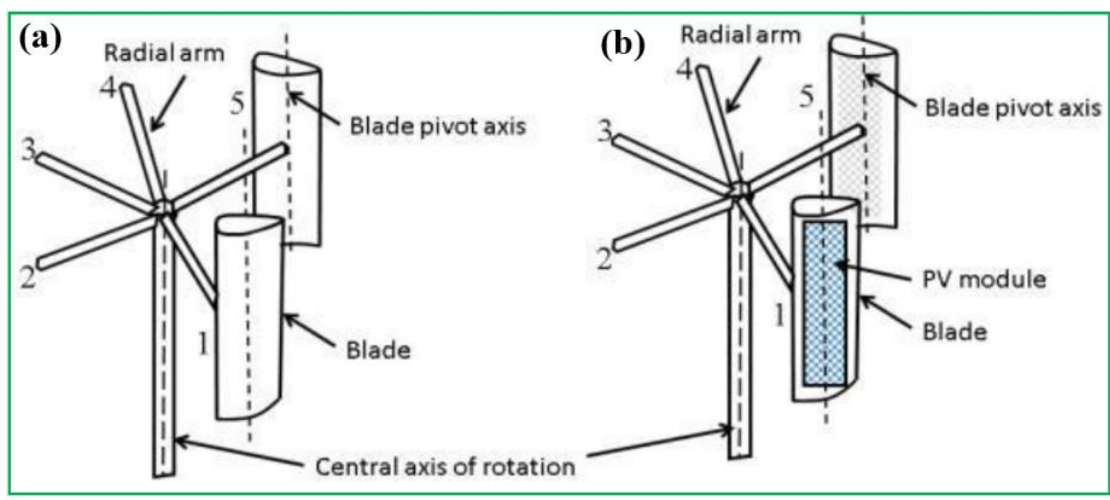

Fig. 30. The schematic diagram of: (a) traditional VAWT; (b) 3DPV-VAWT [39]
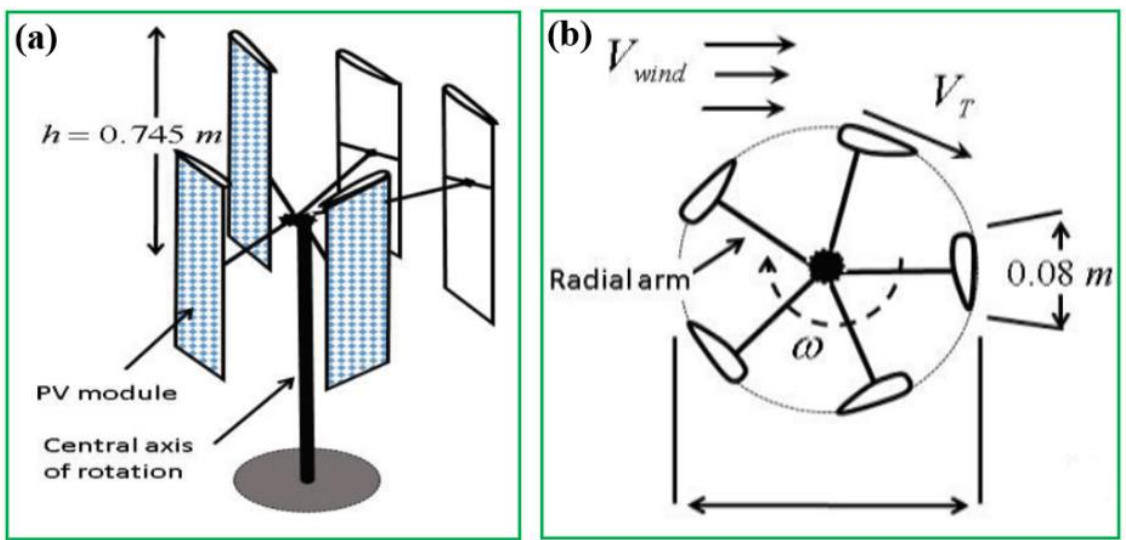

Fig. 31. The schematic diagram of: (a) isometric view; (b) top view [40]
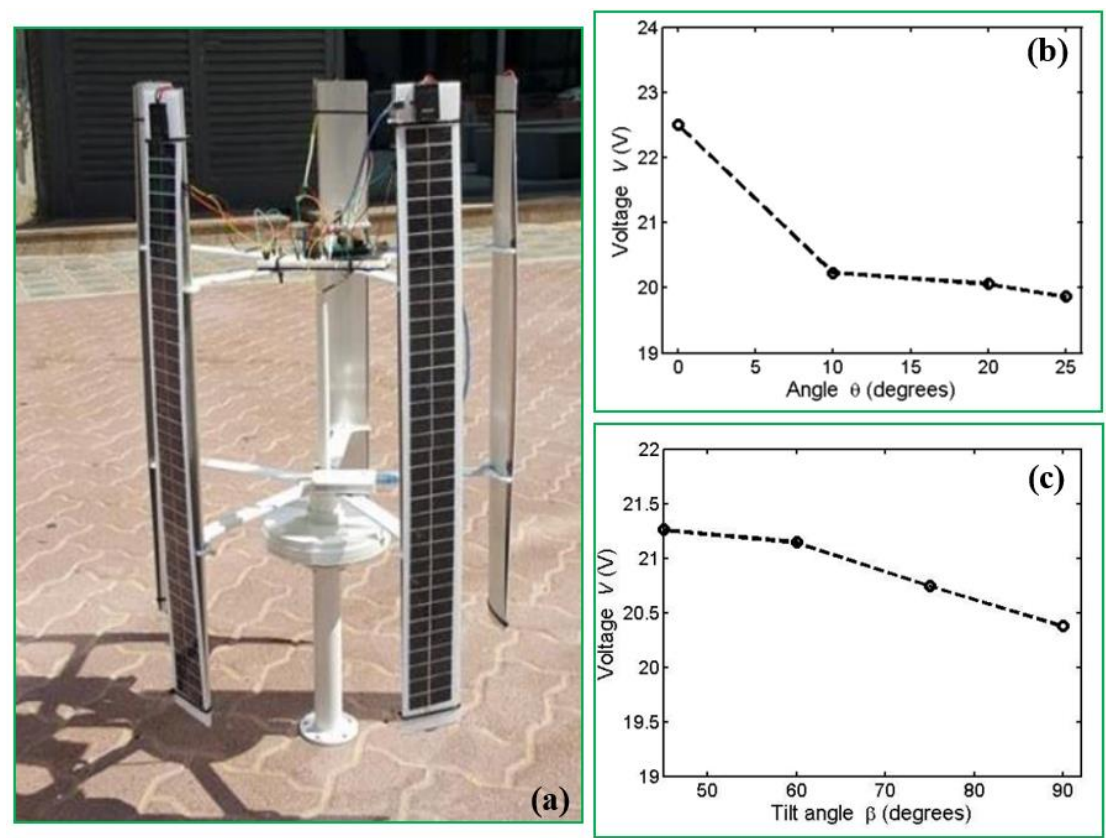

Fig. 32. Experiment: (a) prototype; (b) bending test; (c) title test [39, 40] 
265 Their results reveal that when the bending and title angles of PV modules varies from $0{ }^{\circ}$ to $25^{\circ}$ and from $45^{\circ}$ to $90^{\circ}$, the output voltages decrease from $22.5 \mathrm{~V}$ to $19.6 \mathrm{~V}$ and from $21.3 \mathrm{~V}$ to $20.5 \mathrm{~V}$, respectively. This means that adding the bending and title angles of PV modules will results in a reduction in the output voltage. Furthermore, the merits of the 3DPV-VAWT structure are illustrated as below $[39,40]$ :

- A minimum area can be utilized.

- $\quad$ The rotating 3DPV-VAWT structure has the ability for self-cooling to improve output power.

- There is no need to build a sun tracker since at least one of the rotating PV modules will face the sun at a time.

- The 3DPV-VAWT structure is capable of preventing the dust accumulation on the surface of rotating PV module for long term operation with high efficiency.

\subsection{Cubic SSC structure}

Bernardi et al. [41, 42] built a 3D cubic silicon solar cell (SSC) structure to improve the produced energy density and compared to traditional flat panel. This 3D cubic SSC structure composes of a cube open at the top covered by PV cells both on the exterior and interior surfaces as shown in Fig. 33. Moreover, a similar open parallelepiped of the same base area but twice as high, and a tower with ridged faces are given in Figs. 33 (b) and (c). The structures are made of 9, 17 and 32 commercially available Si solar panels respectively.
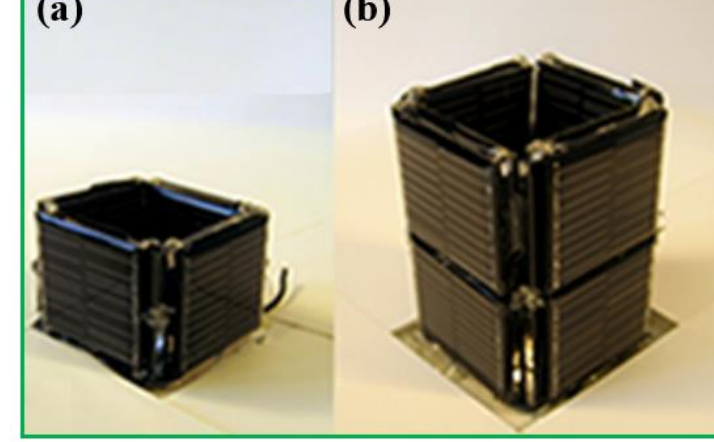

(c)

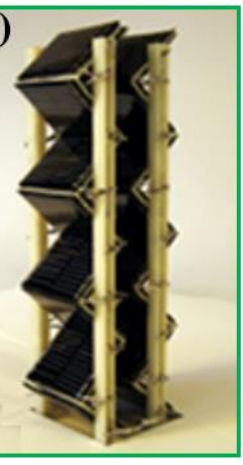

Fig. 33. Schematic of cubic SSC structures [41, 42]

282 Fig. 34 (a) illustrates the computer simulation results are in very good agreement with the testing data. Moreover, the power production could reach nearly twice for the 3DPV model in comparison with the traditional PV panel as presented in Fig. 34 (b). Meanwhile, as indicated in Fig. 34 (c), the bigger improvement can be realized by more complex and taller structures, for example, the open parallelepiped and ridged tower. 


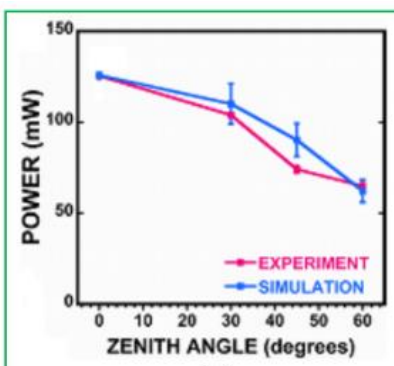

(a)

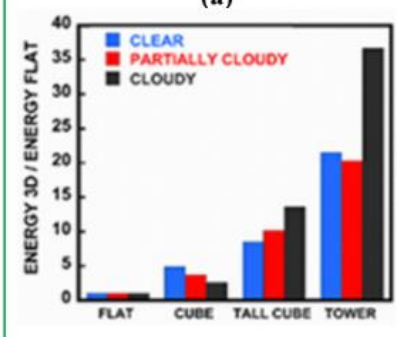

(c)

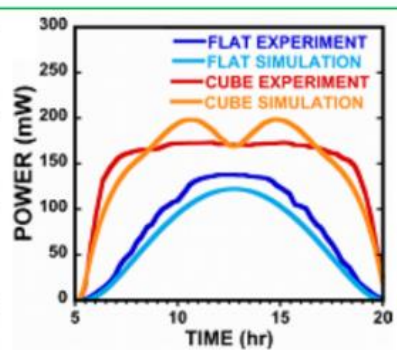

(b)

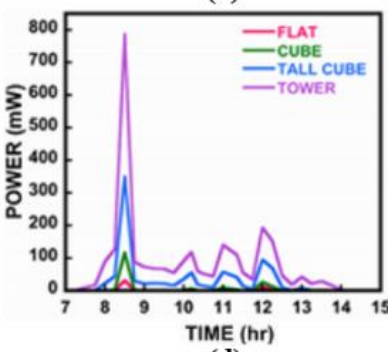

Fig. 34. Results analyses of 3 DPV cubic SSC structure [41, 42]

Specifically, the daily electricity production in a clear winter day are $21.5 \mathrm{Wh}$ for the tower cube, $8.49 \mathrm{Wh}$ for the parallelepiped cube as well as $4.88 \mathrm{Wh}$ for the open cube. Owing to the diffuse light caused by mist, rain and clouds, the cubic SSC structure is able to capture much more light in comparison with flat panel. Furthermore, it can be found from Fig. 34 (d) that the reduction in 3DPV cubic SSC structure electricity output owing to clouds is less significant compared to the conventional flat PV panel. In other words, the cubic SSC structures are less affected by weather condition. Therefore, based on the cubic SSC structures, a novel 3D charger for electric bike [42] is proposed in Boston to meet the demand of urban area development as shown in Fig. 35 , the electricity production is in the range from 2 to $3 \mathrm{MWh} /$ year. This denotes that the 3DPV technology can provide at least 130000 miles per year for a e-bicycle when the weather and wind effects are considered.

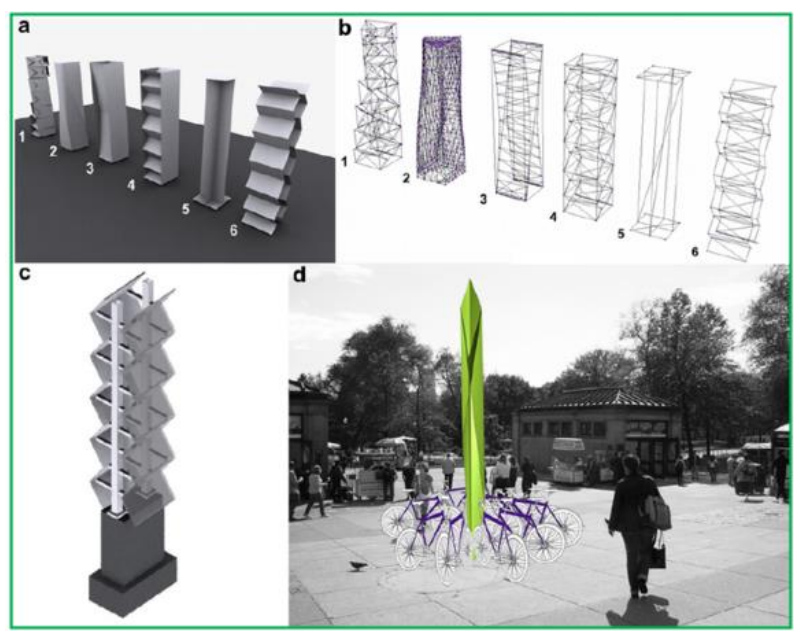

Fig. 35. 3DPV bicycle charger technology: (a) e-bicycle charging tower; (b) internal structure; (c) prototype; (d) drawing of an e-bicycle charging station [42] 


\subsection{Spherical SSC structure}

300 Spherical silicon solar cell (SSC) is composed of silicon with p-n junctions over its surface, this structure could be a better 301 approach. Firstly, the cell surface receives sunlight from all directions. Secondly, the spherical SSC, which is treated as microsphere, has a diameter of approximately $1 \mathrm{~mm}$ that improves the ratio of surface area to volume for a large light-receiving surface. Thirdly, the crystals are generated based on melting granular silicon polycrystals, this contributes to reducing the processing loss because of traditional wafer making, and ensuring a high photoelectric conversion efficiency as well as decreasing issues related to deterioration [43].

The spherical SSC module has very low waste during the fabrication procedure [41], the structure and production process of spherical SSC module are demonstrated in Fig. 36.

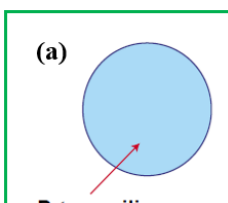

P-type silicon

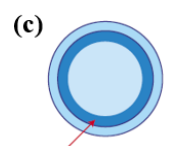

p-n junction boundary (b)

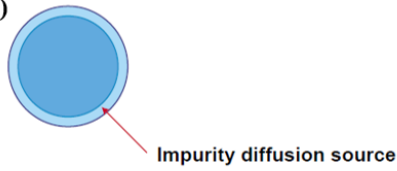

(d)

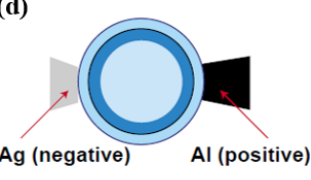

(e)

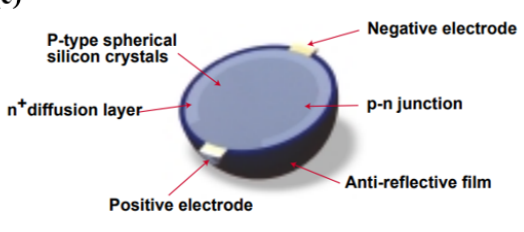

Fig. 36. Structure and production process of spherical SSC module [44]

A typical spherical micro SSC module is descripted in Fig. 37 (a), which adds a white reflector to the back. The reflector would reflect sunlight that passes each cell, thus enhancing the amount of light reaching each cell, the prototype spherical micro SSC module is presented in Fig. 37 (b), which can be used on the sides of vehicles and buildings to exploit their low-directivity features.
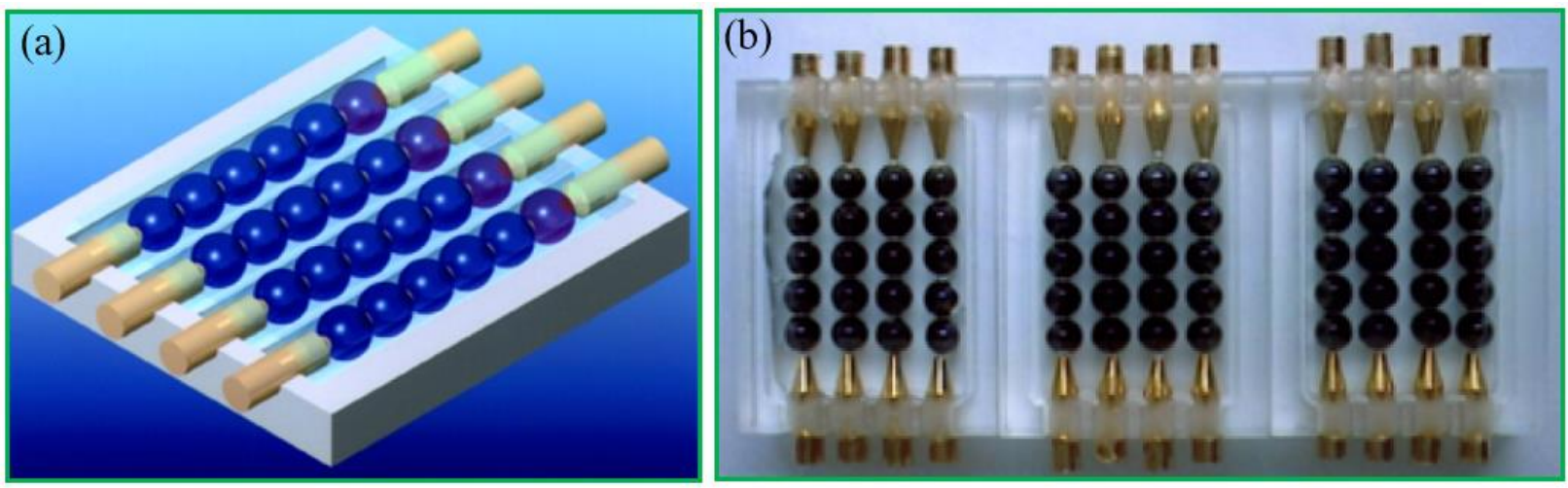

Fig. 37. Photos of spherical SSC: (a) basic module; (b) prototype module [44]

316 Verma et al. [45] proposed a spherical SSC structure to investigate the performance of lensing the light into the substrate as given in Fig. 38. As shown in Fig. 36, the ray trajectories in the simulation field are illustrated when the light indents are at 
angles of $0^{\circ}, 45^{\circ}$ and $60^{\circ}$ individually. According to Fig. 40, the maximum absorption improvement regarding bare silicon absorber is achieved with $3 \mu \mathrm{m}$ wafer thickness. Therefore, the minimum thickness means the minimum material utilization and leads to the maximum expense saving. It is confirmed that an absorption improvement of around $65 \%$ is attained for a $3 \mu \mathrm{m}$ wafer thickness in terms of the bare silicon substrate.

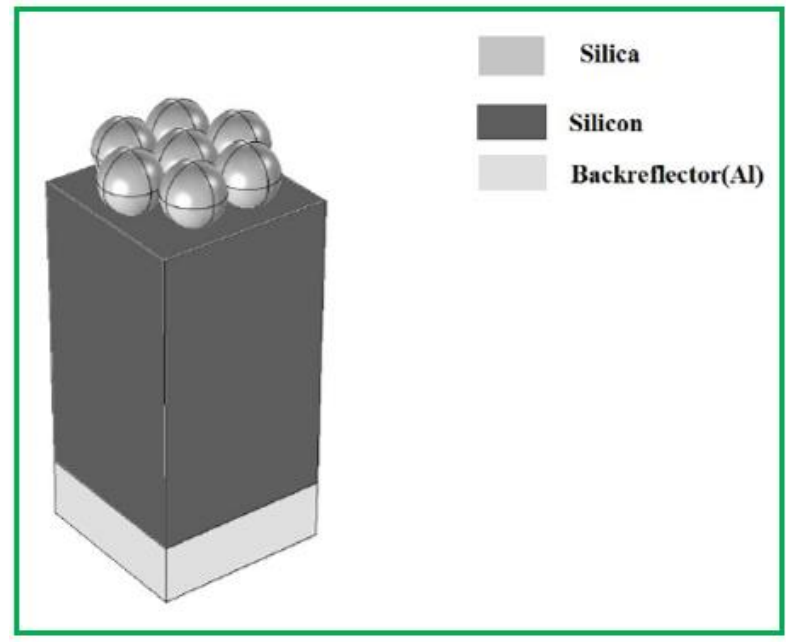

Fig. 38. The spherical SSC module [45]
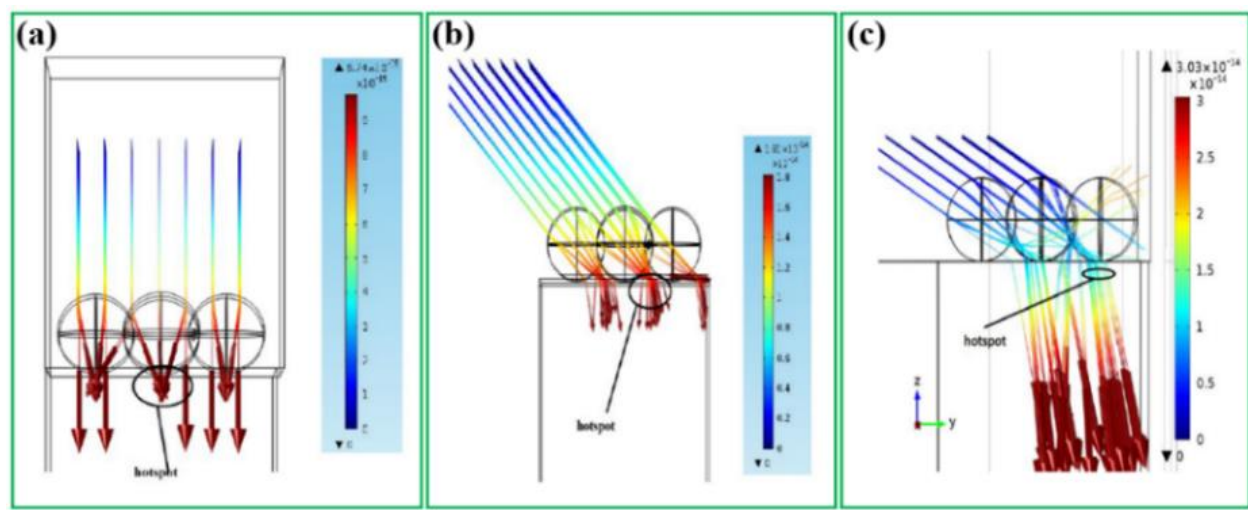

Fig. 39. Ray trajectory in the geometrical field with sunlight incident angle: (a) $0^{\circ}$; (b) $45^{\circ}$; (c) $60^{\circ}$ [45]

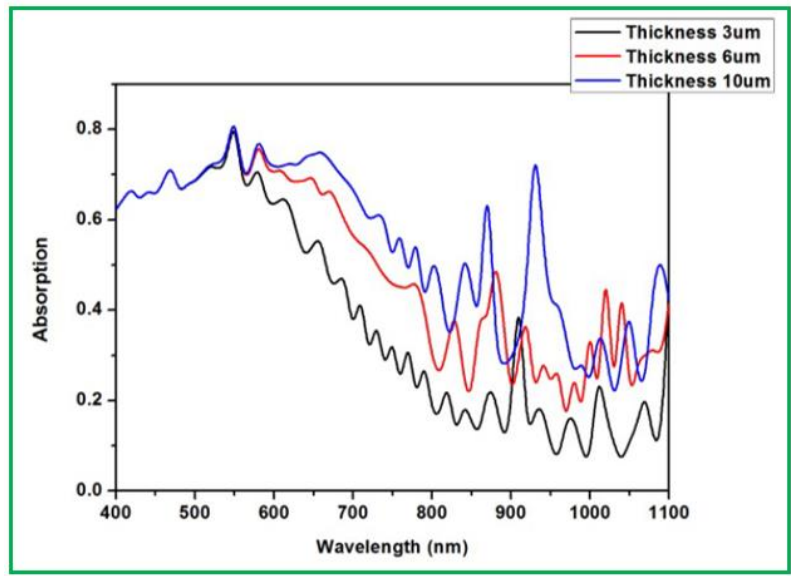

Fig. 40. Light absorption with different thicknesses [45] 


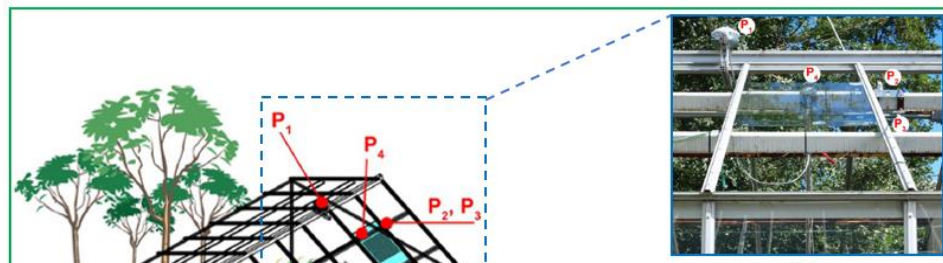

(b)

329 Fig. 41. Configuration of sunlight and shadow measurements: (a) greenhouse roof frames; (b) test points; (c) actual module [46] 330 Cossu et al. [46] designed a novel spherical micro SSC structure with semi-transparent module (STM) applied for the greenhouse to meet the light requirement of tomato as shown in Fig. 41 (a). The first pyranometer (P1) is installed on the roof to assess the horizontal global solar irradiance as given in Fig. 41 (b), while second and third pyranometers (P2 and P3) are positioned at the top and bottom of roof surfaces, respectively. The forth pyranometer (P4) is mounted behind the margin of the semi-transparent 3DPV region in order to test the structure's transparent, and the fifth one (P5) is used to track the shadow of semi-transparent cell region. Meanwhile, the actual module is shown in Fig. 41 (c).

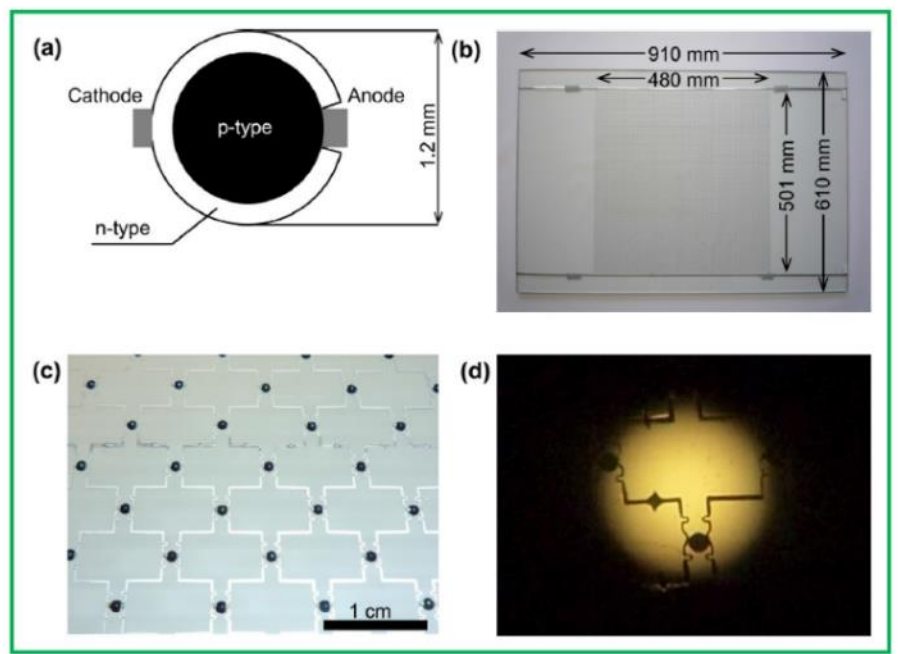

Fig. 42. Spherical SSC: (a) cross-sectional view of the structure; (b) prototype module; (c) actual module; (d) overlapping [46] To be more specific, Fig. 42 (a) presents a $1.2 \mathrm{~mm}$ diameter spherical SSC structure which consists of a n- and p-type semiconductors as the external shell and internal core, respectively. The STM is assembled based on 4800 cells as depicted in Figs. 42 (b) and (c). The 4800 cells are sandwiched between 3-mm-thick glass plates embedded in 2-mm-thick transparent resin. Meanwhile, Fig. 42 (d) displays the overlapping of the solar cells. It is found that the STM energy conversion efficiency is steady at about $0.2 \%$ and not impacted by the slope angle. 


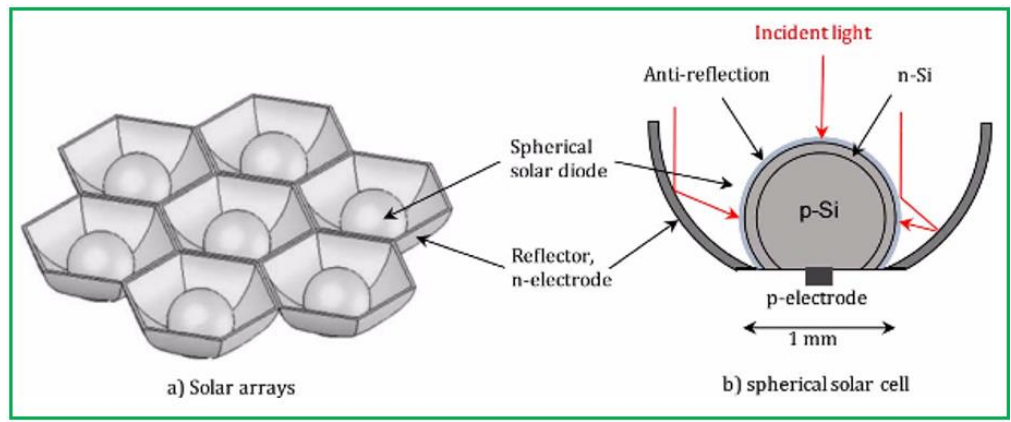

Fig. 43. Schematic of spherical SSC structure $[47,48]$

345 Minemoto et al. $[47,48]$ also proposed a spherical SSC structure to implement a performance assessment in comparison to conventional PV panels as presented in Fig. 43. The structure composes of a p-type substrate surrounded by an n-type layer of semiconductor material. In the meantime, it has a great potential for low-cost and low-waste fabrication. Their results reveal that the conversion efficiency is able to be enhanced up to $18.3 \%$ in comparison to conventional solar PV panel.

Kitamura et al. [49] developed a spherical SSC structure with seven PV cells, and each cell is set in a reflector cup on the substrate as shown in Fig. 44 (a). The directional characteristics of the spherical SSC structure concerning LED light are showed in Fig. 44 (b). It is concluded that the signal-to-peak noise $(\mathrm{S} / \mathrm{N})$ ratio of measured spectrum with a sinusoidal waveform is $25 \mathrm{~dB}$. Based on the spherical SSC structure, an optical wireless voice transmission system is established to offer optical wireless digital-sound transmission and reduce the S/N ratio as shown in Fig. 45.
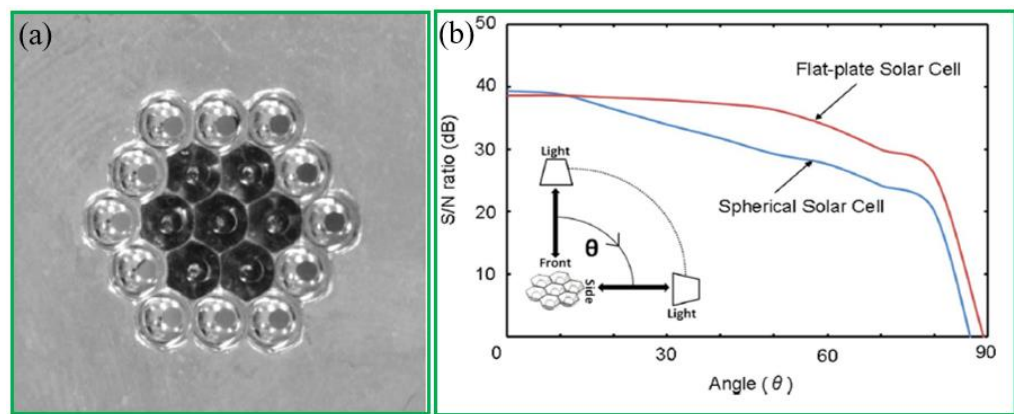

Fig. 44. (a) Actual spherical SSC structure; (b) directional characteristics [49]

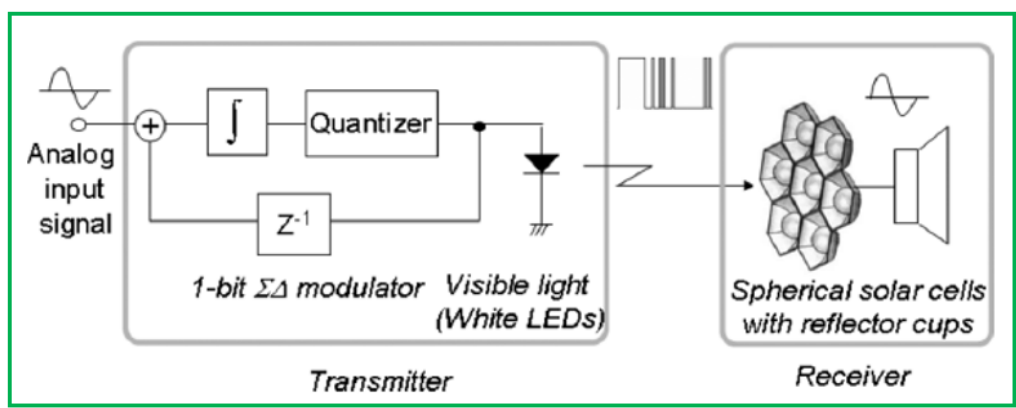

Fig. 45. Optical wireless transmission scheme [49] 


\subsection{SiNW and SiNC structures}

359 Silicon nanowire (SiNW) and Silicon nanocone (SiNC) structures have the potential to improve energy conversion efficiency, 360 particularly for the materials that have low diffusion lengths [50]. Recently, tremendous progress has been made in developing $3613 \mathrm{DPV}$ that can, potentially, be mass deployed. One example is a PV structure that incorporates 3D, single-crystalline n-CdS nanopillars in polycrystalline thin films of p-CdTe to achieve high efficient collection and absorption of light as shown in Figs. 46 and 47.

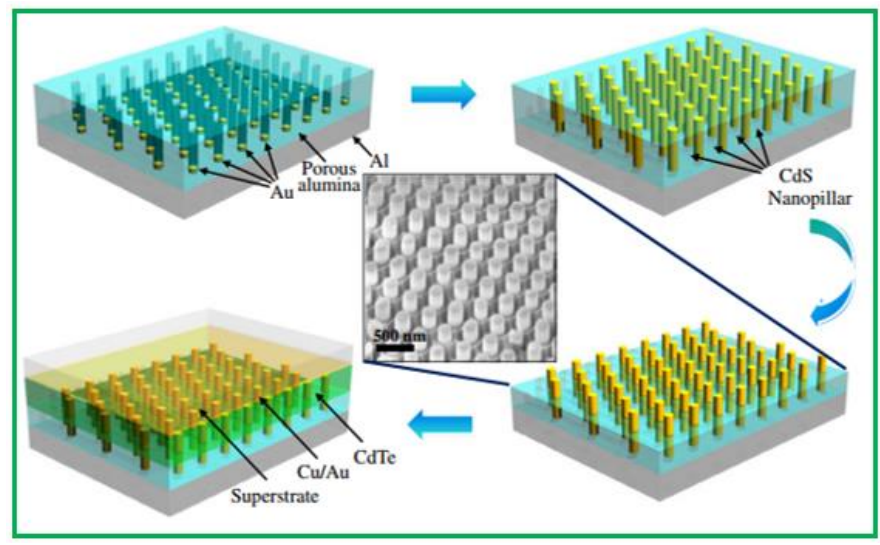

Fig. 46. 3DPV nanostructure [51]

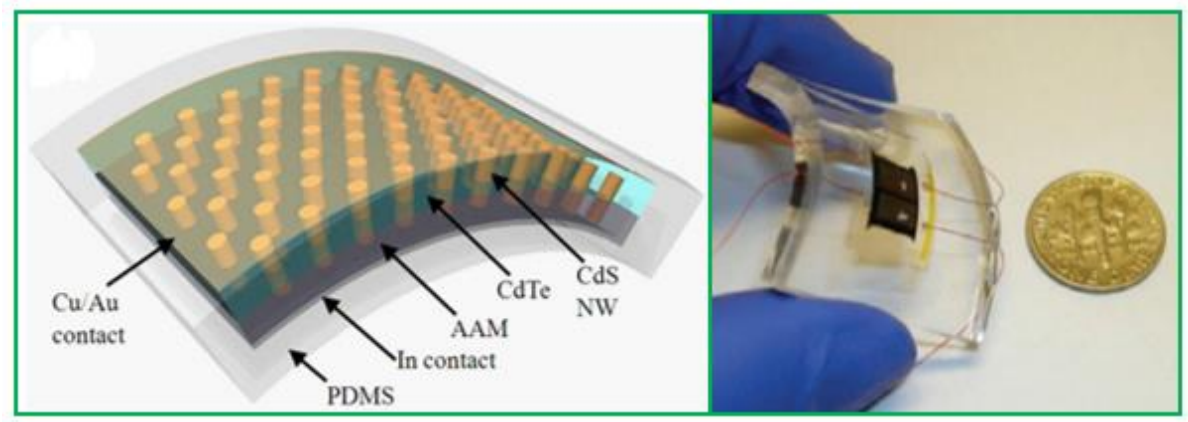

Fig. 47. (a) Artistic rendering; (b) actual structure [51]

368 The carrier collection efficiency is improved based on the geometric configuration of the nano-pillars [51]. It is concluded from 369 Figs. 48 (a) and (b) that the 4-mm-thick PDMS substrate presents the maximum tensile and compressive strain of around 8\% at 370 the top and bottom surfaces, respectively. The conversion efficiency of the 3DPV NW and the I-V features under different 371 bending conditions are given in Figs. 48 (c) and (d). 


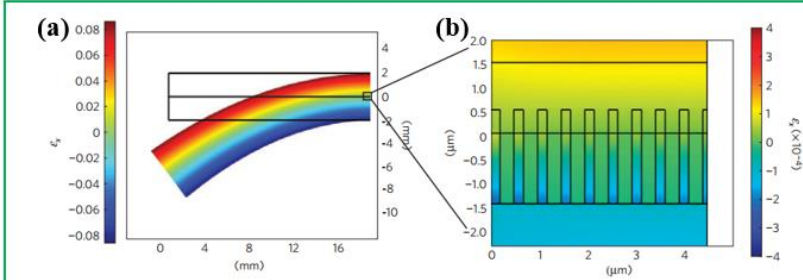

(c)

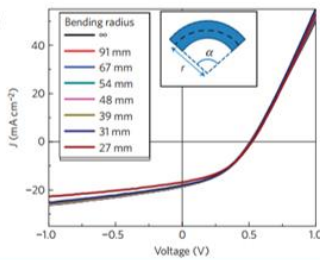

(d)

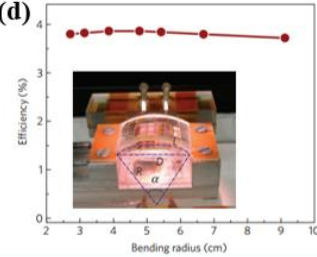

Fig. 48. (a)(b) Structure simulation analyse; (c) I-V characteristics at various bending radii; (d) efficiency [51]

374 Lundgren et al. [52] designed 3D branched nanowire (BNW) tree structures and forest configurations as shown in Figs. 49 and

50. It can be seen from Fig. 51 that the BNW forest structure has the optimal sunlight absorption ability, realizing the maximum absorption of $97 \%$ at $0.5 \mu \mathrm{m}$ wavelength.

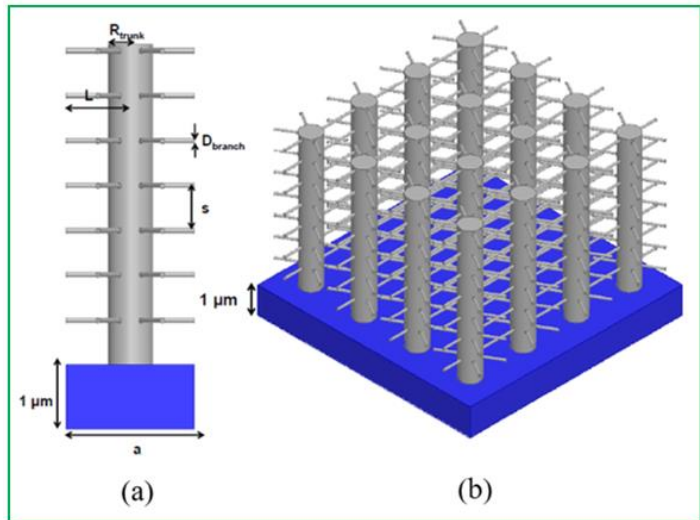

Fig. 49. 3D BNW: (a) single BNW tree; (b) array of BNW trees [52]

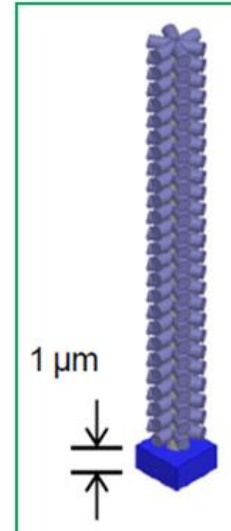

(a)

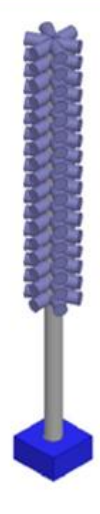

(b)

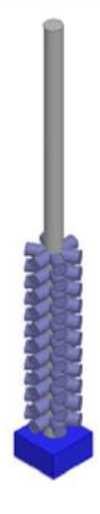

(c)

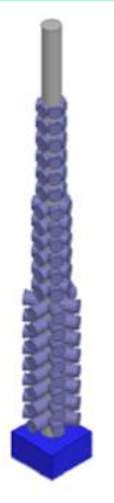

(d)

Fig. 50. 3DPV BNW structures: (a) plain BNW tree; (b) canopy; (c) scrub; (d) conifer [52] 


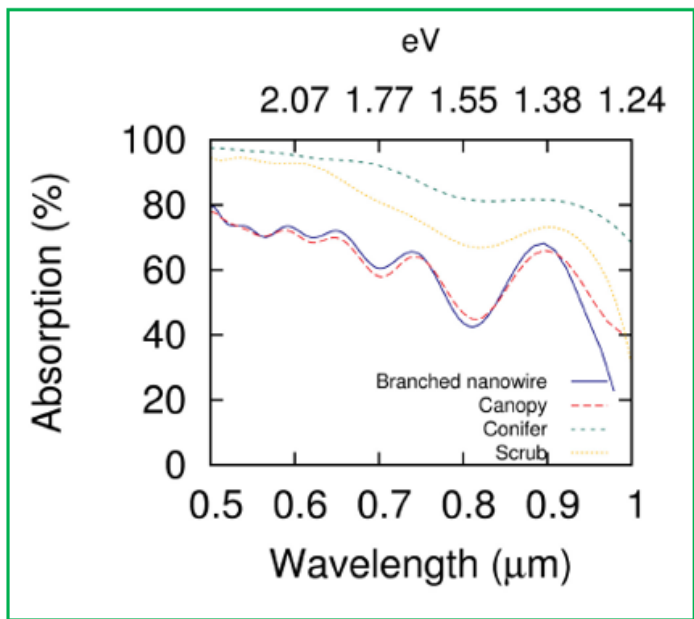

Fig. 51. The comparison of simulation results [52]

Wang et al. [53] proposed an innovative 3DPV NW structure as given in Fig. 52. Each sub-cell is made of a n-type NW core encapsulated in a p-type NW shell, which can be realized via regulating the growth temperature to achieve the switch between the axial growth and core shell.

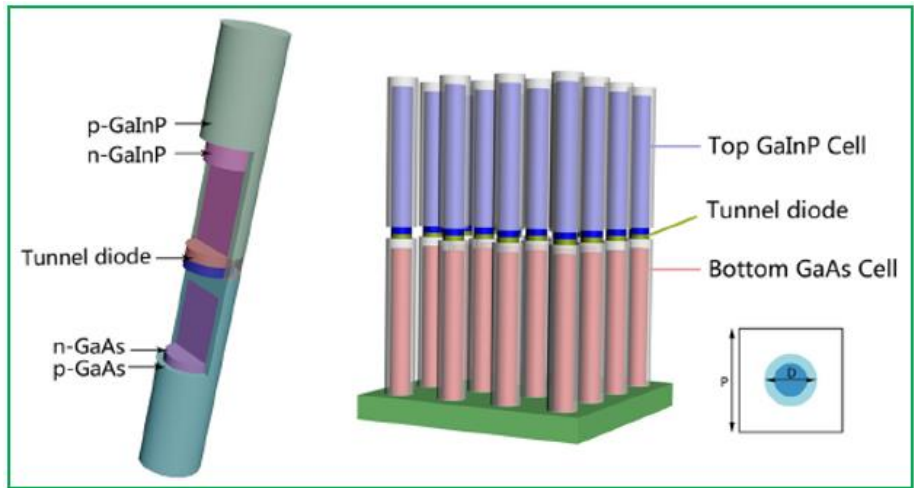

Fig. 52. 3DPV NW structure [53]

Yao et al. [54] demonstrated a selective area grown GaAs n-i-p nanowire array on top of a Si cell, in which they saw voltage addition and reached a total efficiency of $11.4 \%$ as shown in Fig. 53. This is an encouraging indicator that high efficiency can be achieved in the nanowire-on-Si architecture [55].

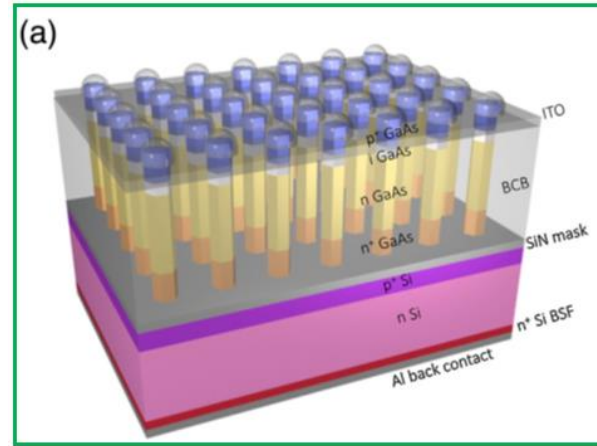

(b)

Fig. 53. SiNW solar cell: (a) structure; (b) Current-voltage curves [54] 
Li et al. [56] studied the optical structure features of silicon nanowire (SiNW) and silicon nanocone (SiNC). According to Fig. 54, the SiNW is established based on a circular cylinder with hemisphere top whereas the SiNC is setup as five isometric subwires. Their results show that the SiNC is superior over the SiNW in terms of light-concentration performance because of its continuous diameter, while the sunlight-absorption performance of the SiNC arrangement is worse compared to the SiNW arrangement.

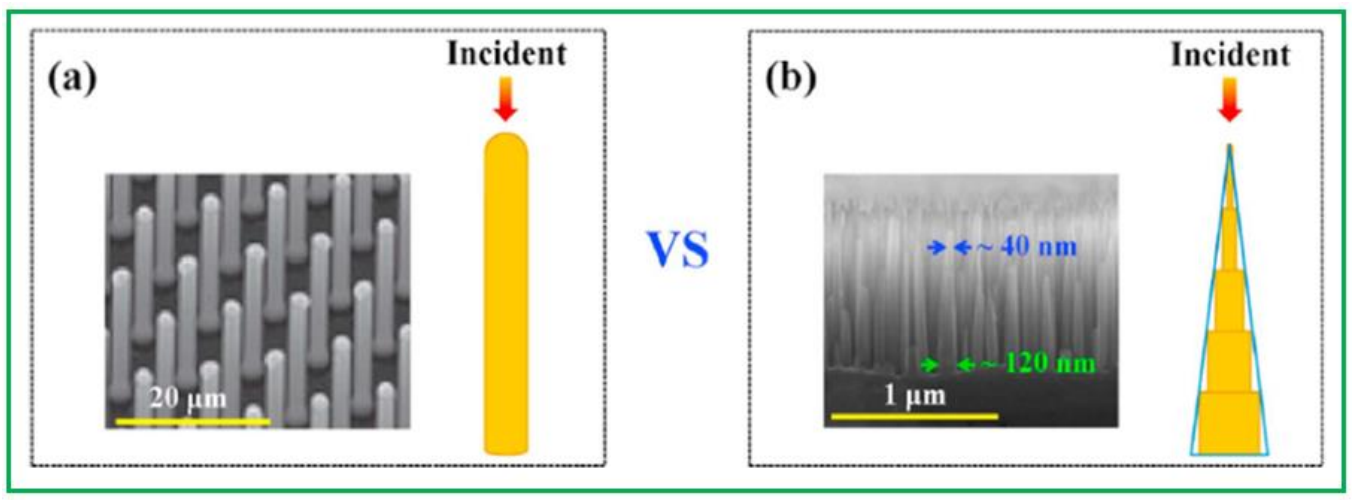

Fig. 54. The schematic diagram of structures: (a) SiNW; (b) SiNC [56]

Xu et al. [57] analysed the optical absorption of silicon cylindrical nanowires, nanocones and inverted nanocones in order to enhance the efficiency and decrease the cost of solar cells. The schematically diagram of three silicon nanostructures is given in

Fig. 55. To explore the light absorption of these arrays, different nanostructure shapes based on silicon substrate are built by

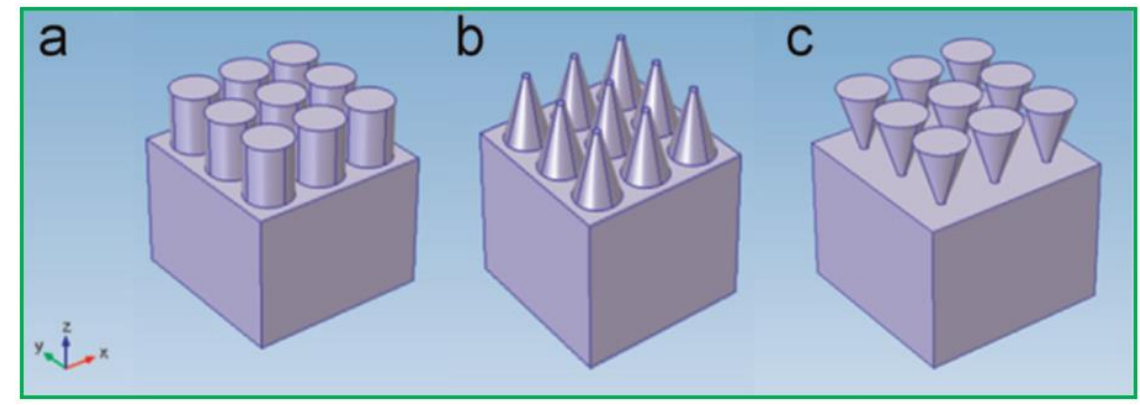

Fig. 55. (a) Cylindrical nanowires; (b) nanocones; (c) inverted nanocones [57]

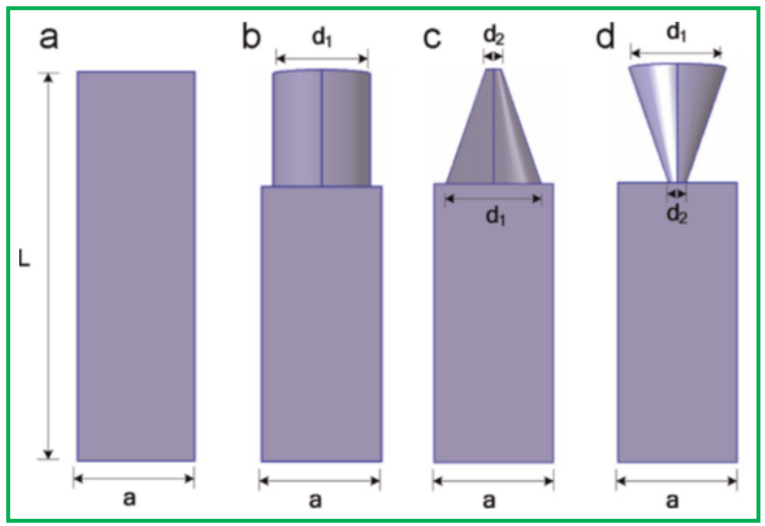

Fig. 56. Different structures: (a) bulk silicon; (b) cylindrical nanowires; (c) nanocones; (d) inverted nanocones [57] 


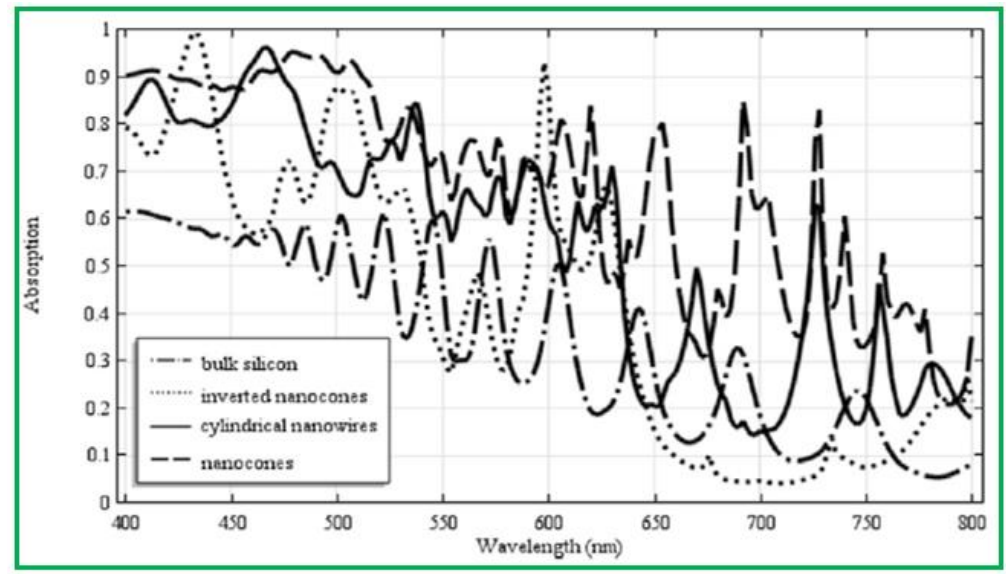

Fig. 57. Simulation results of absorption distribution for different structures at the wavelength range of 400-800 $\mathrm{nm}$ [57]

409 According to Fig. 57, the absorption of cylindrical nanowires and nanocones are higher than the bulk silicon's. Specifically, in 410 the range from 400 to $800 \mathrm{~nm}$, the average absorption of nanocones arrays is $70.2 \%$, which is better than cylindrical nanowires 411 arrays of $55.3 \%$, inverted nanocones arrays of $42.3 \%$ and bulk silicon of $42.2 \%$. Moreover, the reflection of inverted nanocones 412 has the absorption of $95 \%$ in the range from 630 and $800 \mathrm{~nm}$.

\section{$413 \quad 3.8$ Summary}

414 The 3DPV structures have been generalised based on different designs, including the FPM, GS, 3D-DSSC, cubic SSC, spherical 415 SSC, SiNW and SiNC to enhance the absorbing ability of the sunlight from all directions and energy conversion efficiency. They 416 are affected by various factors such as the weather conditions, shadow cast, axial and radial, shapes, materials, spacing, height, angle of solar irradiation, tilt angle, area ratio, fill factor, current density and open circuit voltage, as summarized in Table 3. 
Table 3 The effect factors of 3DPV structures

\begin{tabular}{|c|c|c|c|c|c|c|c|c|c|c|c|c|c|}
\hline \multirow{2}{*}{\multicolumn{2}{|c|}{ 3DPV structure }} & \multicolumn{12}{|c|}{ Effect factors } \\
\hline & & $\begin{array}{l}\text { Weather } \\
\text { conditions }\end{array}$ & $\begin{array}{l}\text { Shadow } \\
\text { cast }\end{array}$ & $\begin{array}{l}\text { Shapes, materials, } \\
\text { spacing and } \\
\text { height }\end{array}$ & $\begin{array}{l}\text { The } \\
\text { effect of } \\
\text { axial }\end{array}$ & $\begin{array}{l}\text { The } \\
\text { effect of } \\
\text { radial }\end{array}$ & $\begin{array}{l}\text { Solar } \\
\text { irradiation } \\
\text { angle }\end{array}$ & $\begin{array}{l}\text { The } \\
\text { effect of } \\
\text { tilt angle }\end{array}$ & $\begin{array}{l}\text { Area } \\
\text { ratio }\end{array}$ & $\begin{array}{l}\text { Fill } \\
\text { factor }\end{array}$ & $\begin{array}{l}\text { Current } \\
\text { density }\end{array}$ & $\begin{array}{l}\text { Open } \\
\text { circuit } \\
\text { voltage }\end{array}$ & $\begin{array}{l}\text { The effect } \\
\text { of the } \\
\text { micro- } \\
\text { lenses }\end{array}$ \\
\hline \multicolumn{2}{|c|}{$\begin{array}{l}\text { FPM structure }[23,24,27,30,32- \\
36]\end{array}$} & $\checkmark$ & $\checkmark$ & $\checkmark$ & $x$ & $x$ & $\checkmark$ & $\checkmark$ & $\checkmark$ & $x$ & $x$ & $x$ & $x$ \\
\hline \multicolumn{2}{|c|}{ GS structure [37] } & $\checkmark$ & $x$ & $\checkmark$ & $x$ & $x$ & $\checkmark$ & $\checkmark$ & $\checkmark$ & $x$ & $x$ & $x$ & $x$ \\
\hline \multicolumn{2}{|c|}{ 3D-DSSC structure [38] } & $x$ & $\checkmark$ & $\checkmark$ & $x$ & $x$ & $\checkmark$ & $x$ & $x$ & $x$ & $x$ & $x$ & $x$ \\
\hline \multicolumn{2}{|c|}{ 3DPV-VAWT structure $[39,40]$} & $\checkmark$ & $\checkmark$ & $\checkmark$ & $x$ & $x$ & $\checkmark$ & $\checkmark$ & $\checkmark$ & $\checkmark$ & $x$ & $\checkmark$ & $\checkmark$ \\
\hline \multirow{2}{*}{$\begin{array}{l}\text { SSC } \\
\text { structure }\end{array}$} & $\begin{array}{l}\text { Cubic SSC structure } \\
{[41,42]}\end{array}$ & $\checkmark$ & $x$ & $\checkmark$ & $x$ & $x$ & $\checkmark$ & $x$ & $x$ & $x$ & $x$ & $\checkmark$ & $x$ \\
\hline & $\begin{array}{l}\text { Spherical SSC } \\
\text { structure [45-49] }\end{array}$ & $x$ & $x$ & $\checkmark$ & $\checkmark$ & $\checkmark$ & $\checkmark$ & $x$ & $x$ & $x$ & $x$ & $x$ & $\checkmark$ \\
\hline \multirow{2}{*}{$\begin{array}{l}\text { Nanoscale } \\
\text { structure }\end{array}$} & $\begin{array}{l}\text { SiNW structure [52- } \\
55]\end{array}$ & $x$ & $x$ & $x$ & $x$ & $x$ & $x$ & $\checkmark$ & $\checkmark$ & $\checkmark$ & $\checkmark$ & $\checkmark$ & $x$ \\
\hline & $\begin{array}{l}\text { SiNC structure [56, } \\
\text { 57] }\end{array}$ & $x$ & $x$ & $x$ & $x$ & $x$ & $x$ & $x$ & $\checkmark$ & $\checkmark$ & $\checkmark$ & $x$ & $x$ \\
\hline
\end{tabular}




\section{The models of 3DPV technology}

Similarly, various kinds of 3DPV models are developed, including Genetic Algorithms (GA), Monte Carlo (MC), CFD-GEOM ${ }^{\mathrm{TM}}$, spherical Silicon Solar Cell (SSC), Green's Function, Finite-Difference Time-Domain (FDTD) as well as Discrete Dipole Approximation (DDA) models.

\subsection{GA model}

Genetic algorithms (GA) are a subclass of what are known as evolutionary algorithms [58]. This model is used to imitate natural progression in design. The GA differ from the traditional techniques because they work on a coded parameter set of the solution, take advantage of an expense function that does not include derivatives, and use pseudo-probabilistic rules [58]. For example, Dey et al. [20] optimised the position of the solar tree panels by the GA model to achieve the minimum of the shadow cast loss, their calculation is carries out by Matlab software, and the flowchart is presented in Fig. 58.

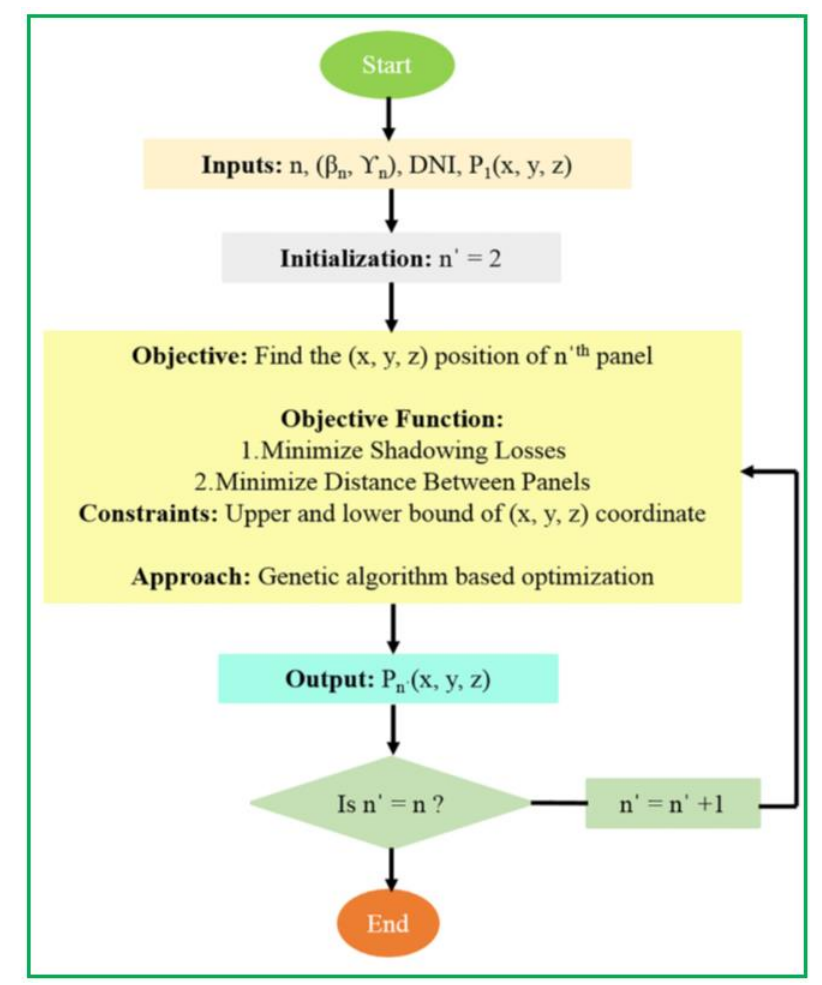

Fig. 58. The optimization procedure flowchart of solar power tree [20]

434 To follow the sun movement, the 3DPV solar power tree is installed with a rotatable structure, meanwhile, the azimuth angle $\left(\gamma_{\mathrm{s}}\right)$ and altitude angle $(\alpha)$ vary from $0^{\circ}$ to $360^{\circ}$ and $0^{\circ}$ to $90^{\circ}$, respectively. The solar irradiance at each sun angle is determined by the solar power tree electricity output. It can be seen from Fig. 59 that the simulation results are in agreement with the experimental data. 


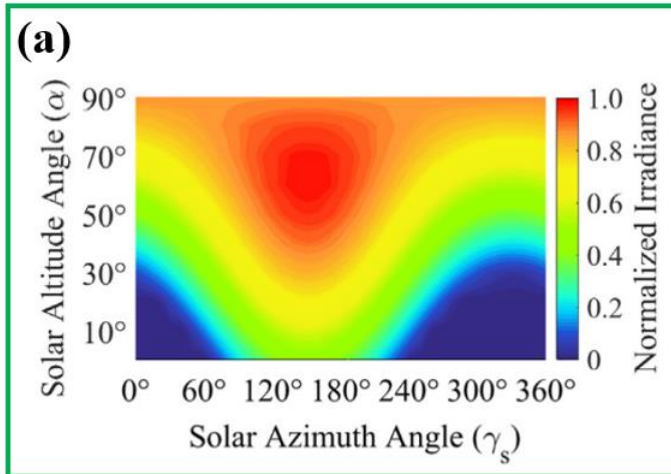

(b)

Fig. 59. 3DPV solar power tree panels: (a) simulation result; (b) experimental result [20]

440 Liu et al. [58] optimized a hybrid PV-hydro system to predict the system performance based on the GA approach. Table 4 gives 441 the optimization process of the system model. It can be found from Fig. 60 that the hybrid system is capable of realizing good 442 complementarity between PV and hydropower by the GA model.

443 Table 4 Model implementation by GA approach [58]

\begin{tabular}{ll}
\hline Item & Equation \\
\hline Fitness function & $\mathrm{f}(\mathrm{t})=\alpha \times\left(\mathrm{P}_{\mathrm{pv}}, \mathrm{t}+\mathrm{P}_{\mathrm{H}, \mathrm{t}}\right)+\beta\left[\sum_{\mathrm{i}}^{24}\left(\Delta \mathrm{P}_{\mathrm{t}}\right)^{2} / 24\right]$ \\
Design of genetic operator & $\mathrm{P}_{\mathrm{i}}=\frac{\mathrm{f}_{\mathrm{i}}}{\sum_{\mathrm{j}=1}^{\mathrm{N}} \mathrm{f}_{\mathrm{i}}}$ \\
& $\mathrm{a}_{\mathrm{kj}}=\mathrm{a}_{\mathrm{kj}}(1-\mathrm{b})+\mathrm{a}_{\mathrm{jj}} \mathrm{b} ; \mathrm{a}_{\mathrm{j}}=\mathrm{a}_{\mathrm{ij}}(1-\mathrm{b})+\mathrm{a}_{\mathrm{kj}} \mathrm{b}$ \\
Crossover operator & $\mathrm{a}_{\mathrm{ij}}=\mathrm{a}_{\mathrm{ij}}+\left(\mathrm{a}_{\mathrm{ij}}-\mathrm{a}_{\max }\right) \times \mathrm{f}(\mathrm{g}), \mathrm{r}>0.5$ \\
Mutation operation & $\mathrm{a}_{\mathrm{ij}}=\mathrm{a}_{\mathrm{ij}}+\left(\mathrm{a}_{\min }-\mathrm{a}_{\mathrm{ij}}\right) \times \mathrm{f}(\mathrm{g}), \mathrm{r} \leq 0.5$ \\
\hline
\end{tabular}

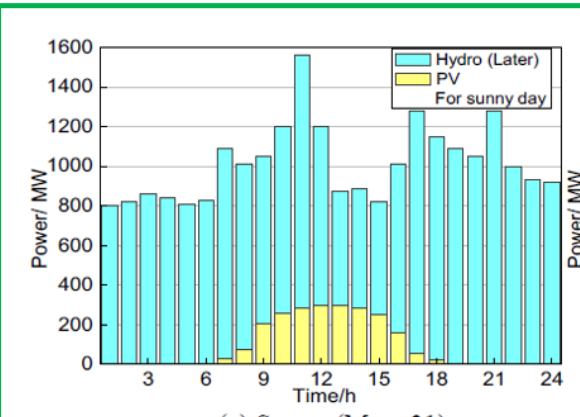

(a) Sunny (May. 31)

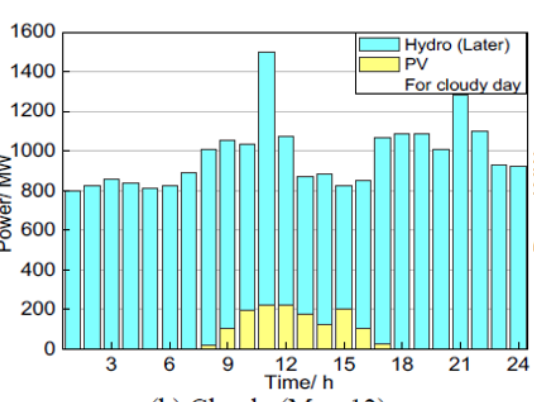

(b) Cloudy (Mar. 12)

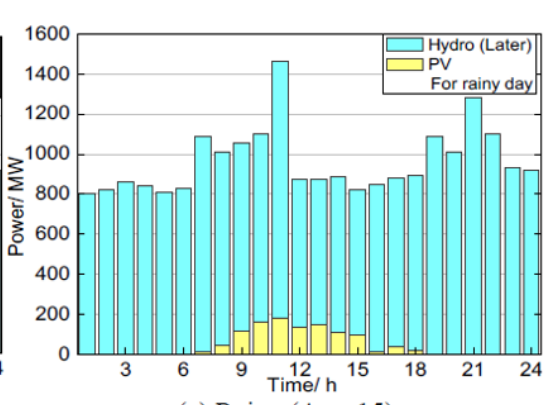

(c) Rainy (Apr. 15)

Fig. 60. The optimization results of PV system by GA approach [58]

Myers et al. [59] used the 3DPV model to assess energy production based on the GA approach as well. Fig. 61 illustrates electricity output obtained by the GA model. It is found that the optimized 3DPV model can generate much more electricity in comparison to the traditional flat panel. Furthermore, the 3DPV electricity production variation is much more even. 


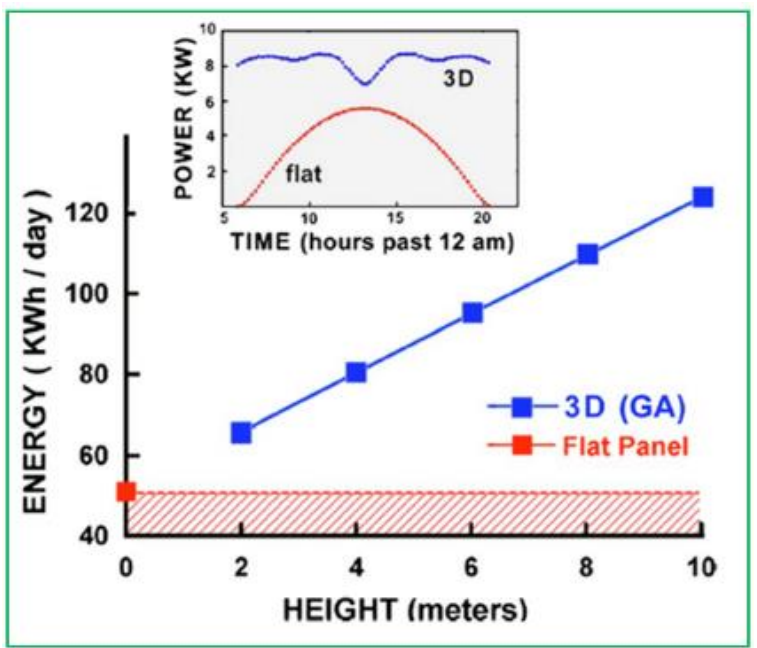

Fig. 61. Comparison between 3DPV and conventional flat PV technologies [59]
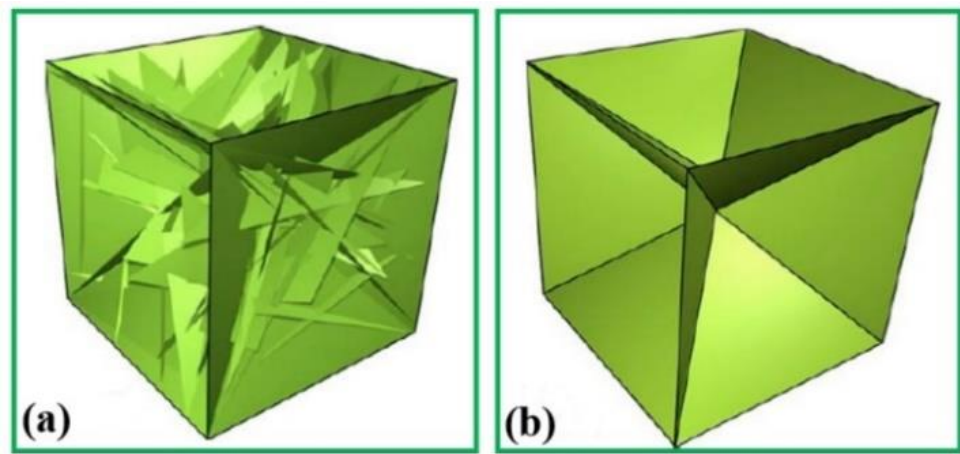

Fig. 62. Schematic diagram of 3DPV models: (a) GA-optimized model; (b) GA- simplified model [60]

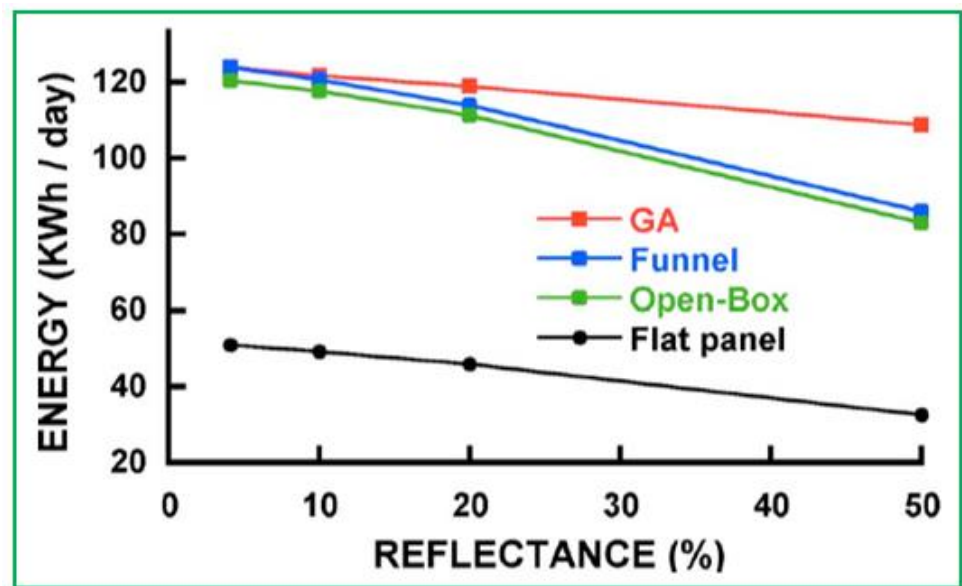

Fig. 63. Energy comparison in different cases [60]

456 Fig. 62 (a) shows the shape of the GA model that is a box with its five visible faces caved in toward the midpoint [60]. A 457 simplified GA model is displayed in Fig. 62 (b). This demonstrates that the energy generated is only less $0.03 \%$ compared to the 458 initial GA model output. As descripted in Fig. 63, the growing reflectivity reduces linearly in all cases, but the GA optimized 459 models have a much slower rate than all other cases. This indicates that the 3DPV GA model is able to optimize the shapes so 
that materials within a comparatively wide reflectance range could be utilized without obvious deterioration of their performance

$461 \quad[60]$.

\section{$462 \quad 4.2$ MC model}

463 The Monte Carlo (MC) model is primarily employed to calculate the radiation exchange matrix and has been utilized in the 464 simulation process of radiation transport for various applications [25, 26]. In this model, the rays are obtained based on the cosine 465 law and the Planck's law [25]. The MC model considers the effects of geometry and shadow cast on the energy absorbed, the 466 mathematical model is given in Table 3.

467 Table 5 The calculation process $[25,26]$

\begin{tabular}{|c|c|}
\hline Description & Equation \\
\hline The net incoming energy & $\mathrm{Q}_{\lambda, \mathrm{i}}=\mathrm{q}_{\lambda, \mathrm{i}} \mathrm{A}_{\mathrm{i}}=\varepsilon_{\lambda, \mathrm{i}} \mathrm{A}_{\mathrm{i}} \mathrm{E}_{\mathrm{b} \lambda, \mathrm{i}}-\sum_{\mathrm{j}=1}^{\mathrm{M}} \mathrm{R}_{\lambda, \mathrm{j}} \mathrm{A}_{\mathrm{j}} \mathrm{E}_{\mathrm{b} \lambda, \mathrm{j}}$ \\
\hline The total radiation flux & $\mathrm{Q}_{\mathrm{i}}=\mathrm{q}_{\mathrm{i}} \mathrm{A}_{\mathrm{i}}=\mathrm{A}_{\mathrm{i}} \int_{0}^{\infty} \varepsilon_{\lambda, \mathrm{i}} \mathrm{E}_{\mathrm{b} \lambda, \mathrm{i}} \mathrm{d} \lambda-\sum_{\mathrm{j}=1}^{\mathrm{M}} \mathrm{A}_{\mathrm{j}} \int_{0}^{\infty} \mathrm{R}_{\lambda, \mathrm{j}} \mathrm{E}_{\mathrm{b} \lambda, \mathrm{j}} \mathrm{d} \lambda$ \\
\hline The total emissivity of a surface & $\varepsilon_{\mathrm{i}}=\frac{\int_{0} \varepsilon_{\lambda, \mathrm{i}} \mathrm{E}_{\mathrm{b} \lambda, \mathrm{i}} \mathrm{d} \lambda}{\int_{0}^{\infty} \mathrm{E}_{\mathrm{b} \lambda, \mathrm{j}} \mathrm{d} \lambda}=\frac{\int_{0} \varepsilon_{\lambda, \mathrm{i}} \mathrm{E}_{\mathrm{b} \lambda, \mathrm{i}} \mathrm{d} \lambda}{\sigma \mathrm{T}_{\mathrm{i}}^{4}}$ \\
\hline The total radiation exchange matrix & $\mathrm{R}_{\mathrm{ij}}=\frac{\int_{0}^{\infty} \mathrm{R}_{\lambda, \mathrm{ij}} \mathrm{E}_{\mathrm{b} \lambda, \mathrm{i}} \mathrm{d} \lambda}{\int_{0}^{\infty} \mathrm{E}_{\mathrm{b} \lambda, \mathrm{j}} \mathrm{d} \lambda}=\frac{\int_{0}^{\infty} \varepsilon_{\lambda, \mathrm{j} j} \mathrm{E}_{\mathrm{b} \lambda, \mathrm{i}} \mathrm{d} \lambda}{\sigma \mathrm{T}_{\mathrm{j}}^{4}}$ \\
\hline The directional reflectivity of glass & $\rho=\frac{1}{2}\left[\left(\frac{\mathrm{n}^{2} \cos \theta-\sqrt{\mathrm{n}^{2}-\sin ^{2} \theta}}{\mathrm{n}^{2} \cos \theta+\sqrt{\mathrm{n}^{2}-\sin ^{2} \theta}}\right)^{2}+\left(\frac{\cos \theta-\sqrt{\mathrm{n}^{2}-\sin ^{2} \theta}}{\cos \theta+\sqrt{\mathrm{n}^{2}-\sin ^{2} \theta}}\right)^{2}\right]$ \\
\hline The whole energy emitted via the boundary surface elements & $E=\sum_{j=1}^{M} E_{j}=\sum_{j=1}^{M} \varsigma_{j} \sigma T_{j}^{4} A_{j}$ \\
\hline The number of rays emitted & $N_{j}=\frac{E_{j}}{E} N_{R}$ \\
\hline
\end{tabular}

The whole calculation process of the MC algorithm for the 3DPV model is demonstrated in Fig. 64. As indicated in Fig. 65, the 3DPV model increases the sunlight capture by $118 \%$ and $34 \%$ for heating and cooling seasons respectively in Miami, by contrast,

471 the obtained solar energy could be improved by $322 \%$ and 57\% for winter and summer individually in Seattle. It is revealed that 472 the 3DPV model is able to improve sunlight capture by about 4-6 times in comparison with a flat panel and collect more solar 473 energy at higher latitude. 


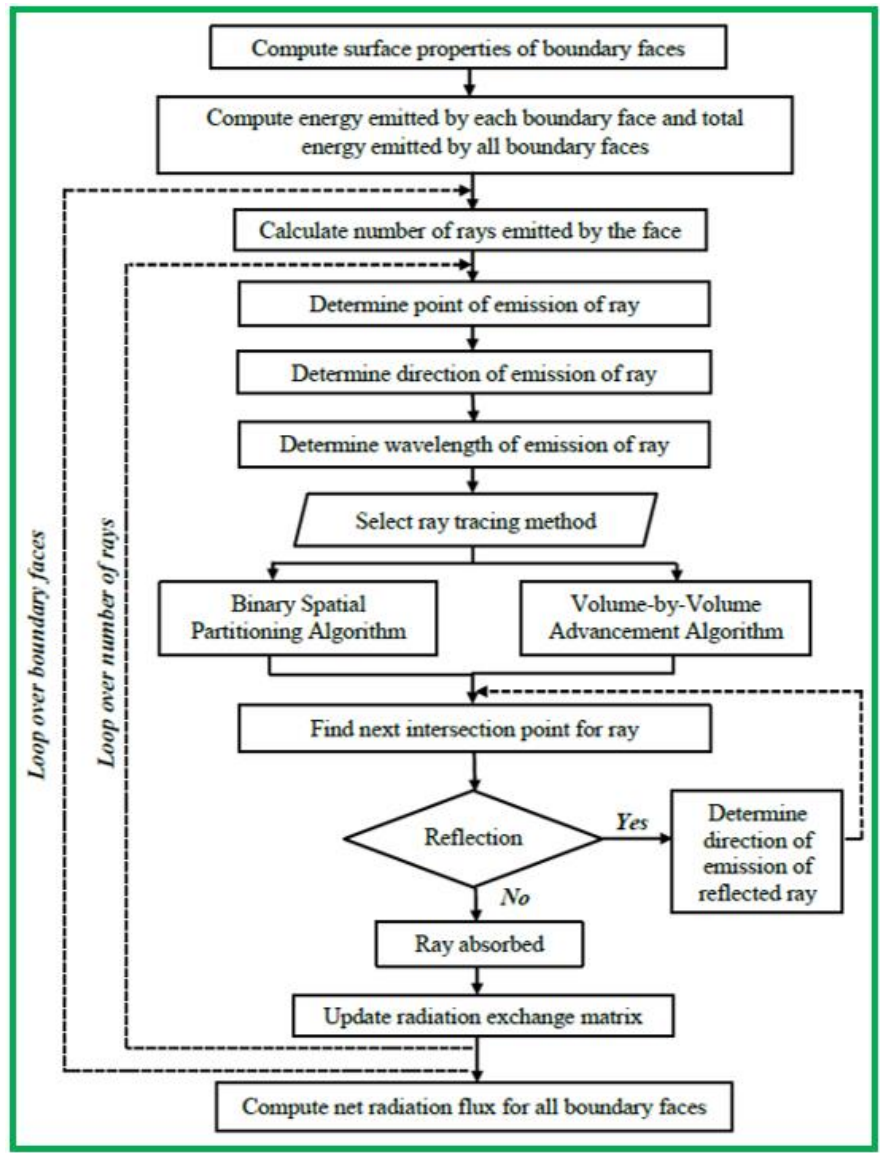

Fig. 64. The whole calculation process of MC model [25]

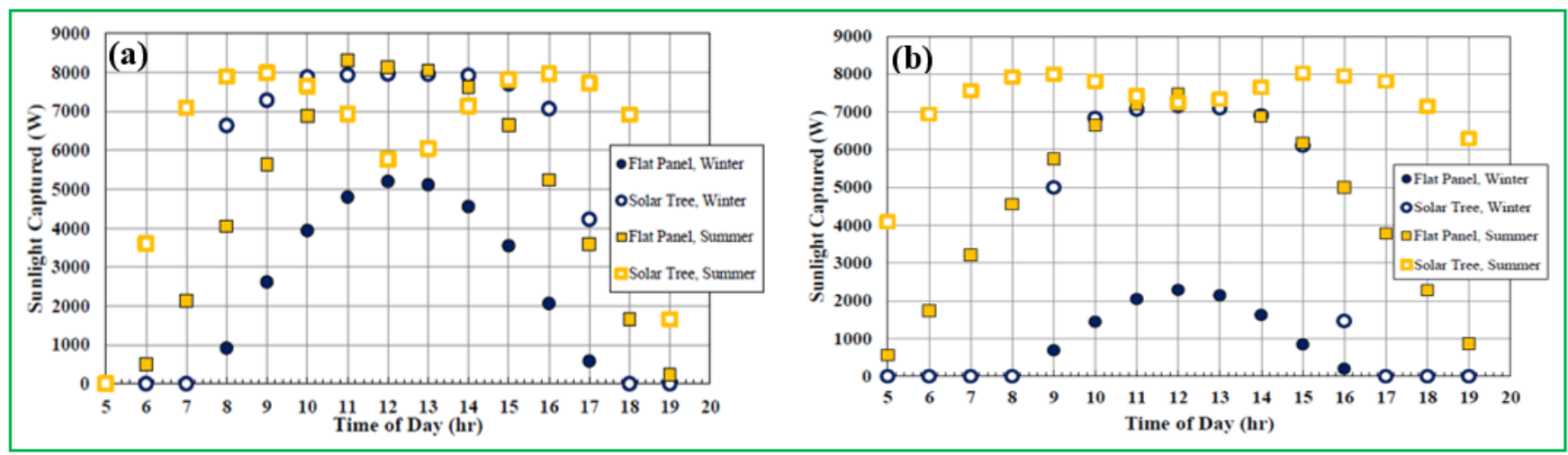

Fig. 65. Comparison between flat panel and solar tree based on MC model: (a) in Miami; (b) in Seattle [25, 26]

\subsection{CFD-GEOMTM model}

480 Verma [26, 61] investigated the 3DPV performance by the CFD-GEOM software. According to Fig. 66, a normal surface mesh 481 utilized for the solar tree is comprised of 10496 triangular elements, the top surface of each leaf is discretized through 8 -10 triangular meshes such that the solar radiation flux on each leaf can be adequately resolved. 


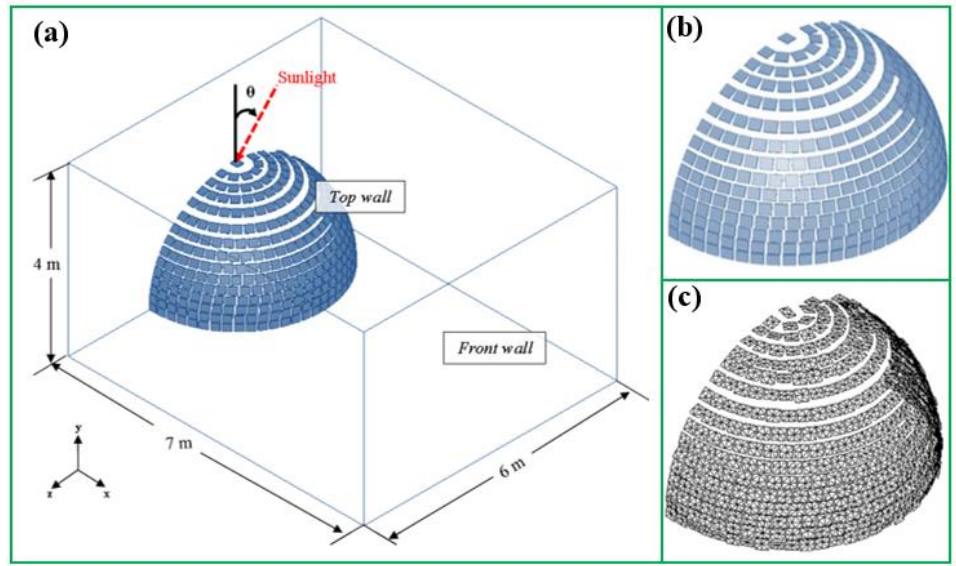

484 Fig. 66. CFD-GEOM model: (a) the computational domain of single-layer solar power tree model; (b) geometric model (c) surface mesh with triangular elements [26]

486 According to Fig. 67, a finite fraction of the solar tree leaves always receives radiation at near-normal angle, thereby tracking the sun's position passively. It is observed that, for near-normal incidence $\left(\theta=0^{\circ}, 20^{\circ}\right)$, traditional solar flat panels can absorb more solar energy than the 3DPV solar tree model. By contrast, at solar incidence angle of $40^{\circ}$ or higher, the $3 \mathrm{DPV}$ solar tree model can absorb more solar energy than the traditional one. However, in terms of the shallow angle of incidence $\left(\theta=80^{\circ}\right)$, the 3DPV model is found to collect four to six times more solar radiation than traditional one. From the radiation flux predicted for the flat panel, it is found that, the traditional solar panel is far more sensitive to the solar irradiation angle compared with the 3DPV solar power tree.

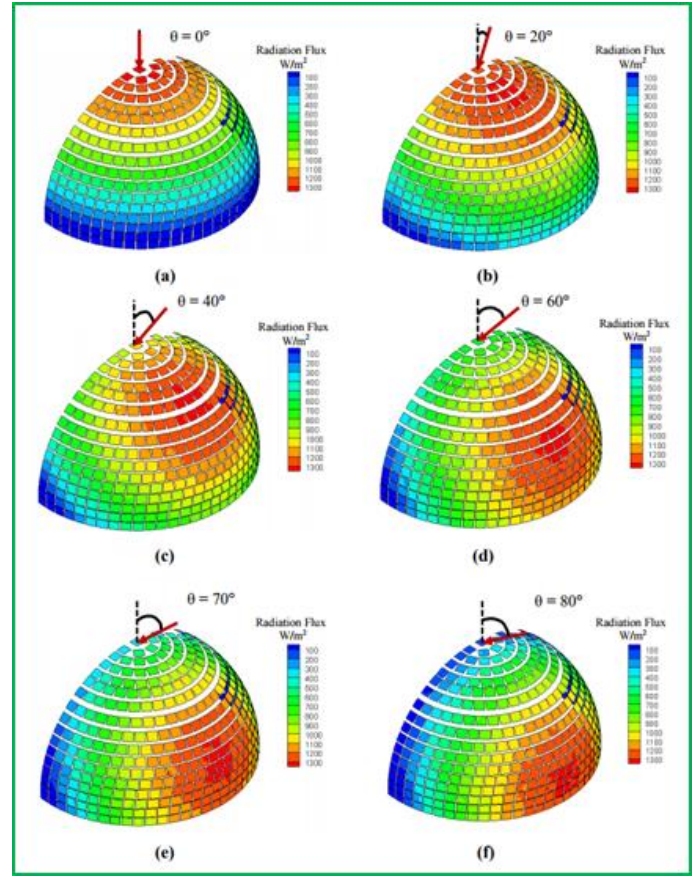

494 Fig. 67. The radiation flux for incidence angle (a) $\theta=0^{\circ}$; (b) $\theta=20^{\circ}$; (c) $\theta=40^{\circ}$; (d) $\theta=60^{\circ}$; (e) $\theta=70^{\circ}$ and (f) $\theta=80^{\circ}[26,61]$ 


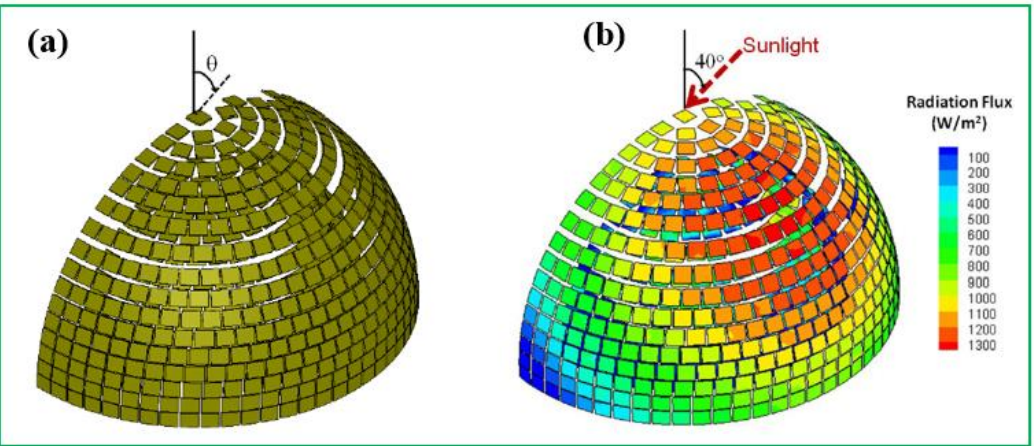

496 Fig. 68. Double-layer 3DPV model: (a) geometry, (b) radiation flux on a double-layer solar tree for $40^{\circ}$ incidence angles [26, 497 61]

498 To further increase the solar radiation capture capacity, a second layer of solar leaves is augmented to the 3DPV model as 499 presented in Fig. 65. It is confirmed that the second layer of leaves is capable of enhancing the absorbed sunlight by $15-30 \%$.

\subsection{SSC model}

501 Gharghi et al. [43] developed a 3DPV model of spherical silicon solar cell (SSC) for material process optimization and advanced device design. The basic calculation model of the spherical SSC is illustrated in Fig. 69 while its mathematical model is given in Table 6.
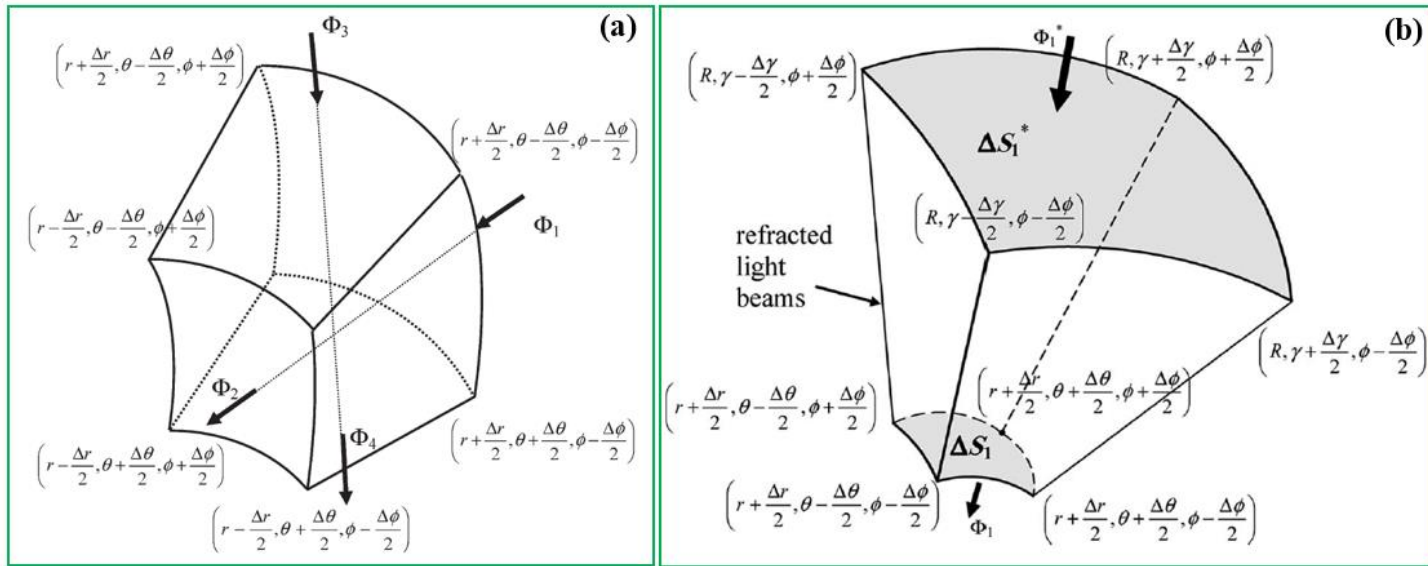

Fig. 69. Numerical model of spherical SSC model: (a) initial model; (b) optimize model [43]

Table 6 The equation of SSC model [42]

\begin{tabular}{ll}
\hline Description & Equation \\
\hline Photo-carrier generation rate & $\Phi_{\mathrm{i}}=\left[\iint_{\Delta \mathrm{S}} \mathrm{S}_{0}(\lambda)\left[1-\mathrm{R}_{\mathrm{f}}(\lambda, \gamma)\right] \cos (\gamma)\right] \exp [-\alpha(\lambda) \chi]$ \\
Solar-weighted generation & $\mathrm{G}(\mathrm{r}, \theta, \Phi)=\frac{\left[\Phi_{1}+\Phi_{3}-\Phi_{2}-\Phi_{4}\right]}{\left[\mathrm{r}^{2} \sin \theta \cdot \Delta \mathrm{r} \cdot \Delta \theta \cdot \Delta \Phi\right]}$ \\
Current density & $\mathrm{I}_{\mathrm{e}}=\left|\iint_{\mathrm{r}=\mathrm{R}_{\mathrm{n}}}\left(\mathrm{J}_{\mathrm{p}} \cdot \mathrm{a}_{\mathrm{r}}\right) \mathrm{r}^{2} \sin \theta \mathrm{d} \theta \mathrm{d} \Phi\right|$ \\
\hline
\end{tabular}


Kitamura et al. [49] developed a system model of spherical SSC with 1-bit $\Delta \Sigma$-modulated white-LED lamp and an earphone including a balanced-armature receiver, their whole simulation process is shown in Fig. 70. To be more specific, the noise factor is assumed as 1 , the components with amplifying and addition functions are supplemented to the end of the 1-bit $\Delta \Sigma$ modulator to make the transmitter produce normalized " 0 " and " 1 " pulses.

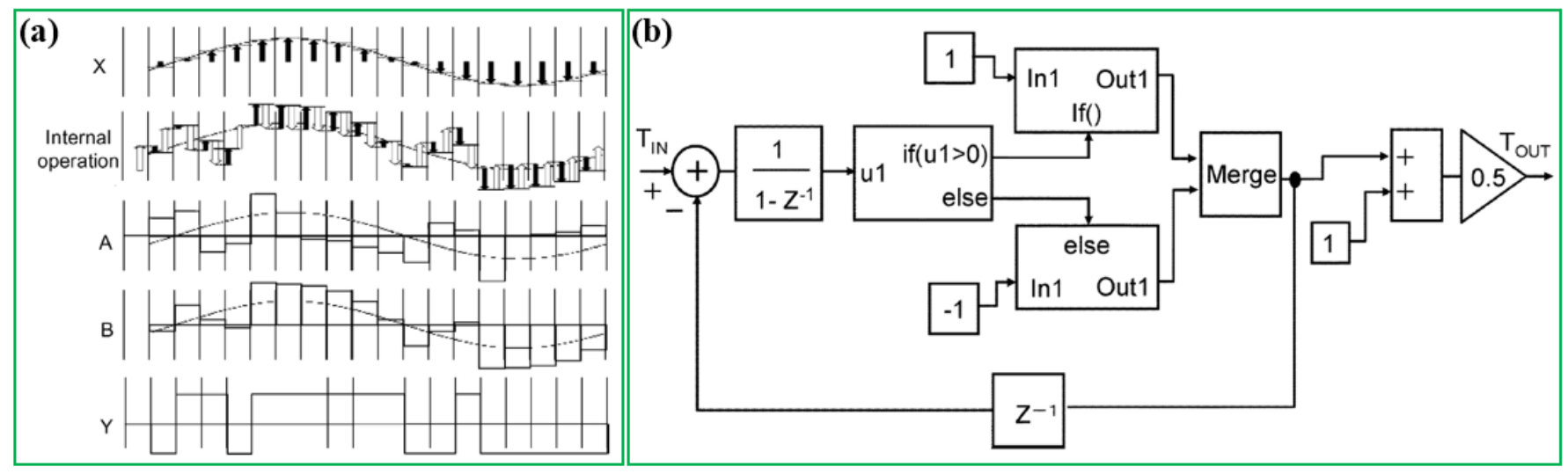

Fig. 70. (a) Principle of 1-bit $\Delta \Sigma$ modulation; (b) simulation process [49]

\subsection{Green's function model}

The Green's function is able to decrease the requirement for homogeneous production assumption utilized in the calculation of traditional model. Additionally, it can satisfy the equations with point source and essential boundaries, the actual source can be utilized to obtain a normal solution. For example, Ali et al. [62] developed a 3DPV analytical model by using the Green's function to assess the open circuit voltage, conversion efficiency, fill factor and current density. The diagram of the radial p-n junction nanowire PV cell is given in Fig. 71.

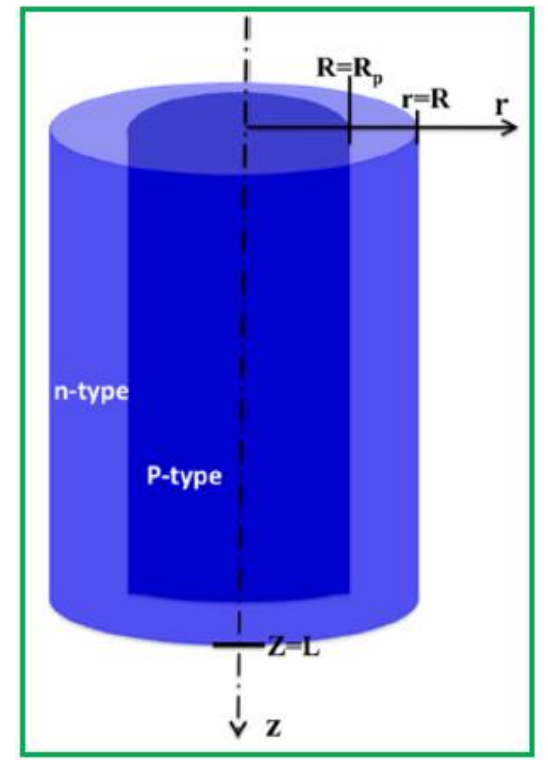

Fig. 71. 3DPV geometry model of radial p-n junction [62] 
The solar cell total current is given as:

$524 \quad \mathrm{I}=\mathrm{I}_{\mathrm{dark}}(\mathrm{V})-\mathrm{I}_{\mathrm{sc}}$

525 where $I_{\text {dark }}(V)$ is the voltage dependent dark current $(A) ; I_{s c}$ is the short circuit current $(A)$.

526 The electron equation is written as:

$527 \quad \frac{\partial \mathrm{n}}{\partial \mathrm{t}}=\mathrm{G}_{\mathrm{L}}-\mathrm{U}_{\mathrm{n}}+\frac{1}{\mathrm{q}}\left(\nabla \cdot \mathrm{J}_{\mathrm{e}}\right)$

528 where $\mathrm{G}_{\mathrm{L}}$ is the generation rate of carriers; $\mathrm{U}_{\mathrm{n}}$ is the net recombination rate of the minority carriers; $\mathrm{J}_{\mathrm{e}}$ is the electron current 529 density $\left(\mathrm{A} / \mathrm{m}^{2}\right)$.

530 The dark current is expressed as:

$531 \quad I_{\text {dark }}=\left(\mathrm{I}_{\mathrm{o}}^{\mathrm{e}}+\mathrm{I}_{\mathrm{d}}^{\mathrm{h}}\right)\left[\exp \left(\frac{\mathrm{V}}{\mathrm{V}_{\mathrm{t}}}\right)-1\right]+\mathrm{I}_{\mathrm{o}}^{\mathrm{dep}}\left[\exp \left(\frac{\mathrm{V}}{2 \mathrm{~V}_{\mathrm{t}}}\right)-1\right]$

where $V_{t}$ is the voltage due to thermal potential $(V) ; I_{o}^{e}$ is the electrons current $(A) ; I_{o}^{h}$ is the holes reverse saturation current $(A)$.

$533 \quad \mathrm{I}_{\mathrm{o}}^{\mathrm{dep}}$ is the depletion region recombination current as:

$534 \quad \mathrm{I}_{\mathrm{o}}^{\mathrm{dep}}=\frac{\mathrm{qn}_{\mathrm{i}} 2 \pi\left(\Delta \mathrm{r}_{2}+\Delta \mathrm{r}_{3}\right)^{2} \mathrm{~L}}{2 \sqrt{\tau_{\mathrm{n}}} \tau_{\mathrm{p}}}$

535 The short circuit current is written as:

$536 \quad \mathrm{I}_{\mathrm{sc}}=\int\left[\mathrm{I}_{\mathrm{sc}}^{\mathrm{e}}(\lambda)+\mathrm{I}_{\mathrm{sc}}^{\mathrm{h}}(\lambda)+\mathrm{I}_{\mathrm{sc}}^{\mathrm{dep}}(\lambda)\right] \mathrm{d} \lambda$

537 where $\mathrm{I}_{\mathrm{sc}}^{\mathrm{dep}}(\lambda)$ is the contribution of the depletion region to the light-generated current $(\mathrm{A})$.

538 Based on the Green's function theory, a point source is defined at r', therefore, the equation turns into uniform when $r \neq r^{\prime}$.

539 Table 6 illustrates the transform equations on the basis of the Green's function theory in the p-type region.

540 Table 7 Green's function equations [62]

\begin{tabular}{ll}
\hline Description & Equation \\
\hline Deriving the concentration expression & $\Phi_{\mathrm{i}}=\int \Delta \mathrm{n}\left(\mathrm{r}^{\prime}\right)\left[\frac{\partial}{\partial \mathrm{r}^{\prime}} \mathrm{r}^{\prime} \frac{\partial}{\partial \mathrm{r}^{\prime}} \mathrm{G}_{1}\left(\mathrm{r}, \mathrm{r}^{\prime}\right)-\frac{\mathrm{r}^{\prime} \mathrm{G}_{1}\left(\mathrm{r}, \mathrm{r}^{\prime}\right)}{\mathrm{L}_{\mathrm{n}}^{2}}\right] \mathrm{dr} \mathrm{r}^{\prime}=\Delta \mathrm{n}(\mathrm{r})$ \\
\hline P-type region & $=\int d \mathrm{r}^{\prime} \mathrm{r}^{\prime}\left(-\mathrm{g}_{\mathrm{o} 1}\right)\left(\mathrm{r}^{\prime}\right) \mathrm{G}_{1}\left(\mathrm{r}, \mathrm{r}^{\prime}\right)-\left.\mathrm{G}_{1}\left(\mathrm{r}, \mathrm{r}^{\prime}\right) \mathrm{r}^{\prime} \frac{\partial \Delta \mathrm{n}\left(\mathrm{r}^{\prime}\right)}{\partial \mathrm{r}^{\prime}}\right|_{\text {surface }}+\left.\mathrm{r}^{\prime} \frac{\partial \Delta \mathrm{n}\left(\mathrm{r}, \mathrm{r}^{\prime}\right)}{\partial \mathrm{r}^{\prime}} \Delta \mathrm{n}\left(\mathrm{r}^{\prime}\right)\right|_{\text {surface }}$ \\
\hline & $\left(\frac{\partial^{2}}{\partial \mathrm{r}^{2}}+\frac{1}{\mathrm{r}} \frac{\partial}{\partial \mathrm{r}}-\frac{1}{\mathrm{~L}_{\mathrm{n}}^{2}}\right) \mathrm{G}_{1}\left(\mathrm{r}, \mathrm{r}^{\prime}\right)=\frac{1}{\mathrm{r}} \delta\left(\mathrm{r}-\mathrm{r}^{\prime}\right)$ \\
& $\mathrm{G}_{1}\left(\mathrm{r}, \mathrm{r}^{\prime}\right)=\xi_{1}\left(\frac{\mathrm{r}<}{\mathrm{Ln}}\right) \xi_{2}\left(\frac{\mathrm{r}>}{\mathrm{Ln}}\right)$ \\
\hline
\end{tabular}


The model is utilized for both p-n silicon and p-i-n radial PV cells, meanwhile, its precision has been validated by comparing with previously published numerical and experimental results, as given in Fig. 72. The errors of $\mathrm{J}_{\mathrm{sc}}$ and $\mathrm{V}_{\mathrm{oc}}$ decrease from 3.7\% to $0.03 \%$ and from $1.7 \%$ to $1.3 \%$, respectively.

\begin{tabular}{ll}
\hline Description & Equation \\
\hline The optical generation rate & $\mathrm{G}_{\mathrm{ph}}=\frac{|\vec{\nabla} \cdot \overrightarrow{\mathrm{S}}|}{2 \mathrm{~h} \omega}=\frac{\varepsilon|\overrightarrow{\mathrm{E}}|^{2}}{2 \mathrm{~h}}$ \\
The doping-dependent mobility & $\mu_{\mathrm{dop}}=\mu_{\min }+\frac{\mu_{\mathrm{d}}}{1+\left(\mathrm{N} / \mathrm{N}_{0}\right)^{\mathrm{A}}}$ \\
The current-voltage relationship & $\mathrm{J}=\mathrm{J}_{\mathrm{SC}}-\mathrm{J}_{0}\left(\exp ^{\mathrm{V} / \mathrm{v}_{\mathrm{c}}}-1\right)$ \\
Thermal voltage & $\mathrm{V}_{\mathrm{c}}=\frac{\mathrm{K}_{\mathrm{B}} \mathrm{T}_{\mathrm{c}}}{\mathrm{q}}$ \\
\hline
\end{tabular}

Fig. 72. Comparison between Green's function model and experimental data [62]

\subsection{FDTD model}

Lundgren et al. [52] designed a 3D branched nanowire (BNW) tree model by using the finite-difference time-domain (FDTD) approach to study the sunlight absorption rates for four configurations. Wang et al. [53] proposed an innovative 3DPV NW model to investigate the model performance via the FDTD approach. The basic equations are given in Table 8 .

Table 8 The calculation equations of 3DPV NW model [53]

It can be seen from Fig. 73 (a) that the optical production becomes more spread in the 3DPV NW model when the wavelength raises whereas more and more sunlight could be absorbed and transmitted through the bottom solar cell. Moreover, more cells are capability of capturing sunlight in various regions, which appears a promising ability to realize an excellent current matching as shown in Fig. 73 (b). Furthermore, according to Fig. 73 (c), majority of the photo-carriers are produced with a filling ratio of 

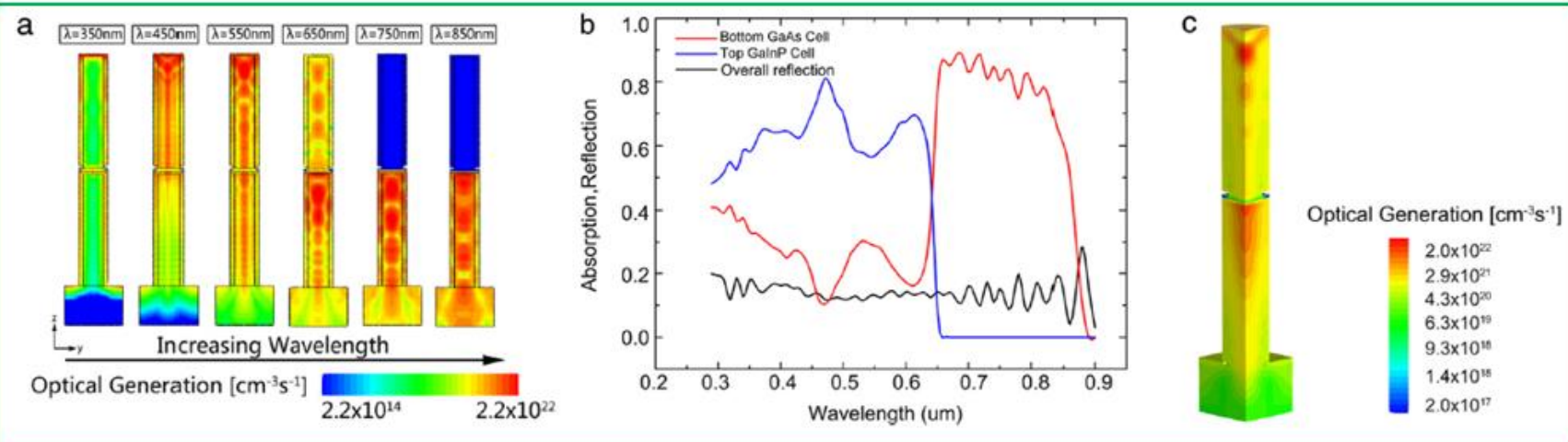

Fig. 73. Simulation results: (a) optical production profiles; (b) absorption of the sub-cells and overall reflectance; (c) total photogeneration profiles [53]

\subsection{DDA model}

The discrete dipole approximation (DDA) is a normal approach to estimate scattering of electromagnetic waves based on composition and particles of arbitrary geometry [63].

The typical equation of DDA is given as [63]:

$\alpha_{i}^{-1} P_{i}-\sum G_{i j} P_{j}=E_{i}^{\text {inc }}$

where $\alpha$ is the tensor of dipole polarizability; $\mathrm{E}$ is incident electric region; $\mathrm{G}$ is the free-space Green's tensor; $\mathrm{P}_{\mathrm{i}}$ is the unknown dipole polarization.

Li et al. [56] studied the optical characteristics of silicon nanowire (SiNW) and silicon nanocore (SiNC). The absorption spectra and extinction are determined by using the DDA approach. Fig. 74 illustrates the extinction and absorption efficiencies for the monomer SiNW and SiNC at different wavelengths.
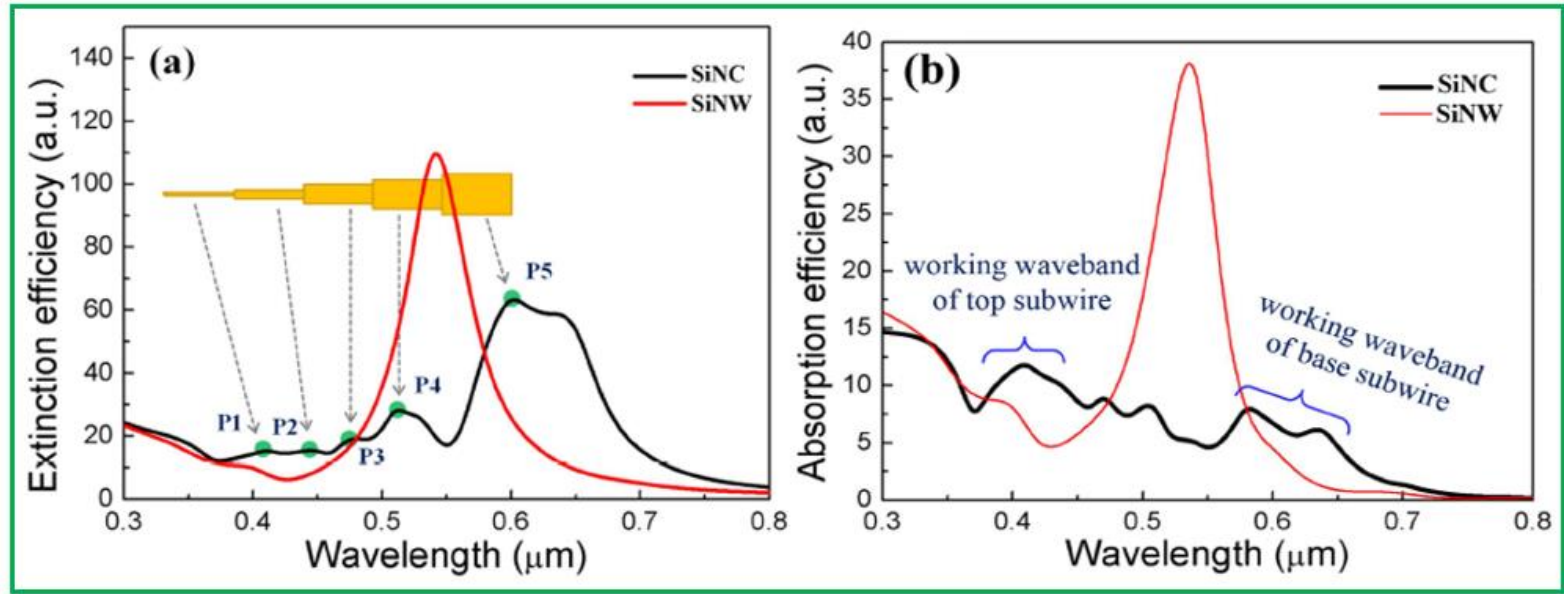

Fig. 74. The simulation results: (a) extinction efficiency; (b) absorption efficiency [56] 
573 These results demonstrate that the biggest difference of the surface coverage rate is only approximately $1.5 \%$, which is quite 574 smaller in comparison to counterpart value in sunlight-concentration of $20.8 \%$. Moreover, the concentrated sunlight is not 575 capable of being effectively absorbed and converted to photo-generation carriers.

$576 \quad 4.8$ Summary

577 The 3DPV models are more accurate and comprehensive investigation techniques based on different approaches including GA, 578 MC, CFD-GEOM ${ }^{\mathrm{TM}}$, SSC, Green's function, FDTD and DDA to calculate the solar energy conversion efficiency. The 579 comparison of various 3DPV models on the basis of assumption, boundary condition, error and scope of applications is illustrated 580 in Table 9 


\begin{tabular}{|c|c|c|c|c|c|}
\hline \multirow[t]{2}{*}{ Model names } & \multirow[t]{2}{*}{ Assumption conditions } & \multirow[t]{2}{*}{ Boundary conditions } & \multicolumn{3}{|c|}{ Key findings } \\
\hline & & & Approaches used & Error analysis & Scope of applications \\
\hline GA model $[20,58-60]$ & $\begin{array}{l}\text { (1) Diffused radiation is assumed as } \\
\text { zero; (2) The tilt angle is setup } \\
0^{\circ}<\beta<90^{\circ} \text {; (3) The azimuth angle of } \\
\text { surface is defined ranging from } \\
0^{\circ}<\gamma<360^{\circ} \text {; }\end{array}$ & $\begin{array}{l}\text { The boundary conditions is given as: } \\
\begin{array}{l}\mathrm{H}_{\mathrm{t}, \text { min }} \leq \mathrm{H}_{\mathrm{t}} \leq \mathrm{H}_{\mathrm{t} \text { max }} ; \mathrm{L}_{\mathrm{t}, \text { min }} \leq \mathrm{L}_{\mathrm{t}} \leq \mathrm{L}_{\mathrm{t} \text { max }} \\
\mathrm{Q}_{\mathrm{t}, \text { min }} \leq \mathrm{Q}_{\mathrm{t}} \leq \mathrm{Q}_{\mathrm{t}, \text { max }} ; \mathrm{V}_{\mathrm{t} \text {,min }} \leq \mathrm{V}_{\mathrm{t}} \leq \mathrm{V}_{\mathrm{t}, \text { max }}\end{array}\end{array}$ & $\begin{array}{l}\text { The algorithm is carried out by } \\
\text { using Matlab software. }\end{array}$ & $\begin{array}{l}\text { The numerical results } \\
\text { is a good agreement } \\
\text { with test data. }\end{array}$ & $\begin{array}{l}\text { (1) GA model is utilized for } \\
\text { locating of the solar panels } \\
\text { avoiding to the losses of } \\
\text { shading; (2) This model can } \\
\text { be used to optimum the } \\
\text { system performance. }\end{array}$ \\
\hline MC model $[25,26]$ & $\begin{array}{l}\text { (1) All the walls are assumed to have } \\
\text { an emissivity of } 0.5 \text {; (2) } 100 \text { million } \\
\text { rays are traced. }\end{array}$ & $\begin{array}{l}\text { (1) The incident photon bundle is set up as } \\
\mathrm{R}_{\mathrm{R}} \leq \mathrm{\rho}_{\lambda} ; \text {; (2) The direction of the reflected } \\
\text { photon bundle is assumed as: } \mathbf{R}_{\mathrm{s}} \leq \alpha_{\mathrm{s}} \text {; }\end{array}$ & $\begin{array}{l}\text { (1) The photon bundles are } \\
\text { calculated by the cosine law and } \\
\text { the Planck's law; (2) Ray } \\
\text { tracing is obtained by BSP and } \\
\text { VVA algorithms. }\end{array}$ & $\begin{array}{l}\text { The error is about } \\
0.0425 \% \text {. }\end{array}$ & $\begin{array}{l}\text { (1) The MC model can } \\
\text { consider any obstructions in } \\
\text { the geometry and shading } \\
\text { influences; (2) All } \\
\text { wavelengths are able to be } \\
\text { gathered and processed; (3) } \\
\text { The model is utilized to } \\
\text { evaluate the radiation } \\
\text { transport of thermal chemical } \\
\text { vapor deposition reactors. }\end{array}$ \\
\hline CFD-GEOM $^{\mathrm{TM}}$ model [61] & $\begin{array}{l}\text { (1) The atmospheric scattering } \\
\text { influences is ignored; }\end{array}$ & $\begin{array}{l}\text { (1) The boundary condition is assumed as } \\
1 \mathrm{~m} \times 1 \mathrm{~m} \times 5 \mathrm{~m} \text {; (2) A constant heat flux } \\
\text { wall boundary condition is used for the top } \\
\text { and front surfaces of the domain; (3) The } \\
\text { input solar flux is defined as } 1362 \mathrm{~W} / \mathrm{m}^{2} \text { in } \\
\text { the simulation process; (4) The remaining } \\
\text { surfaces of the domain as well as the solar } \\
\text { leaves are treated as isothermal walls at a } \\
\text { temperature of } 300 \mathrm{~K} \text {. }\end{array}$ & $\begin{array}{l}\text { (1) 3D model is discretized by } \\
\text { the unstructured mesh; (2) The } \\
\text { model is solved by using the } \\
\text { CFD-GEOM }{ }^{\mathrm{TM}} \text { software. }\end{array}$ & $\begin{array}{l}\text { The mean difference } \\
\text { between CFD model } \\
\text { and test result is less } \\
\text { than } 0.06 \% \text { at any } \\
\text { surface. }\end{array}$ & $\begin{array}{l}\text { (1) The model is used to } \\
\text { assess the impact of the angle } \\
\text { of solar irradiation; (2) The } \\
\text { model is able to investigate } \\
\text { the system performance. }\end{array}$ \\
\hline SSC model [43] & $\begin{array}{l}\text { (1) The angular gradient of the carrier } \\
\text { concentration is regarded as zero; } \\
\text { (2) The antireflection coating (ARC) is } \\
\text { ignored; } \\
\text { (3) A smooth spherical surface is } \\
\text { assumed in the model. }\end{array}$ & $\begin{array}{l}\text { (1) The outer surface boundary condition is } \\
\text { shown } \\
\left.\mathrm{D}_{\mathrm{p}}\left(\nabla \delta_{\mathrm{p}}\right)\right|_{\mathrm{r}=\mathrm{R}} \cdot \mathrm{a}_{\mathrm{n}}=\left.\mathrm{D}_{\mathrm{p}} \frac{\partial \delta_{\mathrm{p}}}{\partial \mathrm{r}}\right|_{\mathrm{r}=\mathrm{R}}=-\mathrm{S}_{\mathrm{rv}} \cdot \delta_{\mathrm{p}} \\
\text { (2) The first radial boundary condition is } \\
\text { given as: } \mathrm{n}_{(\mathrm{r}=\mathrm{Rp})}=\frac{\mathrm{n}_{\mathrm{i}}^{2}}{\mathrm{~N}_{\mathrm{a}}}\left(\exp \frac{\mathrm{eV}}{\mathrm{kT}}-1\right) \text {; } \\
\text { (3) The second radial boundary condition is } \\
\text { expressed as: } \\
\left.\mathrm{D}_{\mathrm{p}}\left(\nabla \delta_{\mathrm{p}}\right)\right|_{\mathrm{r}=\mathrm{Ro}} \cdot \mathrm{a}_{\mathrm{n}}=\left.\mathrm{D}_{\mathrm{n}} \frac{\partial \delta_{\mathrm{n}}}{\partial \mathrm{r}}\right|_{\mathrm{r}=\mathrm{Ro}}=\mathrm{L}_{\mathrm{rv}} \cdot \delta_{\mathrm{n}}\end{array}$ & $\begin{array}{l}\text { The spherical SSC model is } \\
\text { calculated via FDM approach. }\end{array}$ & $\begin{array}{l}\text { The error between } \\
\text { numerical model and } \\
\text { test result is less than } \\
8 \% \text {. }\end{array}$ & $\begin{array}{l}\text { (1) the model can reduce the } \\
\text { system cost; (2) the model is } \\
\text { able to enhance material } \\
\text { processing and system } \\
\text { utilization; }\end{array}$ \\
\hline
\end{tabular}




\begin{tabular}{|c|c|c|c|c|c|c|}
\hline \multirow{3}{*}{$\begin{array}{c}\text { Nanoscale } \\
\text { model }\end{array}$} & $\begin{array}{l}\text { Green's } \\
\text { function } \\
\text { model [62] }\end{array}$ & $\begin{array}{l}\text { (1) The ratio is thought as high } \\
\text { between the diameter and rod length; } \\
\text { (2) The doping is assumed as the } \\
\text { uniform and low. }\end{array}$ & $\begin{array}{l}\text { The excess carriers' concentration }(\Delta \mathrm{n}) \text { is } \\
\text { the finite and when } \mathrm{r}=\mathrm{r}_{4} \text {, } \\
\left.\Delta \mathrm{n}\right|_{\mathrm{r} r \mathrm{r}_{4}}=\mathrm{n}_{\mathrm{po}}\left[\exp \left(\frac{\mathrm{V}}{\mathrm{V}_{\mathrm{t}}}\right)-1\right] \text {; } \\
\text { Dirichlete boundary condition: } \\
\left.\mathrm{G}_{2}\left(\mathrm{r}, \mathrm{r}^{\prime}\right)\right|_{\mathrm{r}=\mathrm{R}_{\mathrm{p}}+\Delta \mathrm{r}_{2}} \\
\text { Neuman boundary conditions: } \\
\left.\frac{\mathrm{G}_{2}\left(\mathrm{r}, \mathrm{r}^{\prime}\right)}{\partial \mathrm{r}^{\prime}}\right|_{\mathrm{r}=\mathrm{R}}=\frac{1}{\mathrm{R}}\end{array}$ & $\begin{array}{l}\text { This analytical model is solved } \\
\text { by Green's function approach. }\end{array}$ & $\begin{array}{l}\text { The differences of } \mathrm{V}_{\mathrm{oc}} \\
\text { and } \mathrm{J}_{\mathrm{sc}} \text { reach } 1.7 \% \text { and } \\
3.7 \% \text {, respectively }\end{array}$ & $\begin{array}{l}\text { (1) The Green's function } \\
\text { model contributes to reducing } \\
\text { the assumption conditions; } \\
\text { (2) The model is used to } \\
\text { calculate the efficiency of the } \\
\text { p-i-n and p-n PV cells. }\end{array}$ \\
\hline & $\begin{array}{l}\text { FDTD model } \\
{[52,53]}\end{array}$ & $\begin{array}{l}\text { (1) The tunnel diode is regarded as the } \\
\text { ideal condition; (2) A perfect matching } \\
\text { layer is setup as semi-infinite } \\
\text { substrates. }\end{array}$ & $\begin{array}{l}\text { (1) The minimum cell size of the FDTD } \\
\text { mesh is defined to } 5 \mathrm{~nm} \text {; (2) The number of } \\
\text { nodes per wavelength is assumed as } 20 \text { in } \\
\text { all directions. }\end{array}$ & Based on EMW package. & N/A & $\begin{array}{l}\text { (1) FDTD is used to assess } \\
\text { the absorption rate of } \\
\text { branched nanowire (BNW) Si } \\
\text { solar cell; (2) The model is } \\
\text { capable of investigating the } \\
\text { light trapping impacts of the } \\
\text { nanowires array; (3) The } \\
\text { model is utilized to calculate } \\
\text { 3DPV performance } \\
\text { efficiency. }\end{array}$ \\
\hline & $\begin{array}{l}\text { DDA model } \\
{[63]}\end{array}$ & $\begin{array}{l}\text { (1) The total lengths are assumed as } 1 \\
\mu \text { m; (2) The diameter of the SiNW is } \\
\text { defined as } 83 \mathrm{~nm} \text {; (3) The SiNW and } \\
\text { SiNC are instead of cubic point } \\
\text { dipoles; (4) The optical properties of } \\
\text { metal nanoparticles is regarded as } \\
\text { homogenous. }\end{array}$ & The whole size is defined as $3 \times 3 \times 3 \mathrm{~nm}$. & Based on Lambert-Beer law. & $\begin{array}{l}\text { The error analysis is } \\
\text { about } 1 \% \text {. }\end{array}$ & $\begin{array}{l}\text { The model can be used to } \\
\text { study the optical } \\
\text { performances of } 3 \mathrm{DPV} \\
\text { SiNW and SiNC. }\end{array}$ \\
\hline
\end{tabular}




\section{Challenges and future technological developments}

587 The structures and models of the 3DPV technology are important challenging regions for improving PV panel energy conversion 588 efficiency, which consider the effects of shape, height and spacing of the PV module, weather condition, low-cost base materials, 589 affordable device-processing technology, latitude of the installation, optimal device design and shadow cast and so on. 590 Regardless of being an advanced and promising technique, the 3DPV technology still has some issues that require to be resolved 591 to create the framework for the future development as follows:

- In comparison to the conventional flat panel, the 3DPV technology is less conversion efficient at zenith angles about $0^{\circ}$, because not all modules are directed toward the sun.

- In most structures and models of the 3DPV technology, the reflection from the solar cell surface is assumed as diffuse. However, in reality, most surfaces do not reflect energy isotropically, and exhibit a directional bias. Hence, the true performance of the 3DPV technology should be investigated by considering the composite nature of the solar radiation.

- The shadow cast has significant effect on the module efficiency owing to complicated orientation. This may result in the reduction of overall voltage and current, and decreasing the 3DPV module electricity output.

- The PV panel is orientated at a diverse angle, therefore, it will have different P-V and I-V curves, meanwhile, the voltage established through the inverter will cause severe loss.

- The capture area may be amplified manifold by increasing the number of leaves, but the maximum number of leaves in a solar tree is limited because of several mechanical constraints which must be addressed for practical development of the 3DPV module.

The current 3DPV technologies have never taken into account the effects of wind load and gravitational pull on the 3DPV structures, hence, further research should be focused on this aspect.

- Computer programs should be validated by experimental results, and a completed assessment is extremely essential to investigate their applicability for engineering practices.

- The factor governing the total number of leaves in the tree is the total weight that a branch can withstand, which relies on the weight, shaping and size of the solar leaves. The number of leaves would be limited by the number of branches, since the branches would have to be placed such that leaves on one branch to avoid blocking the leaves on a neighbouring branch.

- In terms of the environment impact, it is hazardous for birds because of the 3DPV module released heat particularly in hot day. Furthermore, in terms of the human being, the reflections can be harmful to human eyes as the PV panels are at various angles. Hence, these hazards should be resolved in the future. 


\section{Conclusions}

$6153 \mathrm{DPV}$ technology is a novel skill to realize the optimum solar energy collection, to be more specific, the 3DPV module has 616 multiple orientations that permit effective capturing of off-peak sunlight, in the meantime, it can reabsorbs the reflected light as 617 well. This paper presents various 3DPV structures and reviews the effects of different factors on the conversion efficiency. 618 Furthermore, the analytical and numerical models of the 3DPV technology are summarized to clarify the complicated calculation 619 process. Consequently, some key findings are drawn as follows:

620 1) The $3 \mathrm{DPV}$ technology can absorb solar radiation more effectively in comparison to the conventional PV technology for any 621 geographic location and season, especially at high latitude and during winter period, and increase the sunlight captured 622 approximately $15-30 \%$.

2) The 3DPV structure optimum design could be realized and incorporated for sustainable installation for power generation, and the appropriate engineering software is used to predefine the anticipated parameters that will meet the operational

4) For angle of incidence above $40^{\circ}$, the $3 \mathrm{DPV}$ structure is more efficient than the conventional solar PV structure in terms of capturing sunlight. Meanwhile, it has a better temperature distribution compared with the planar configuration. specifications.

3) The 3DPV structure has high impact on electricity output, it can be used to explore multi-dimension space, and absorb the reflected rays. The 3DPV technology model is capable of analysing complex energy conversion mechanism for achieving optimisation design.

5) The average absorptions of SiNC, cylindrical SiNW and inverted SiNC arrays, and bulk silicon are 70.2\%, 55.3\%, 42.3\% and $42.2 \%$ respectively in the wavelength range of 400 to $800 \mathrm{~nm}$.

6) The MC model has the highest accuracy with the maximum error of $0.0425 \%$ in the 3DPV models. Furthermore, the negative temperature distributions in 3D models are less than those in 2D models or any other configurations.

7) For future development, the 3DPV computer models should be further validated by testing results, and a complete estimation is needed to increase the confidence of their applications. The influences of shape, height and spacing of the solar cell, weather condition, wind load, gravitational pull, low-cost base materials, affordable device-processing technology, latitude of the installation, optimal device design and shadow cast should be taken into account in the 3DPV models. An optimum design for the 3DPV technology is tremendously needed, which is able to enhance the sunlight absorption rate and energy conversion efficiency. 


\section{References}

643 [1] McCormick PG, Suehrcke H. The effect of intermittent solar radiation on the performance of PV systems. Solar Energy 2018; 644 171: 667-674.

645 [2] Xiong G, Zhang J, Shi D, He Y. Parameter extraction of solar photovoltaic models using an improved whale optimization 646 algorithm. Energy Conversion and Management 2018; 174: 388-405.

647 [3] Cuce E, Cuce PM, Karakas IH, Bali T. An accurate model for photovoltaic (PV) modules to determine electrical 648 characteristics and thermodynamic performance parameters. Energy Conversion and Management 2017; 146: 205-216.

649 [4] Xue H, Birgersson E, Stangl R. Correlating variability of modeling parameters with photovoltaic performance: Monte Carlo simulation of a meso-structured perovskite solar cell. Applied Energy 2019; 237: 131-144.

[5] Jaksik J, Moore HJ, Trad T, Okoli OI, Uddin MJ. Nanostructured functional materials for advanced three-dimensional (3D) solar cells. Solar Energy Materials and Solar Cells 2017; 167: 121-132.

[6] Hoang S. The environmental history of solar photovoltaic cells. Wellesley College. Available at: <https://repository.welles

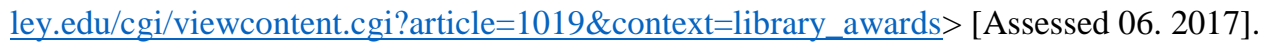

[7] Skandalos N, Karamanis D. PV glazing technologies. Renewable and Sustainable Energy Reviews 2015; 49: 306-322.

[8] Bernardi M, Ferralis N, Wan JH, Villalon R, Grossman JC. Solar energy generation in three-dimensions. Available at: 〈https://arxiv.org/vc/arxiv/papers/1112/1112.3266v1.pdf > [Assessed 05.2016].

[9] Mussard M, Amara M. Performance of solar photovoltaic modules under arid climatic conditions: A review. Solar Energy 2018; 174: 409-421.

[10] Bora B, Kumar R, Sastry OS, Prasad B, Mondal S, Tripathi AK. Energy rating estimation of PV module technologies for different climatic conditions. Solar Energy 2018; 174: 901-911.

[11] Assoa YB, Gaillard L, Ménézo C, Negri N, Sauzedde F. Dynamic prediction of a building integrated photovoltaic system thermal behaviour. Applied Energy 2018; 214: 73-82.

[12] Alnaqi AA, Moayedi H, Shahsavar A, Nguyen AK. Prediction of energetic performance of a building integrated photovoltaic/thermal system thorough artificial neural network and hybrid particle swarm optimization models. Energy Conversion and Management 2019; 83: 137-148.

[13] Zhu L, Li Q, Chen M, Cao K, Sun Y. A simplified mathematical model for power output predicting of building integrated photovoltaic under partial shading conditions. Energy Conversion and Management 2019; 180:831-843.

[14] Alice MO. Impact of three-dimensional photovoltaic structure on solar power generation. University of KwaZulu-Natal Durban, South Africa. Available at < https://researchspace.ukzn.ac.za/bitstream/handle/10413/14248/Mafimidiwo_Alice_O luf unmayo_2016.pdf?sequence=1\&isAllowed=y $>$ [Assessed 11. 2016]. 
[15] Dimitrokali E, Mackrill J, Jones G, Ramachers Y, Cain R. Moving Away from flat solar panels to PV trees: exploring ideas and people's perceptions. Procedia Engineering 2015; 118: 1208-1216.

674 [16] Moiz M, Tomar RS, Thakur V, Arya R. Vishwakarma S. Design and development of solar tree to be install in campus of TRUBA group of institutes, Bhopal. IDES joint International conferences on IPC and ARTEE, 2017.

[17] Prasad AA, Taylor RA, Kay M. Assessment of direct normal irradiance and cloud connections using satellite data over Australia. Applied Energy 2015; 143: 301-311.

[18] Nespoli L, Medici V. An unsupervised method for estimating the global horizontal irradiance from photovoltaic power measurements. Solar Energy 2017; 158: 701-710.

680 [19] Nespoli L, Medici V. An unsupervised method for estimating the global horizontal irradiance from photovoltaic power measurements. Solar Energy 2017; 158: 701-710.

682 [20]Dey S, Lakshmanan MK, Pesala B. Optimal solar tree design for increased flexibility in seasonal energy extraction. Renewable Energy 2018; 125: 1038-1048.

684 [21] Pandey C. Application of printing techniques in hybrid photovoltaic technologies. Helsinki Metropolia University of Applied Sciences Bachelor of Engineering Media Engineering Thesis. Available at: < https://www.theseus.fi/bitstream/han dle/10024/94266/Bachelor+thesis_C.Pandey.pdf?sequence=1 > [Assessed 18.04.2015].

[22] Cao W, Li Z, Yang Y, Zheng Y, Yu W, Afzal R, Xue J. "Solar tree": Exploring new form factors of organic solar cells. Renewable Energy 2014; 72: 134-139.

[23] Mafimidiwo OA, Saha AK. Incorporating a three dimensional photovoltaic structure for optimum solar power generation the effect of height. Journal of Energy in Southern Africa 2016; 27 (2): 22-29.

[24] Suto T, Yachi T. Power-generation characteristics of an FPM by simulation with shadow-effect analysis. Photovoltaic Specialists Conference (PVSC), 37th IEEE Photovoltaic Specialists Conference, 2011.

[25] Verma N. Modeling. Radiation transport in biomimetic configuration of solar cells for enhanced sunlight capture using the Monte Carlo method 2014 [Master's Thesis] Available at: $<$ https://etd.ohiolink.edu/!etd.send file?accession=osu139721319 $\underline{2 \& \text { disposition=inline }}>$ [Assessed 10. 2014].

[26] Verma N, Mazumder S. Monte Carlo simulation of sunlight transport in solar trees for effective sunlight capture. Journal of Solar Energy Engineering 2015; 137: 1-9.

[27] Takahashi A, Nishiwaki T, Yachi T. Arrangement of Fibonacci sequence photovoltaic modules for power generation forest. 5th International Conference on Renewable Energy Research and Applications, 20-23 Nov 2016, Birmingham, UK.

[28] Yuji A, Yachi T. A novel photovoltaic module assembled three-dimensional. Photovoltaic Specialists Conference (PVSC), 2010 35th IEEE, pp. 002811-002816, 2010. 
[29] Rawat N, Vidhyarthi VM, Awasthi N. Solar tree: New proposed model for harnessing solar energy and its scope in India. International Journal of Scientific \& Engineering Research Volume 8, Issue 10, October-2017, ISSN 2229-5518.

[30] Suzumoto S, Yachi T. Output power characteristics of three-dimensional photovoltaic module using Fibonacci numbers. Photovoltaic Specialists Conference (PVSC) IEEE 39th, pp. 1484-1488, 2013.

[31] Mochizuki Y, Yachi T. Arrangement of Fibonacci number photovoltaic modules for power generation woods. 3rd International Conference on Renewable Energy Research and Applications, Milwakuee, USA 19-22 Oct 2014.

[32] Mochizuki Y, Yachi T. Relationship between power generated and series/parallel solar panel configurations for 3D Fibonacci PV modules. $6^{\text {th }}$ Internatinoal Conference on Renewable Energy Research and Applications. San Diego, CA, USA, pp 126-130 Nov 2017.

[33] Khan H, Gaur P. Design of solar tree with photovoltaic panels using Fibonacci pattern, Advanced Research in Electrical and Electronic Engineering, ISSN: 2349-5812 Volume 2, pp. 67-71, 2015.

[34] Hyder F, Sudhakar K, Mamat R. Solar PV tree design: a review. Renewable and Sustainable Energy Review. 2018; 82: 1079-1096.

[35] Association ECOPOWER Solar tree. Available from 〈http://www.association-ecopower.com/eco-marketing.html〉.

[36] Hyder F, Baredar P, Sudhakar K, Mamat R. Performance and land footprint analysis of a solar photovoltaic tree. Journal of Cleaner Production 2018; 187: 432-448.

[37] Benguar AND, Casiano PGT, Valdehueza TL, Tan DA. Golden ratio applied in the orientation of solar cells in a golden spiral solar panel. International Journal of Development Research 2018; 8 (5): 20416-20420.

[38] Liu Y, Wang H, Shen H, Chen W. The 3-dimensional dye-sensitized solar cell and module based on all titanium substrates. Applied Energy 2010; 87 (2): 436-441.

[39] Tarabsheh A, Akmal M, Hareb M, Kahla M, Qadir A, Mohammad E. A modified hybrid photovoltaic wind system. $5^{\text {th }}$ IET International Conference on Renewable Power Generation (RPG), London, 2016, pp. 1-3.

[40] Tarabsheh A, Akmal M, Hareb M. Analysis of photovoltaic modules attached with a vertical-axis wind turbine. $6^{\text {th }}$ International Conference on Clean Electrical Power (ICCEP), Santa Margherita Ligure, 2017, pp. 41-45.

[41] Bernardi M, Ferralis N, Wan JH, Villalon R, Grossman JC. Solar energy generation in three dimensions. Energy Environment Science 2012; 5: 6880-6884.

[42] Bernardi M, Ferralis N, Wan JH, Villalon R, Grossman JC. Solar energy generation in three-dimensions [Thesis]. Available at: 〈https://arxiv.org/vc/arxiv/papers/1112/1112.3266v1.pdf〉 [Assessed 05.2016].

[43] Gharghi M, Hua B, Stevens G, Sivoththaman S. Three-dimensional modeling and simulation of p-n junction spherical silicon solar cells. Electron Devices, IEEE Transactions on, vol. 53, pp. 1355-1363, 2006. 
[44] Nakata J. Spherical cells promise to expand applications for solar power. Available at: < http://sphelarpower.com/technolo gy/pdf/01_AEI_200110.pdf> [Assessed 10.2001].

[45] Verma S, Banerjee P, Kumar M, Roy AB, Mondal NC, Kundu A. Spherical silica micro-lenses for enhanced light absorption in thin crystalline silicon solar cell. 2016 21st Century Energy Needs - Materials, Systems and Applications (ICTFCEN), Kharagpur, 2016, pp. 1-4.

[46] Cossu M, Yano A, Li Z, Onoe M, Nakamura H, Matsumoto T, Nakata J. Advances on the semi-transparent modules based on micro solar cells: First integration in a greenhouse system. Applied Energy 2016; 162: 1042-1051.

[47] Minemoto T, Murozono M, Yamaguchi Y, Takakura H, Hamakawa Y. Design strategy and development of spherical silicon solar cell with semi-concentration reflector system. Solar Energy Materials and Solar Cells 2006; 90 (18-19): 3009-3013.

[48] Minemoto T, Takakura H. Fabrication of spherical silicon crystals by dropping method and their application to solar cells. Japan Society of Applied Physics 2007; 46 (7A): 4016-4020.

[49] Kitamura K, Sasaki S, Matsuya Y, Douseki T. Optical wireless digital-sound transmission system with 1-Bit $\Delta \Sigma$-modulated visible light and spherical Si solar cells. IEEE Sensors Journal, vol. 10, no. 11, pp. 1753-1758, Nov. 2010.

[50] Ali NM, Rafat NH. Modeling and simulation of nanorods photovoltaic solar cells: A review. Renewable and Sustainable Energy Reviews 2017; 68: 212-220.

[51] Kapadia R, Fan Z, Takei K, Javey A. Nanopillar photovoltaics: Materials, processes, and devices. Nano Energy 2012; 1(1): $132-144$.

[52] Lundgren C, Lopez R, Redwing J, Melde K. FDTD modeling of solar energy absorption in silicon branched nanowires. Optics Express 2013; 21: 392-400.

[53] Wang S, Yan X, Zhang X, Li J, Ren X. Axially connected nanowire core-shell p-n junctions: a composite structure for highefficiency solar cells. Nanoscale Research Letters 2015; 10: 1-7.

[54] Yao M, Cong S, Arab S, Huang N, Povinelli ML, Cronin SB, Dapkus PD, Zhou C. Tandem Solar Cells Using GaAs Nanowires on Si: Design, Fabrication, and Observation of Voltage Addition. Nano Letter. 2015; 15: 7217-7224.

[55] Otnes G, Borgström MT. Towards high efficiency nanowire solar cells. Nano Today 2017; 12: 31-45.

[56] Li Y, Li M, Fu P, Li R, Song D, Shen C, Zhao Y. A comparison of light-harvesting performance of silicon nanocones and nanowires for radial-junction solar cells. Scientific Report 5, 2015. Available at < https://www.nature.com/articles/srep11532〉 [Accessed 26.06.2015].

[57] Xu Z, Qiao H, Huangfu H, Li X, Guo J, Wang H. Optical absorption of several nanostructures arrays for silicon solar cells. Optics Communications 2015; 356: 526-529. 
761 [58] Liu L, Sun Q, Wang Y, Liu Y, Wennersten R. Research on short-term optimization for integrated hydro-PV power system based on genetic algorithm. Energy Procedia 2018; 152: 1097-1102.

763 [59] Myers B, Bernardi M, Grossman JC. Three-dimensional photovoltaics. American Institute of Physics 2010; 96 (7): 1-4.

[60] Alfughi Z. Optimal farm design with parabolic shape photovoltaic panels using multi-objective optimization. Master thesis 2015. Available at: < https://pdfs.semanticscholar.org/01e2/56b004aa498dbb7708899e7df6889041ee41.pdf > [Assessed 04. 2015].

[61] Verma N. Modeling radiation transport in biomimetic configuration of solar cells for enhanced sunlight capture using the Monte Carlo method. The Ohio State University, 2014. Available at: < https://etd.ohiolink.edu/!etd.send file?accession=osu $1397213192 \&$ disposition=inline $>$.

[62] Ali NM, Allam NK, Haleem AMA, Rafat NH. Analytical modeling of the radial pn junction nanowire solar cells. Journal of Applied Physics 2014; 116: 1-7.

[63] Yurkin MA, Maltsev VP, Hoekstra AG. The discrete dipole approximation for simulation of light scattering by particles much larger than the wavelength. Journal of Quantitative Spectroscopy and Radiative Transfer. 2007; 106 (1-3): 546-557.

\section{Nomenclature \\ A $\quad$ Area $\left(\mathrm{m}^{2}\right)$ \\ i Number of the layers \\ r $\quad$ Radius (m).}

\section{Greek Letters}

$\alpha \quad$ Altitude angle $\left({ }^{\circ}\right)$

$\beta \quad$ Surface tilt angle $\left(^{\circ}\right)$

$\gamma \quad$ Surface azimuth angle $\left({ }^{\circ}\right)$

$\gamma_{\mathrm{s}} \quad$ Solar azimuth angle $\left(^{\circ}\right)$

$\theta \quad$ Angle that is made by arc at the centre of circle in radian (rad)

\section{Abbreviations}

BNW Branched nanowire 


\begin{tabular}{|c|c|}
\hline DDA & Discrete dipole approximation \\
\hline DSSC & Dye-sensitized solar cell \\
\hline FDTD & Finite-difference time-domain \\
\hline FPM & Fibonacci number photovoltaic module \\
\hline GA & Genetic algorithms \\
\hline GS & Golden spiral \\
\hline $\mathrm{MC}$ & Monte carlo \\
\hline MPPT & Maximum power point tracking \\
\hline PCBM & Phenyl-C61-butyric acid methyl ester \\
\hline PET & Polyethylene terephthalate \\
\hline PV & Photovoltaic \\
\hline P3HT & Poly 3-hexylthiophene \\
\hline $\mathrm{SSC}$ & Cubic silicon solar cell \\
\hline STM & Semi-transparent module \\
\hline SiNW & Silicon nanowire \\
\hline $\mathrm{SiNC}$ & Silicon nanocone \\
\hline VAWT & Vertical axis wind turbine \\
\hline 3DPV & Three dimensional photovoltaic \\
\hline
\end{tabular}

